\title{
A MODELLING STUDY OF THE 1976 CLIMATE REGIME SHIFT IN THE NORTH PACIFIC OCEAN
}

\author{
By \\ Qiuying $\mathrm{Wu}$ \\ B. Sc. (Atmosphere Science) Nanjing University, \\ M. Sc. (Meterorology) Nanjing Institute of Meteorology \\ A THESIS SUBMITTED IN PARTIAL FULFILLMENT OF \\ THE REQUIREMENTS FOR THE DEGREE OF \\ MASTER OF Sc. \\ in \\ THE FACULTY OF GRADUATE STUDIES \\ OCEANOGRAPHY
}

We accept this thesis as conforming

to the required standard

THE UNIVERSITY OF BRITISH COLUMBIA

February 1998

(C) Qiuying $\mathrm{Wu}, 1998$ 
In presenting this thesis in partial fulfilment of the requirements for an advanced degree at the University of British Columbia, I agree that the Library shall make it freely available for reference and study. I further agree that permission for extensive copying of this thesis for scholarly purposes may be granted by the head of my department or by his or her representatives. It is understood that copying or publication of this thesis for financial gain shall not be allowed without my written permission.

Department of Earth and Ecean Sciences, Oceanggraptry

The University of British Columbia Vancouver, Canada

Date Mar.2, 1998 


\begin{abstract}
During the 1976 climate regime shift, the Aleutian low deepened. Many studies have shown that the oceanic shift was mainly driven by the atmospheric dynamics. In this thesis numerical studies to investigate the oceanic interdecadal variation as the result of the 1976 climate shift have been carried out with the GFDL OGCM. Two interdecadal experiments are performed. One is forced by monthly wind stress climatology for 19761988 and relaxed to monthly SST climatology from the same time period. The other is forced by monthly wind stress climatology for 1952-1975 and monthly SST climatology from the same time period. The same sea surface salinity monthly climatology data is used throughout all the experiments.

The simulated ocean circulations exhibit significant interdecadal variations. The gyre circulations are spun up both in the subarctic region and the subtropical region, except in the northern and eastern part of the Gulf of Alaska where the gyral circulation is weakened.
\end{abstract}

The large scale surface cooling in the central North Pacific and the warming along the west coast of North America are simulated. The intensified surface Ekman drifts are very important in generating the thermal variation near the surface, especially in mid and high latitudes.

The deepening of the Aleutian Low generates stronger surface divergence in the subarctic area and stronger convergence in the subtropic. Consequently the upwelling in the subarctic region is increased, with a maximum increase of $108 \%$ at a depth of $60 \mathrm{~m}$. The downwelling in the subtropical area is enhanced as well. Along the coast of North America above $40^{\circ} \mathrm{N}$, there is an increase in downwelling, which is consistent with the 
weakening of the Alaskan gyre. The significant variations in upwelling in the subarctic and downwelling in subtropical regions are confined approximately above a few hundred meters depth. By working with the large vertical temperature gradients, they produce large scale subsurface thermal variation, with the cooling in the subarctic and warming in the subtropic. The depth range of the subsurface thermal variation is limited to above $650 \mathrm{~m}$ depth.

The meridional circulation and heat transport are changed consequently. In low latitudes the poleward heat transport is increased. In the mid latitudes the equatorward heat transport is increased and mainly contributed by the meridional component, though the gyre and diffusion components are not negligible. The heat transport in high latitudes, poleward and very small, is increased.

The estimation of the salinity effect on the current studies shows that a change in surface salinity forcing fields by an amount of $0.0817 \mathrm{ppt}$ in subarctic area does not have significant impacts on the results of this study. 
$\begin{array}{ll}\text { Abstract } & \text { ii }\end{array}$

List of Tables $\quad$ vi

List of Figures vii

Acknowledgement xii

1 Introduction $\quad 1$

2 Description of the model $\quad 4$

2.1 The equations of the model .................. . . 4

2.2 Domain, resolution, bottom topography and time stepping . . . . . . 7

2.3 Boundary conditions . . . . . . . . . . . . . . . 9

2.4 The choice of parameters . . . . . . . . . . . . . 12

3 Surface Forcing Fields And Model Runs 13

3.1 The derivation of surface wind stress forcing field . . . . . . . . . 13

3.2 The derivation of SST and SSS climatologies as relaxation fields . . . . . 14

3.3 Model spin up and the design of interdecadal experiments . . . . . . . 16

4 Basic climatological run results $\quad 24$

4.1 The vertically integrated transport . . . . . . . . . . . . . 24

4.2 The velocity . . . . . . . . . . . . . . . . 28

4.2 .1 The horizontal velocity ................ 28 
4.2 .2 The vertical velocity ................ 31

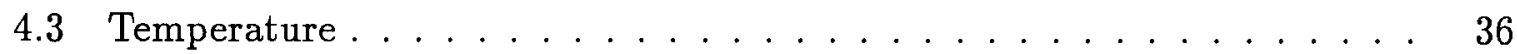

4.4 Meridional circulation and heat transport . . . . . . . . . . . 38

5 Climate Regime Shift $\quad 45$

5.1 Variations in transport streamfunction ............. 47

5.2 Variations in velocity and associated variations in temperature . . . . . 48

5.2.1 Variations in horizontal velocity and associated variations in temperature ........................ 48

5.2.2 Variations in vertical velocity and associated variations in temper-

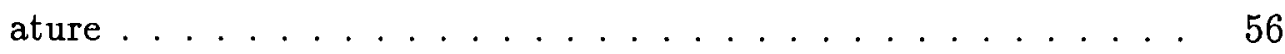

5.3 Variations in meridional mass and heat transport . . . . . . . . 68

6 An Estimate of the Salinity Effect $\quad 76$

6.1 Introduction . . . . . . . . . . . . . . . 76

6.2 Design of the experiment . . . . . . . . . . . . 76

6.3 Results of the experiment ................... 78

$\begin{array}{llc}7 & \text { Conclusions } & \mathbf{8 3}\end{array}$ 


\section{List of Tables}

2.1 The vertical resolution of the model ocean . . . . . . . . . . . . 9

6.1 The value of zonally averaged vertical velocity at each latitude during DJF for Exp.C and the difference between Exp.S and Exp.C. The units are $\mathrm{cm} /$ day. . . . . . . . . . . . . . . . . . .

6.2 The value of total meridional heat transport at each latitude in January for Exp.C and the difference between Exp.S and Exp.C. The units are

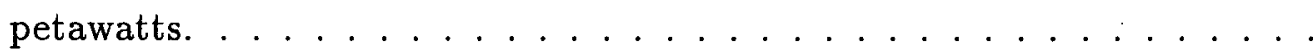




\section{List of Figures}

2.1 The smoothed topography of the ocean model, with depth in kilometers.

3.1 Zonally averaged zonal wind stress. Solid line represents COADS wind stress. Dashed line indicates Hellerman wind stress. The units are $d y n / \mathrm{cm}^{2} .15$

3.2 Averaged kinetic energy density of the model ocean as a function of time in months during spin-up by surface wind stress forcing and Newtonian temperature and salinity relaxation at the surface. . . . . . . . .

3.3 (a) The winter (DJF) wind stress climatology field for the period of 1952 -

75 (pre-1976) (b) for the period of 1976-88 (post-1976). The units are dyn $/ \mathrm{cm}^{2}$.

3.4 (a) The winter (DJF) wind stress climatology field of 1976-88 (post-1976) minus that of $1952-75$ (pre-1976). (b) The zonally averaged zonal stress as a function of latitude. Dashed line indicates the 1976-88 (post-1976) climatology in DJF. Solid line represents the 1952-75 (pre-1976) climatology in DJF. The units are $d y n / \mathrm{cm}^{2}$. . . . . . . . . . . . . . 2

3.5 The SST from the post-1976 (1976-88) climatology minus the pre-1976 (1952-75) climatology in winter (DJF). The contour interval is $0.4\left({ }^{\circ} \mathrm{C}\right)$. .

4.1 The vector plots of surface wind stress for (a) January and (b) July. The units are $d y n / \mathrm{cm}^{2} \ldots \ldots \ldots \ldots \ldots$

4.2 The vertically integrated transport streamfunction for (a) January and (b) July. The contour values are $\pm 1, \pm 2, \pm 3, \pm 5, \pm 7, \pm 9, \pm 11, \pm 13, \pm 15$, $\pm 20, \pm 25, \pm 30, \pm 35, \pm 40, \pm 45$ Sv. . . . . . . . . . . . . 
4.3 The simulated current velocity at $15 \mathrm{~m}$ depth in (a) January and (b) July. The vector scales are $30 \mathrm{cms}^{-1}$. NPC $=$ North Pacific Current, $\mathrm{NEC}=$ North Equatorial Current, NECC=North Equatorial Countercurrent, $\mathrm{SEC}=$ South Equatorial Current, $\mathrm{CC}=$ California Current, $\mathrm{A}=\mathrm{Alaska}$

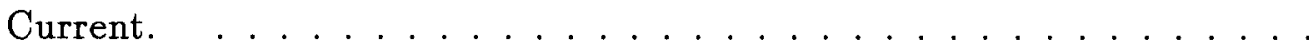

4.4 The simulated current velocity at the fourth model layer of $130 \mathrm{~m} \mathrm{depth}$ in (a) January and (b) July. The vector scales are $30 \mathrm{cms}^{-1}$.

4.5 The simulated vertical velocity at $60 \mathrm{~m}$ depth in (a) DJF and (b) JJA. The light grey area indicates upwelling. The dark grey area downwelling. The contour values are $\pm 10, \pm 20, \pm 50, \pm 100, \pm 200, \pm 250, \pm 300 \mathrm{~cm} /$ day. .

4.6 The zonally averaged vertical velocity at $60 \mathrm{~m}$ depth in DJF (solid line) and JJA (dash-dotted line). The value of velocity between $10^{\circ} \mathrm{N}$ and $60^{\circ} \mathrm{N}$ is multiplied by 5 for better visualization. . . . . . . . . . . . . . .

4.7 The observed SST (upper panel) and simulated SST (lower panel) in DJF and JJA respectively.

4.8 The simulated meridional mass transport (megatons/s) in January. Solid contours denote clockwise circulation; dashed contours, anti-clockwise circulation. . . . . . . . . . . . . . . . . 39

4.9 The simulated meridional mass transport (megatons/s) in July. . . . . . 40

4.10 The simulated total and three fractional meridional heat transports (petawatts) in January (a) and in July (b). Northward heat transport is positive. . .

5.1 Average kinetic energy density of the model ocean as a function of time in months for Exp.B (pre-1976) (solid line) and Exp.C (post-1976) (dashdotted line). . . . . . . . . . . . . . . . . . 
5.2 The vertically integrated transport streamfunction in January at sixth year of Exp.B (pre-1976) and Exp.C (post-1976). The contour values are $\pm 1, \pm 2, \pm 3, \pm 5, \pm 7, \pm 9, \pm 11, \pm 13, \pm 15, \pm 20, \pm 25, \pm 30, \pm 35, \pm 40, \pm 45, \pm 50$

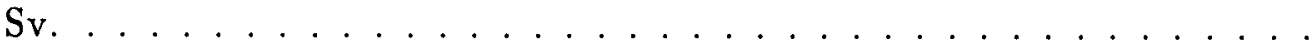

5.3 The difference between Exp.C and Exp.B in vertically integrated transport streamfunction in January at the sixth year. The contour values are $\pm 1, \pm 2, \pm 3, \pm 5, \pm 7, \pm 9, \pm 11, \pm 13, \pm 15, \pm 20$ Sv . . . . . . . . . . .

5.4 (a) The difference in surface current ( $15 \mathrm{~m}$ depth) between the post-1976 and pre-1976 in January at the sixth year. (b) The surface current velocity at $15 \mathrm{~m}$ depth for pre-1976 case in January at the sixth year. . . . . . . .

5.5 The simulated variation in SST between post-1976 case and pre-1976 case in DJF at sixth year. The contour interval is $0.4^{\circ} \mathrm{C} \ldots \ldots \ldots \ldots$

5.6 (a) The meridional section of the difference in meridional velocity component $\mathrm{V}$ along $155^{\circ} \mathrm{W}$ in January at the sixth year between the post-1976 and the pre-1976 cases. (b) The meridional section of $\mathrm{V}$ for the pre-1976 case. The contour intervals in both (a) and (b) are $1 \mathrm{~cm} / \mathrm{s}$, with solid contours for northward flow and dashed contours for southward flow. .

5.7 (a) The meridional section of the difference of the zonal velocity component $\mathrm{U}$ along $155^{\circ} \mathrm{W}$ in January at the sixth year between post-1976 and pre-1976. (b) The meridional section of $U$ for the pre-1976 case. The contour values in both (a) and (b) are $\pm 1, \pm 2, \pm 3, \pm 4, \pm 5, \pm 10, \pm 15, \pm 20$ $\mathrm{cm} / \mathrm{s}$, with solid contours for eastward flow and dashed contours for westward flow. NPC=North Pacific Current, NEC=North Equatorial Current, NECC=North Equatorial Countercurrent, $\mathrm{SEC}=$ South Equatorial Current, EUC=Equatorial Undercurrent, EIC=Equatorial Intermediate Current. 
5.8 (a) The difference of vertical velocity at $60 \mathrm{~m}$ depth in DJF between the post-1976 case and pre-1976 case. The light grey indicates positive anomaly (i.e. either the upwelling is increased or the downwelling is decreased), dark grey negative anomaly. (b) The vertical velocity at $60 \mathrm{~m}$ depth in DJF for the pre-1976 case. The light grey indicates upwelling, dark grey downwelling, The contour values in both (a) and (b) are \pm 10 , $\pm 20, \pm 50, \pm 100, \pm 200, \pm 250, \pm 300 \mathrm{~cm} /$ day . . . . . . . . . .

5.9 The zonally averaged vertical velocity $(\mathrm{cm} /$ day) at $60 \mathrm{~m}$ depth in DJF for the pre-1976 case (solid line) and the post-1976 case (dot-dashed line)

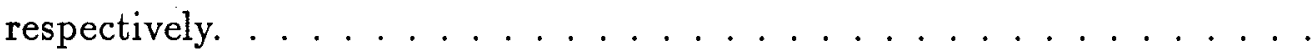

5.10 The meridional section of vertical velocity change in DJF along $155^{\circ} \mathrm{W}$ between the post-1976 case and the pre-1976 case. The contour values are $\pm 2, \pm 4, \pm 6, \pm 8, \pm 10, \pm 20, \pm 30, \pm 40, \pm 50 \mathrm{~cm} /$ day . . . . . . . . .

5.11 (a) The meridional section of temperature change along $155^{\circ} \mathrm{W}$ in DJF between the post-1976 case and the pre-1976 case. The contour interval is $0.2^{\circ} \mathrm{C}$. (b) The meridional section of temperature distribution along $155^{\circ} \mathrm{W}$ for the pre-1976 case in DJF. The contour interval is $1^{\circ} \mathrm{C} \ldots \ldots$

5.12 (a) The meridional section of temperature variation along the date line $\left(180^{\circ}\right)$ in DJF between the post-1976 case and the pre-1976 case. The contour interval is $0.2^{\circ} \mathrm{C}$.

5.13 (a) The difference in meridional mass transport between the post-1976 case and the pre-1976 case in January. The contour interval is 5 megatons/s.

5.14 (a) The total meridional heat transport for the post-1976 case (dashed curve) and the pre-1976 case (solid curve) in January. (b) The redrawn total meridional heat transport between $30^{\circ} \mathrm{N}$ and $60^{\circ} \mathrm{N}$ for better visualization. Units are in petawatts. . . . . . . . . . . . . . . 
5.15 (a) The meridional heat transport contributed by the overturning component for the post-1976 case and the pre-1976 case in January. (b) The redrawn overturning component of heat transport between $40^{\circ} \mathrm{N}$ and $60^{\circ} \mathrm{N}$ for better visualization. Units are in petawatts. . . . . . . . . . .

5.16 (a) The gyre component of the meridional heat transport for the post-1976 case and the pre-1976 case in January. (b) The diffusion component of the meridional heat transport for the post-1976 case and the pre-1976 case in January. Units are in petawatts. . . . . . . . . . . . . .

6.1 The difference in vertical velocity pattern at depth $60(\mathrm{~m})$ during DJF between Exp.S (post-1976 with salinity modified) and Exp.C (post-1976). The light grey indicates positive values, the dark grey negative values. The contour intervals are $\pm 0.5, \pm 1, \pm 2, \pm 3 \mathrm{~cm} /$ day. In most areas, the difference is less than 0.5. Indeed, it is unimportant in comparison with the magnitude of vertical velocity shown in Fig. 5.5. . . . . . . . . . 


\section{Acknowledgement}

I would like to express my gratitude to my supervisor, Dr. William Hsieh, for his encouragement, guidance and support during my study. I would like to thank Dr. Susan Allen, Dr. Lionel Pandolfo and Dr. Richard Pawlowicz for their comments and suggestions. I also would like to thank Dr. Benyang Tang for his comments and help.

I would like to acknowledge Warren Lee for his help on running the model and fellow students- Fred Tangang for his help on processing the COADS data and Steve Bograd for fruitful discussions.

I am indebted to the manager of the departmental computer system, Denis Laplante, for his help with my computer problems. 


\section{Chapter 1}

\section{Introduction}

A major abrupt climate regime shift occurred in the North Pacific around 1976, as reported by Douglas et al. [1982], Mclain [1983], Nitta and Yamada [1989], Trenberth [1990], Graham [1991], Ebbesmeyer et al. [1991], Tabata [1991] and Trenberth and Hurrell [1994]. This large scale atmospheric and oceanic climate change, lasting from about 1976 till 1988, is characterized by the intensification and southward shift of the Aleutian low pressure system in the winter half year. It is this system that transported warmer air along the west coast of North America and into Alaska, and cold air over the central North Pacific. Consequently the air temperature and sea surface temperature (SST) increased along the west coast of North America and Alaska, but the SST decreased over the central North Pacific. By inference, the surface wind stress also changed.

Changes in biological productivity have been reported as well. Mysak [1986] noted that the migration patterns of fish were altered due to changes in the ocean currents and temperatures. Venrick et al [1987], who found an increasing concentration of chlorophyll a in the central North Pacific since the late 1970's, identified the increase in winter winds and the decrease in surface temperatures as the mechanism responsible for the increased productivity. McFarlane and Beamish [1992] proposed that the cooling of the central North Pacific ocean increased nutrient supply to the surface waters, thereby improving primary productivity. In particular, they documented substantial increases in sablefish. Beamish and Bouillon [1993] found that there is a significant relationship between the Aleutian low pressure index and the annual North Pacific ocean salmon production. 
Observed changes in the North Pacific ocean SSTs can be largely accounted for by the atmospheric changes, Trenberth and Hurrell [1994] indicated that the dominant atmosphere-ocean relation in the North Pacific is one where atmospheric changes lead the SSTs by one to two months. Alexander [1992] pointed out that observed changes in the North Pacific ocean SSTs can be largely accounted for by the atmospheric changes through the associated changes in surface fluxes and mixing in the upper layers of the ocean and the deepening of the mixing layer through entrainment. Graham [1994] and Miller et al. [1994] used numeric models forced by observed wind and heat fluxes to investigate numerically the mechanism of the interdecadal variability of the Pacific ocean. Their studies supported the idea that the 1976 oceanic climate shift was primarily driven by atmospheric dynamics. Lagerloef [1995] investigated the interdecadal variation in the Alaska gyre and suggested that the upper ocean climatic variability in this region is primarily wind forced.

However, these papers only studied the surface waters of the Pacific Ocean, trying to clarify the importance of the atmosphere in driving the interdecadal variability of the ocean. It is also important to understand how the subsurface waters changed in response to the atmospheric driving during the 1976 climate shift.

This study will investigate the oceanic response, especially that of the subsurface waters, to the atmospheric dynamic forcing associated with the 1976 climate shift. To this aim, we will use the GFDL modular ocean model (MOM), developed originally at the Geophysical Fluid Dynamics Laboratory (GFDL) at Princeton. The interdecadal variations in major oceanic variables, such as transport streamfunction, currents, subsurface temperature, upwelling-downwelling velocities, meridional circulation and heat transport, will be examined. Furthermore, according to the observed salinity trends at station $\mathrm{P}$ [Freeland and Whitney, 1997] an estimation of the effect of variations in sea surface salinity forcing fields is performed. 
The thesis is organized as follows: Chapter 2 introduces the GFDL ocean general circulation model, its resolution and boundary conditions etc. In Chapter 3 , the data for the initial distribution of model ocean variables and surface forcing fields are described and the design of the numerical experiments are presented. Chapter 4 describes the climatological run to show that the model generally reproduces the major features of the climatological ocean fields. In Chapter 5 the climate shift experiments are performed with the model ocean forced by either the pre-1976 surface winds and SST monthly climatologies or the post-1976 climatologies. The changes in the oceanic circulation are analysed. Chapter 6 conducts an experiment to study how variations of the surface salinity forcing field might affect the results of present study. Conclusions are given in Chapter 7 . 


\section{Chapter 2}

\section{Description of the model}

\subsection{The equations of the model}

The ocean general circulation model used in this study is a primitive equation, three dimensional numerical ocean model which was originally developed by $\mathrm{K}$. Bryan and M.D. Cox in the 1960's [Bryan and Cox, 1967]. Later a number of improvements were made to both the structure of the FORTRAN model code and to the mathematical formulation [Semtner, 1974]. In this model, three assumptions were made to the NavierStokes equations- the Boussinesq approximation, hydrostatic assumption and closure. The Boussinesq approximation ignores the density differences except in the buoyancy term. The hydrostatic assumption eliminates the local acceleration and other small terms from the equation of vertical motion. Closure is attained based on the turbulent viscosity hypothesis in which stresses exerted by unresolved small scales of motion are represented as enhanced molecular mixing.

For notational convenience, let

$$
\begin{aligned}
& m=\sec \phi \\
& n=\sin \phi \\
& f=2 \Omega \sin \phi \\
& u=a \dot{\lambda} / m \\
& v=a \dot{\phi}
\end{aligned}
$$

where $\phi$ is the latitude, $\lambda$ the longitude, $a$ the radius of the earth, $\Omega$ the angular velocity 
of the earth and $(u, v)$ the zonal and meridional components of velocity. The advection operator $\Gamma$ is defined as

$$
\Gamma(\mu)=m a^{-1}\left[(u \mu)_{\lambda}+\left(v \mu m^{-1}\right)_{\phi}\right]+(w \mu)_{z}
$$

where $\mu$ is any scalar variable, $z$ the radial distance and $w$ the vertical component of velocity.

Therefore the equations of motion are given by

$$
\begin{gathered}
u_{t}+\Gamma(u)-f v=-m a^{-1}\left(p / \rho_{0}\right)_{\lambda}+F^{u}, \\
v_{t}+\Gamma(v)+f u=-a^{-1}\left(p / \rho_{0}\right)_{\phi}+F^{v}
\end{gathered}
$$

where the unit value is taken for the density $\rho_{0}, F^{u}$ and $F^{v}$ are the eddy viscosity terms. $p$ is the local pressure and given by the hydrostatic relation

$$
p(z)=p^{s}+\int_{z}^{0} g \rho d z
$$

where $p^{s}$ is the pressure at the surface of the ocean.

The continuity equation and state equation are

$$
\begin{gathered}
w_{z}+m a^{-1}\left[u_{\lambda}+(v / m)_{\phi}\right]=0, \\
\rho=\rho(T, S, z)
\end{gathered}
$$

where $\rho$ is the density, $T$, the temperature and $S$ the salinity. In the present model, the density is approximated by a polynomial with the coefficients fitted to the standard Knudsen formula. The details are given in Bryan and Cox [1972]. 
The conservation equations for the tracers (temperature and salinity) are

$$
\begin{aligned}
& T_{t}+\Gamma(T)=F^{T}, \\
& S_{t}+\Gamma(S)=F^{S},
\end{aligned}
$$

In the above equations, $F^{u}, F^{v}, F^{T}$ and $F^{S}$, representing the effects of turbulent mixing, are given by

$$
\begin{gathered}
F^{u}=A_{M V} u_{z z}+A_{M H} a^{-2}\left[\nabla^{2} u+\left(1-m^{2} n^{2}\right) u-2 n m^{2} v_{\lambda}\right] \\
F^{v}=A_{M V} v_{z z}+A_{M H} a^{-2}\left[\nabla^{2} v+\left(1-m^{2} n^{2}\right) v-2 n m^{2} u_{\lambda}\right] \\
F^{T}=A_{T V} T_{z z}+A_{T H} a^{-2} \nabla^{2} T \\
F^{S}=A_{T V} S_{z z}+A_{T H} a^{-2} \nabla^{2} S
\end{gathered}
$$

where $\nabla$ is the Laplacian operator. In the model, Laplacian closure is adopted for horizontal mixing and expressed as

$$
\nabla^{2} \mu=m^{2} \mu_{\lambda \lambda}+m\left(\mu_{\phi} / m\right)_{\phi}
$$

Four mixing coefficients $A_{M H}, A_{T H}, A_{M V}$ and $A_{T V}$ are the horizontal eddy viscosity, horizontal eddy diffusivity, vertical eddy viscosity and vertical eddy diffusivity, respectively. The subscripts $\mathrm{M}, \mathrm{T}, \mathrm{V}$ and $\mathrm{H}$ correspond respectively to 'momentum', 'tracer', 'vertical' and 'horizontal'. The choice of values for the mixing coefficients will be described later in this chapter. 


\subsection{Domain, resolution, bottom topography and time stepping}

The model ocean studied in this thesis covers the domain of the equatorial and North Pacific from $125^{\circ} \mathrm{E}$ to $70^{\circ} \mathrm{W}$ longitudinally and $20^{\circ} \mathrm{S}$ to $60^{\circ} \mathrm{N}$ latitudinally, with a slightly modified coastline. The horizontal resolution of the model ocean is $1^{0}$ latitude by $1^{0}$ longitude over the entire model domain.

To obtain the geometry and bathymetry of the model ocean, several steps were taken. First, a depth data set for the model domain was extracted from a global $1^{0} * 1^{0}$ ocean bottom topography data set, [Gate and Nelson, 1975], which was centered at the half degree latitude and longitude. For the sake of numerical computation, some simplifications were introduced, such as the closure of Sea of Okhotsk, Japan Sea and other island seas, the elimination of the Hawaiian Islands and other small islands. In particular it is worth noting that the shallow area of the Bering Sea along the southwest coast of Alaska was masked out since the depth change between the Pacific and the shallow Bering Sea allows the propagation of fast topographic waves [LeBlond and Mysak, 1978] which can greatly restrict the size of the integration time step.

The location of every datum in the original depth dataset matches the centre position of the model t-grid box, where the tracer variables are located, so no interpolation was needed to get the value of ocean depth for each t-grid box. A nine-point smoothing operator was applied to the ocean depth data at the model t-grids to smooth the bottom topography. Finally these depth values were used to specify the number of vertical levels at each model grid point. The final bathymetry and geometry for the model is shown in Figure 2.1.

There are 15 levels in the vertical. The thickness and mid-depth of each layer are shown in Table 2.1. The choice of such a vertical resolution is intended to give maximum resolution in the upper thermocline. The resolution in the abyssal circulation is lower. 


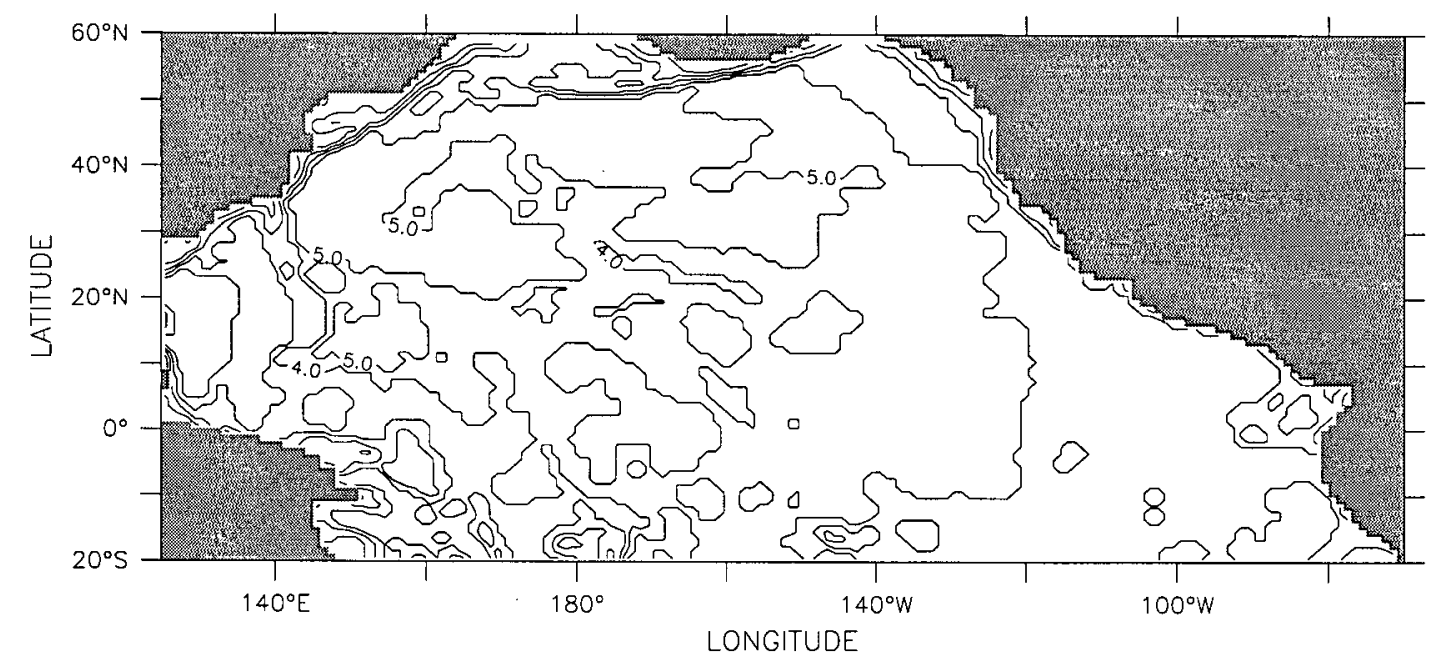

Figure 2.1: The smoothed topography of the ocean model, with depth in kilometers. 


\begin{tabular}{|ccc|}
\hline level & thickness $(\mathrm{m})$ & mid-depth(m) \\
\hline 1 & 30 & 15 \\
2 & 30 & 45 \\
3 & 40 & 80 \\
4 & 60 & 130 \\
5 & 100 & 210 \\
6 & 140 & 330 \\
7 & 200 & 500 \\
8 & 280 & 740 \\
9 & 380 & 1070 \\
10 & 480 & 1500 \\
11 & 600 & 2040 \\
12 & 700 & 2690 \\
13 & 800 & 3440 \\
14 & 900 & 4290 \\
15 & 960 & 5220 \\
\hline
\end{tabular}

Table 2.1: The vertical resolution of the model ocean

The time integration is performed with alternate applications of centered and Euler backward difference scheme in a ratio of $17: 1$. The advantage of such an alternate time stepping scheme lies in the fact that the instability contained in the second order centered scheme can be suppressed by infrequently taking a Euler backward step. The size of the time stepping (for momentum, tracers and stream function) is 1800 seconds.

\subsection{Boundary conditions}

The surface boundary conditions for temperature and salinity can be written as

$$
A_{H V}(T, S)_{z}=\left(Q^{t}, Q^{s}\right)
$$

where $Q^{t}$ and $Q^{s}$ are the fluxes of temperature and salt through the surface. The calculation of heat fluxes (latent, sensible, radiation) by bulk formulae are very involved. The calculation of fresh water flux (or salt flux) needs data for evaporation and precipitation 
which are poorly known. Therefore, to keep our surface boundary conditions simple, we used Newtonian linear damping conditions for the surface tracer flux terms. These boundary conditions are easier to handle and more stable. They take the following form [Bryan and Cox, 1967, 1968 and Cox, 1970]

$$
\begin{aligned}
& Q^{t}=\left(T_{1}-T_{0}\right) / \tau_{R}, \\
& Q^{s}=\left(S_{1}-S_{0}\right) / \tau_{R},
\end{aligned}
$$

where $T_{1}$ and $S_{1}$ are the model ocean temperature and salinity at the uppermost level, $T_{0}$ and $S_{0}$ are the reference temperature and salinity, and $\tau_{R}$ is a restoring time scale. Newtonian damping in the form of equations (2.14) and (2.15) restores model temperature and salinity to prescribed reference values which are usually the climatological fields.

For the experiments in this study, climatological values of surface temperature and salinity for different periods are used for different experiments. Details of the surface temperature and salinity climatological data used here are given in Chapter 3.

The wind stress forcing applied to the surface of the ocean is expressed by

$$
A_{M V}(u, v)_{z}=\left(\tau^{\lambda}, \tau^{\phi}\right)
$$

where $\tau^{\lambda}$ and $\tau^{\phi}$ are the zonal and meridional components of the wind stress field. A detailed description of wind stress climatology used in the experiments is given in Chapter 3.

At the surface, a rigid lid condition $w=0$ is applied, filtering out-the fast external gravity waves which could otherwise seriously restrict the size of the time step in the numerical integration. 
The lateral boundaries on the eastern, western and northern wall of the basin are set to be nonslip, insulating and impermeable, i.e.

$$
\begin{gathered}
u=v=0, \\
T_{\phi}=T_{\lambda}=0, \\
S_{\phi}=S_{\lambda}=0 .
\end{gathered}
$$

Along the southern nonslip boundary of the model ocean at $20^{\circ} \mathrm{S}$, a Newtonian relaxation of the tracer variables (temperature and salinity) to the observed annual mean climatological values [World Ocean Atlas, 1994] is applied from the surface down to the bottom with a relaxation time scale of one year, which could reduce the artificial effect of walling off the exchange of tracers at the latitude of $20^{\circ} \mathrm{S}$, where the real ocean is not blocked.

The bottom is considered to be insulating, impermeable and free-slip, i.e.

$$
\begin{gathered}
T_{z}=0, S_{z}=0, \\
w=-m u a^{-1} H_{\lambda}-v a^{-1} H_{\phi} .
\end{gathered}
$$

Another bottom boundary condition is

$$
\begin{gathered}
A_{M V}\left(u_{z}, v_{z}\right)=\left(\tau_{B}^{\lambda}, \tau_{B}^{\phi}\right), \\
\tau_{B}^{\lambda}=c d b o t * u * \sqrt{u^{2}+v^{2}}, \\
\tau_{B}^{\phi}=c d b o t * v * \sqrt{u^{2}+v^{2}},
\end{gathered}
$$

In the model, the bottom drag coefficient $c d b o t$ is set to zero by the free-slip condition, thus the bottom stress terms $\tau_{B}^{\lambda}$ and $\tau_{B}^{\phi}$ are zero. Hence, at the bottom,

$$
u_{z}=v_{z}=0
$$




\subsection{The choice of parameters}

Bryan et al. [1975] gave a detailed explanation on choosing the horizontal mixing coefficients. Since the model adopts the no-slip condition along the lateral boundaries, a viscous boundary layer needs to be resolved. If the boundary layer cannot be resolved, a computational mode can spread to the ocean interior and cause the numerical solution to become inaccurate. They found a relationship between the horizontal grid spacing $\triangle$ and the eddy viscosity $A$ based on Munk [1950] for resolving the boundary layer:

$$
A>\beta(\triangle \sqrt{3} / \pi)^{3}
$$

where $\beta$ is the gradient of $f$ in the meridional direction. Another computational consideration is that when the centered spatial differencing scheme is used and the Reynolds number is larger than a certain critical value, a computational mode can be excited. Chen [1971] gave the derivation of this stability criterion, which is

$$
R_{e_{\text {grid }}}=U \triangle / A_{M}<2
$$

The combined requirement on the horizontal eddy viscosity for a certain horizontal grid spacing was plotted by Bryan et al [1975]. Based on the stability requirement for $A_{M H}$, a value of $2.5 * 10^{8} \mathrm{~cm}^{2} \mathrm{~s}^{-1}$ is chosen for this study.

As for the horizontal diffusion coefficient $A_{T H}$, it can be smaller than the value required for $A_{M H}$ [Bryan et al, 1975]. A value of $2.5 * 10^{7} \mathrm{~cm}^{2} \mathrm{~s}^{-1}$ is chosen for $A_{T H}$ in the current study.

The Richardson number-dependent vertical-mixing coefficients [Pacanowski and Philander, 1981] have been adopted for $A_{M V}$ and $A_{T V}$ in the model.

For all the other model solution techniques the reader is referred to the technical report written by Pacanowski et al in 1991 [Pacanowski et al, 1991]. 


\section{Chapter 3}

\section{Surface Forcing Fields And Model Runs}

\subsection{The derivation of surface wind stress forcing field}

In order to establish a model ocean climatology, the model is spun up from the rest state with an initial three dimensional distribution of climatological temperature and salinity values. The initial fields of model temperature and salinity come from the objectively analyzed $1^{0} * 1^{0}$ annual mean climatological fields [World Ocean Atlas, 1994] which contains 33 standard vertical levels. Thus a vertical interpolation is performed to obtain the required climatological temperature and salinity fields at the model vertical levels.

The wind stress forcing fields applied to (2.16) are calculated from the surface wind speed fields of the COADS (Comprehensive Ocean Atmosphere Data Set) [Woodruff et al, 1987] monthly data on $2^{0}$ latitude by $2^{0}$ longitude grid box. The drag coefficients $C_{d}$ are taken from [Trenberth et al, 1989] and [Large and Pond, 1981], i.e.

$$
\begin{gathered}
\tau=\left[\tau_{\lambda}, \tau_{\phi}\right]=\rho C_{d} V[u, v] \\
C_{d}= \begin{cases}0.1 *(0.49+0.065 V) & \text { for } V>10 \mathrm{cms}^{-1} \\
0.114 & \text { for } 3 \leq V \leq 10 \mathrm{cms}^{-1} \\
0.1 *\left(0.62+1.56 V^{-1}\right) & \text { for } V \leq 3 \mathrm{cms}^{-1}\end{cases}
\end{gathered}
$$

where $V$ is the wind speed, $[\mathrm{u}, \mathrm{v}]$ the wind velocity, and $\rho$ is taken to be the constant value $1.2 \mathrm{Kg} \mathrm{m} \mathrm{m}^{-3}$ over the whole model domain. Because of a number of reasons (sparse data density before the 1950s, different measurement procedures since. 1946 [Ramage, 1987; 
Flohn and Kapal, 1988], and missing data over the model domain in the early 1950s) it was decided that only the data from 1952 to 1992 are to be used for this study. A monthly mean $1^{0} * 1^{0}$ climatology of the wind stress field is obtained for this period after using the NCAR objective analysis subroutine IDSFFT to interpolate over missing data and performing a second interpolation to convert the data on $2^{0} * 2^{0}$ grids to $1^{0} * 1^{0}$ grids overlying the model velocity grid. The resulting year to year (from 1952 to 1992) monthly wind stress field is stored for use in later experiments.

The pattern of monthly mean climatological wind stress field obtained from 1952 through 1992 are quite similar to those in Hellerman and Rosenstein [1983] (not shown). However it is known that the magnitude of the wind stress from Hellerman and Rosenstein is somewhat larger. A zonally averaged wind stress versus latitudes is plotted for both the COADS wind stress and the Hellerman and Rosenstein wind stress (Figure 3.1). It is seen that the curve patterns are basically similar, but the value of the Hellerman and Rosenstein wind stress is about $20-30 \%$ stronger than the COADS values used in this study. Xie and Hsieh [1995] calculated the wind stress from COADS dataset with a constant stress drag coefficient $C_{d}=1.5 * 10^{-3}$, where they found that the Hellerman and Rosenstein wind stress is $10-20 \%$ stronger. Harrison [1989] using the drag coefficient of Large and Pond [1981], but the same data as Hellerman and Rosenstein, obtained wind stress values everywhere smaller than those in Hellerman and Rosenstein.

\subsection{The derivation of SST and SSS climatologies as relaxation fields}

Following the same procedure as the one used in deriving the wind stress forcing fields from COADS dataset, a $1^{0} * 1^{0}$ monthly mean SST climatology based on the COADS dataset for the model domain in the period of 1952 to 1992 was formed. It will be applied to (2.14) as the observed climatological field for stabilizing the model surface 


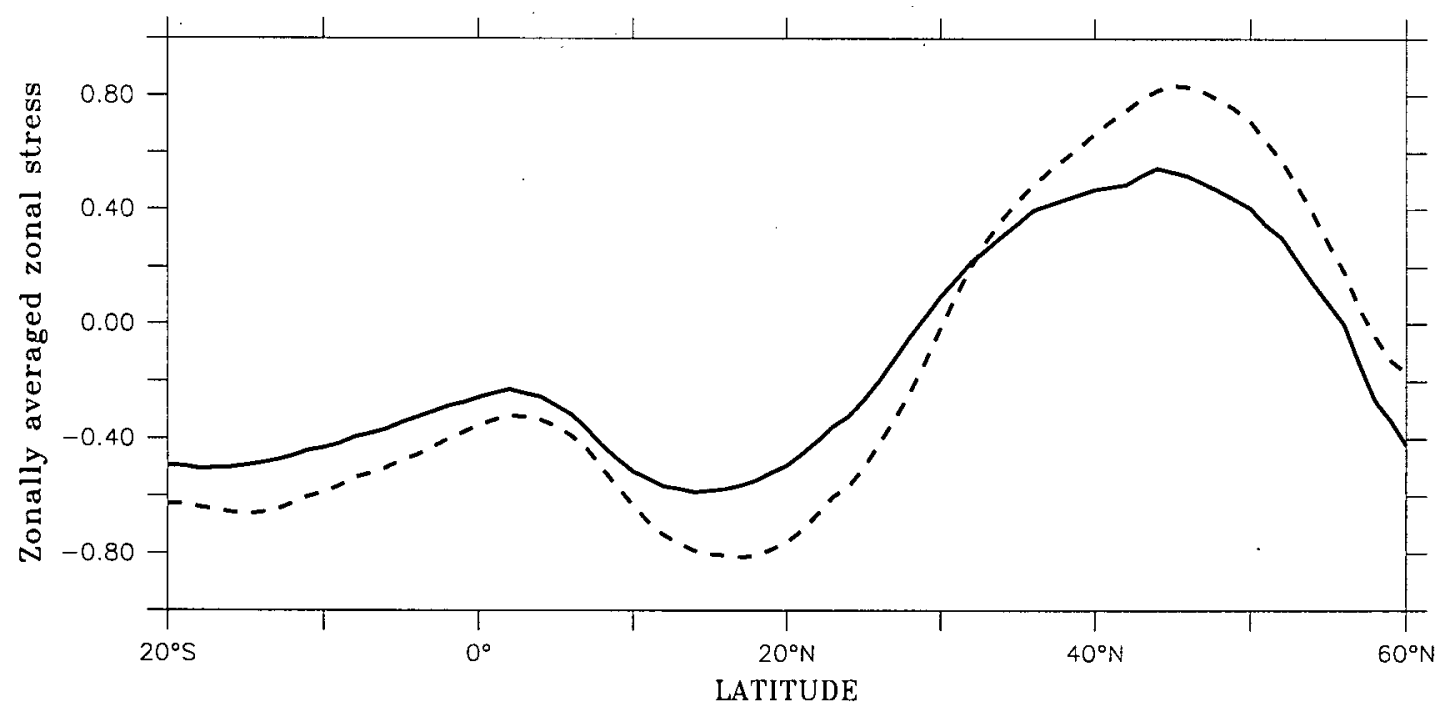

Figure 3.1: Zonally averaged zonal wind stress. Solid line represents COADS wind stress. Dashed line indicates Hellerman wind stress. The units are $d y \mathrm{n} / \mathrm{cm}^{2}$. 
layer temperature near the climatology. Because we do not have year by year monthly salinity data to determine the monthly mean climatology over the particular period, a monthly climatology of sea surface salinity field is extracted from World Ocean Atlas [1994], and it will be used as the surface salinity restoring field in (2.15). It should be pointed out that this sea surface salinity field will be used in all of the experiments even though the surface wind stress and SST forcing are different for different interdecadal experiments. The surface temperature and salinity relaxation time scale $\tau$ in (2.14) and (2.15) is one month. In the ocean interior, all the variables are allowed to evolve freely with time. Since all the surface forcing fields are monthly means, they are linearly interpolated to daily values for model forcing by simply assuming that the monthly mean value applies to the fifteenth of the month.

\subsection{Model spin up and the design of interdecadal experiments}

The model is spun up from the rest state with the surface boundary forced by the monthly climatological wind stress field, relaxed to monthly climatological sea surface temperature and salinity fields described above.

After 21 years of spin-up from the rest state, the model ocean is considered to be in a quasi-equilibrium state, with reasonable seasonal variations in the average kinetic energy density (Fig.3.2), but without significant interannual variations. Meanwhile the time rate of change in the temperature $(\partial T / \partial t)$ averaged over the whole basin shows a change of $\leq 2 \%$ of its average value between year 20 and year 21 for both the winter and summer seasons. This is the climatology run and is referred to as Exp.A or the basic run.

In order to investigate the long-term variations in the oceanic state due to the climatic regime shift of 1976 in atmospheric forcing, two additional numerical experiments are 


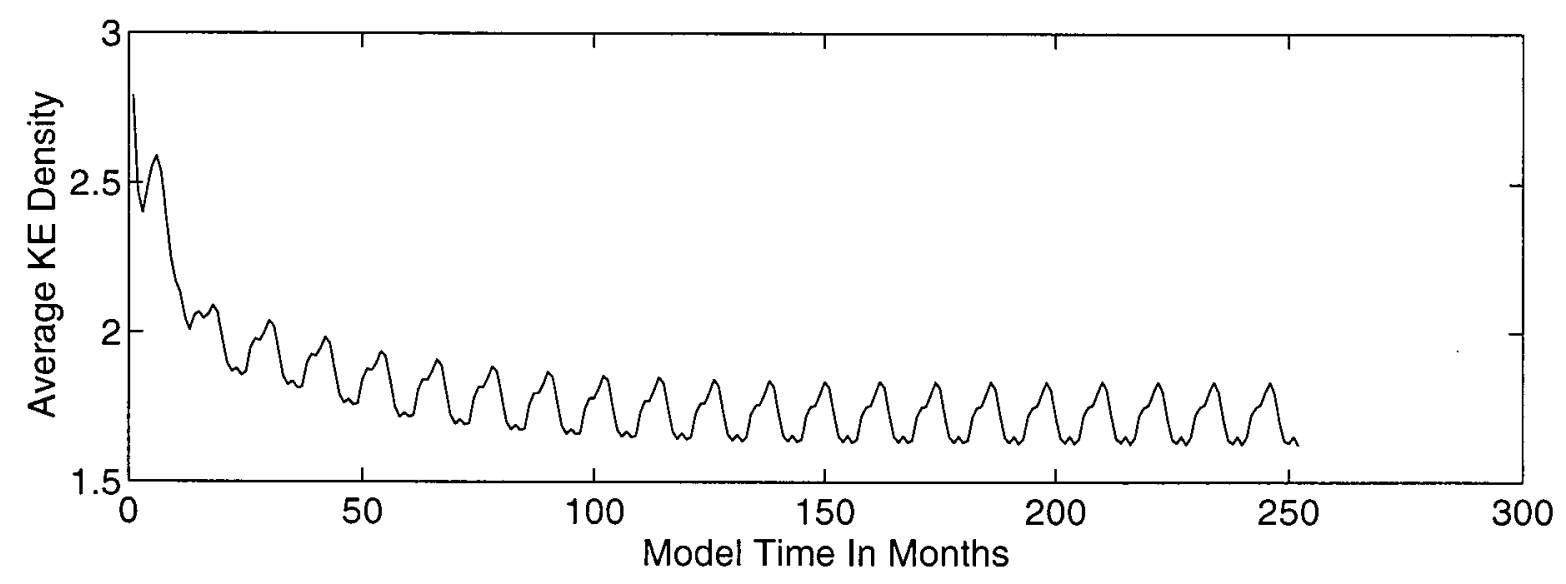

Figure 3.2: Averaged kinetic energy density of the model ocean as a function of time in months during spin-up by surface wind stress forcing and Newtonian temperature and salinity relaxation at the surface.

performed. These experiments are initialized by the equilibrium state of the basic run (i.e., runs continued from the end of Exp.A), but with the surface wind stress and SST forcing fields replaced by the COADS monthly climatologies value from 1952 through 1975 (pre-1976) in Exp.B and from 1976 to 1988 (post-1976) in Exp.C.

As the year to year monthly salinity data for the past four decades are not available, the surface salinity forcing field remains the same during both the pre-1976 and post1976 experiments as in the basic run. The effects of salinity on the upper ocean density 
structure are discussed in Chapter 6.

Six-year runs are carried out for both the pre-1976 climatology and post-1976 climatology cases from the end of the basic run. In order to compare with the results from Exp.B and Exp.C, the basic run (Exp.A) is also extended 6 more years. Variables such as $\mathrm{u}, \mathrm{v}, \mathrm{w}, \mathrm{T}, \mathrm{S}$ and stream function are archived once per month in the final year of each experiment. Since I am interested in the equilibrium solutions rather than the adjustment process leading to the equilibrium, little analysis will be performed for the non-equilibrium stages of the experiments. The analysis of simulated currents, temperature and other variables in the climatological run is given in Chapter 4.

Before proceeding to analyze the simulated results, it is necessary to first look at the difference between the post-1976 and the pre-1976 climatological SST and wind stress fields.

Trenberth and Hurrell [1994] have examined the decade-long change in the atmosphere circulation over the North Pacific by analyzing sea level pressure data. The observations reveal that for November through March from 1976-77 to 1987-88 the pressures in the Aleutian Low are lower than climatology by $3.0 \mathrm{mb}$ averaged over $30^{\circ} \mathrm{N}$ to $65^{\circ} \mathrm{N}, 160^{\circ} \mathrm{E}$ to $140^{\circ} \mathrm{W}$, while no significant change is found in the other months.

The deepening of the Aleutian Low implies an increase in the surface wind stress. Fig. 3.3 shows the surface wind stress field in the winter season from the COADS data set for the pre-1976 case and the post-1976 case. The intensification and southward excursion of the westerlies can be seen. The vector difference between them was calculated by subtracting the pre-1976 climatology from the post-1976 climatology. A cyclonic circulation is present over the North Pacific north of $25^{\circ} \mathrm{N}$ (Fig.3.4a), which means that the cyclonic circulation in the Aleutian Low after 1976 is stronger than before 1976, in agreement with the observation that the sea level pressure is lower after 1976. Fig3.4b is the zonally averaged zonal stress for both the pre-1976 and post-1976 climatologies. The 
(a)

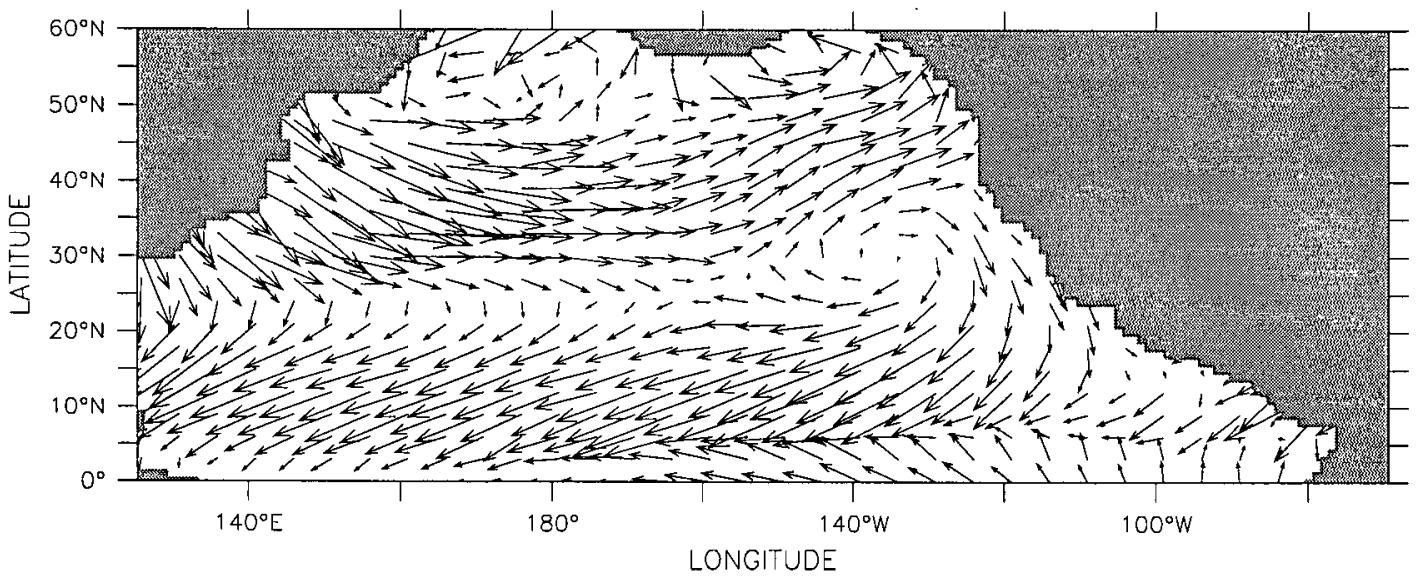

$\longrightarrow 1.00$

(b)

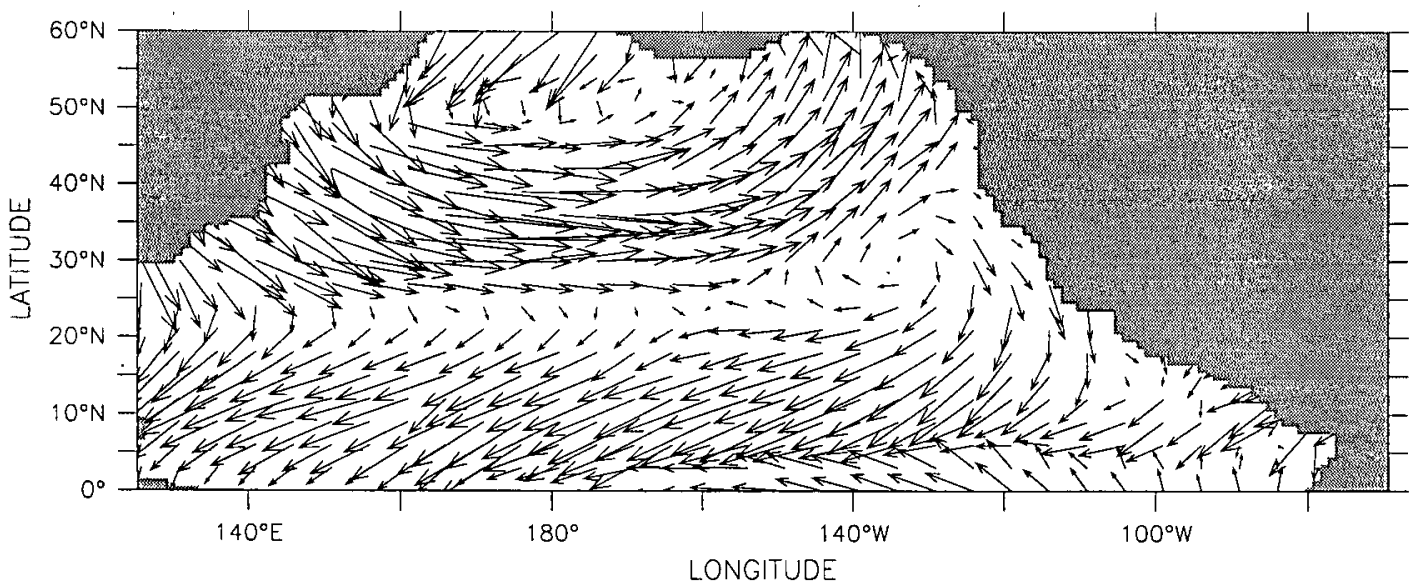

Figure 3.3: (a) The winter (DJF) wind stress climatology field for the period of 1952-75 (pre-1976) (b) for the period of 1976-88 (post-1976). The units are $d y n / \mathrm{cm}^{2}$. 


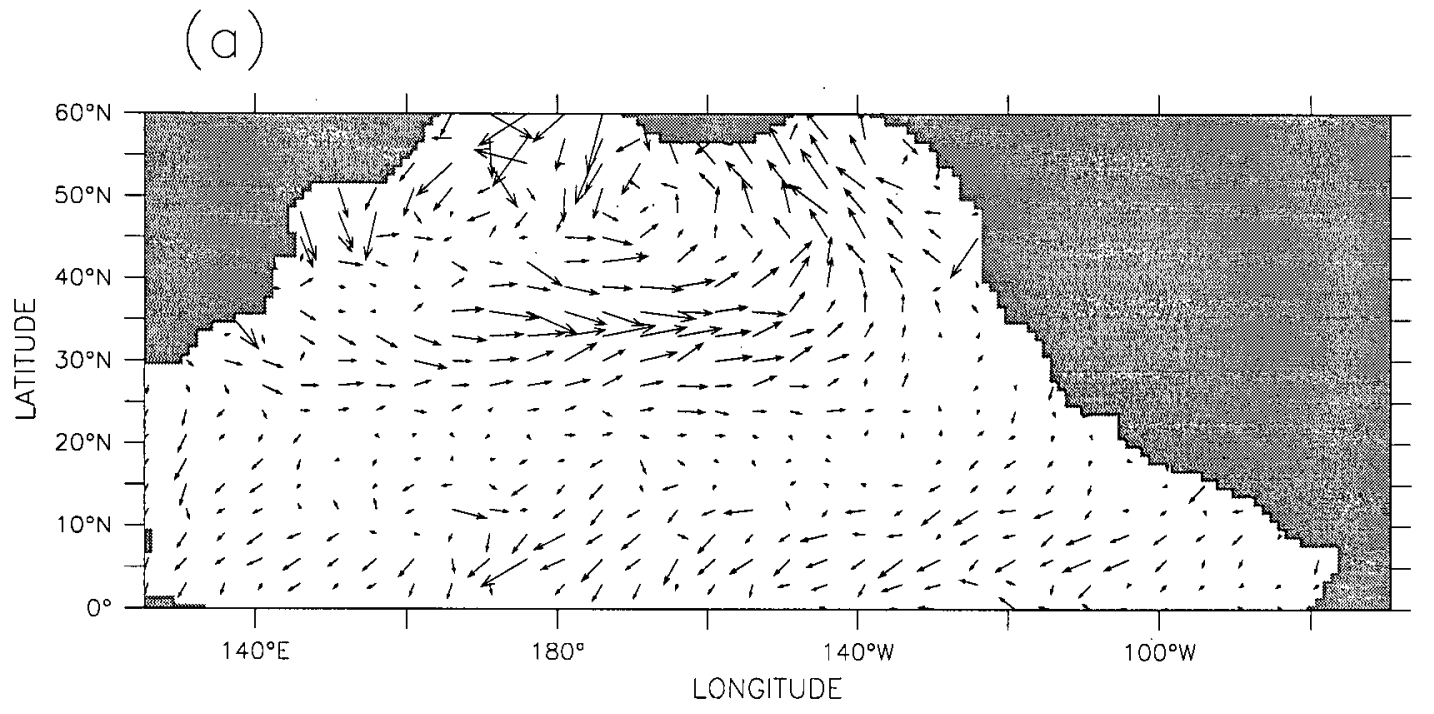

$\longrightarrow \quad 1.00$

(b)

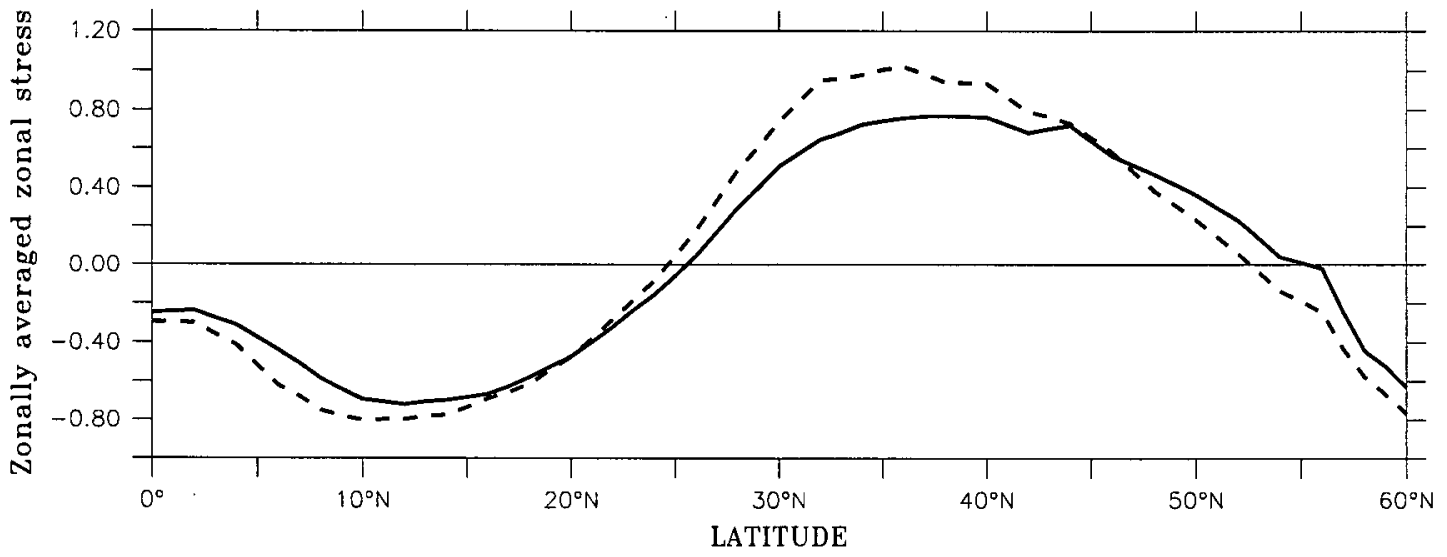

Figure 3.4: (a) The winter (DJF) wind stress climatology field of 1976-88 (post-1976) minus that of 1952-75 (pre-1976). (b) The zonally averaged zonal stress as a function of latitude. Dashed line indicates the 1976-88 (post-1976) climatology in DJF. Solid line represents the 1952-75 (pre-1976) climatology in DJF. The units are $d y n / \mathrm{cm}^{2}$. 
magnitude of zonal stress in the Aleutian low area has increased during 1976-1988 by a maximum amount of about $30 \%$ located at $35^{\circ} \mathrm{N}$. In the tropics the trade wind easterlies for the post-1976 case have also increased. The increas is not as large as that in the westerlies (Fig. 3.4a), however, it could be important in generating stronger northward Ekman transport in the low latitudes, hence causing changes in other variables.

The sea surface temperature (SST) over the North Pacific Ocean has been found to undergo significant changes for the period 1976-88. Fig 3.5 shows the difference in SST between the post-1976 climatology and the pre-1976 climatology in the winter. It depicts the very large regional Pacific temperature anomalies for 1976-88, where warming occurs along the west coast of North America, extending to Alaska (except for the B.C. coast), while cooling occurs in the central and western North Pacific. Miller et al [1994] derived the wintertime (DJF) SST difference field between the six years after regime shift and the six years before the shift. Their pattern was very similar to Fig 3.5. Royer [1989] indicated that there is a warming trend observed lasting from the late of 1970's until the late of 1980's near the Seward station in the Gulf of Alaska and over the northeast Pacific. He also noted that the increase in SST since the 1970s is restricted to latitudes north of $50^{\circ} \mathrm{N}$.

As to the cooling along the B.C. coast shown in Fig. 3.5, S. McKinnell (personal communications) found a similar result with the COADS data. However, his plot of the winter SST anomalies (from the pre-1977 mean) at Langara Island $\left(54.15^{\circ} \mathrm{N}\right)$ from lighthouse observations, shows positive anomalies after 1976. So it is likely that the COADS data are of poor quality in this area. Xie and Hsieh [1995] found that the number of observations of wind stress around this area is fewer than in the other coastal areas further south.

To show the nature of the SST changes associated the SLP changes, Trenberth and 


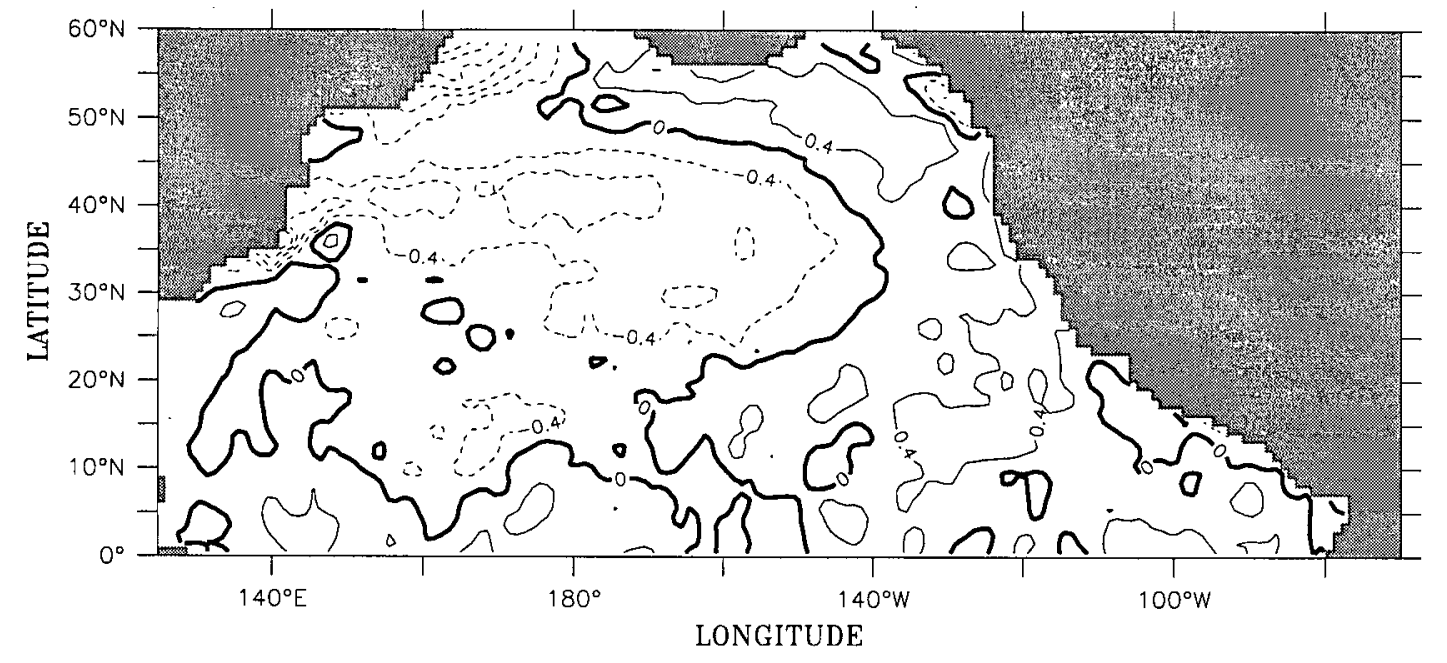

Figure 3.5: The SST from the post-1976 (1976-88) climatology minus the pre-1976 (1952-75) climatology in winter (DJF). The contour interval is $0.4\left({ }^{\circ} C\right)$. 
Hurrell [1994] examined the correlation between sea level pressure and sea surface temperature for 1935 to 1990 , showing that below normal sea level pressure over North Pacific is correlated with cooler SST over the central North Pacific and warmer SST along the West Coast, extending to Alaska. Emery and Hamilton [1985] indicated that an intense Aleutian Low is always associated with warmer coastal waters and higher coastal sea levels.

Indeed the intensified Aleutian Low, implying stronger wind stress, generates increased eastward surface transport towards the California coast, bringing lower salinity, warmer surface water, hence a deepened thermocline and high sea levels along the West Coast. Also because of the intensified Aleutian Low, the winds along the British Columbian coast are stronger, which drive anomalous onshore transports of warmer water from the south. These anomalous onshore transports cause stronger downwelling of a longer duration. As to the cooling in the central North Pacific, it is because anomalous northerly winds in the enhanced Aleutian Low brought cold water from the north into the central North Pacific. Another mechanism for the cold anomaly is that the increased storm activity near the center of an intensified low could enhance the local mixing of surface water with subsurface water, and release larger sensible and latent heat into the atmosphere. Ekman pumping is also a mechanism which could contribute to the SST cooling in the center of the intensified low pressure system [Mysak, 1986 and Trenberth and Hurrell 1994]. 


\section{Chapter 4}

\section{Basic climatological run results}

As described in Chapter 3, the model is spun up from the rest state with the surface boundary forced by the monthly climatological wind stress field and relaxed to monthly climatological sea surface temperature and salinity fields. In this chapter, the simulated results at the quasi-equilibrium state for this climatological run are presented.

The vector plots of surface wind stress for both January and July (Fig.4.1) show that the wind stress in winter is much stronger than that in summer, especially in the high latitude region. Again it reveals the fact that in winter the North Pacific is dominated by the cyclonic gyre (Fig.4.1a) due to the Aleutian Low, while in summer it is controlled by the anti-cyclonic gyre (Fig.4.1b) of the Pacific High.

\subsection{The vertically integrated transport}

The vertically integrated transport streamfunction in Fig.4.2 shows that a typical three

gyre circulation is simulated in the North Pacific Ocean for both seasons. As expected, the pattern of the streamfunction follows the vertical component of the curl of the surface wind stress, approximately satisfying the Sverdrup relation for most of the basin area, although there will always be small frictional effects. In winter, as shown in Fig.4.2a, the subtropical anti-cyclonic gyre (the middle one) has its maximum transport of about 45 Sverdrup $\left(10^{6} \mathrm{~ms}^{-1}\right)$ in the Kuroshio region. In the subarctic region, the subarctic gyre consists of two separated cyclonic gyres in the eastern and western parts. The western boundary transport (Oyashio) reaches $13 \mathrm{~Sv}$. The strength of transport in the center 
Chapter 4. Basic climatological run results

(a)

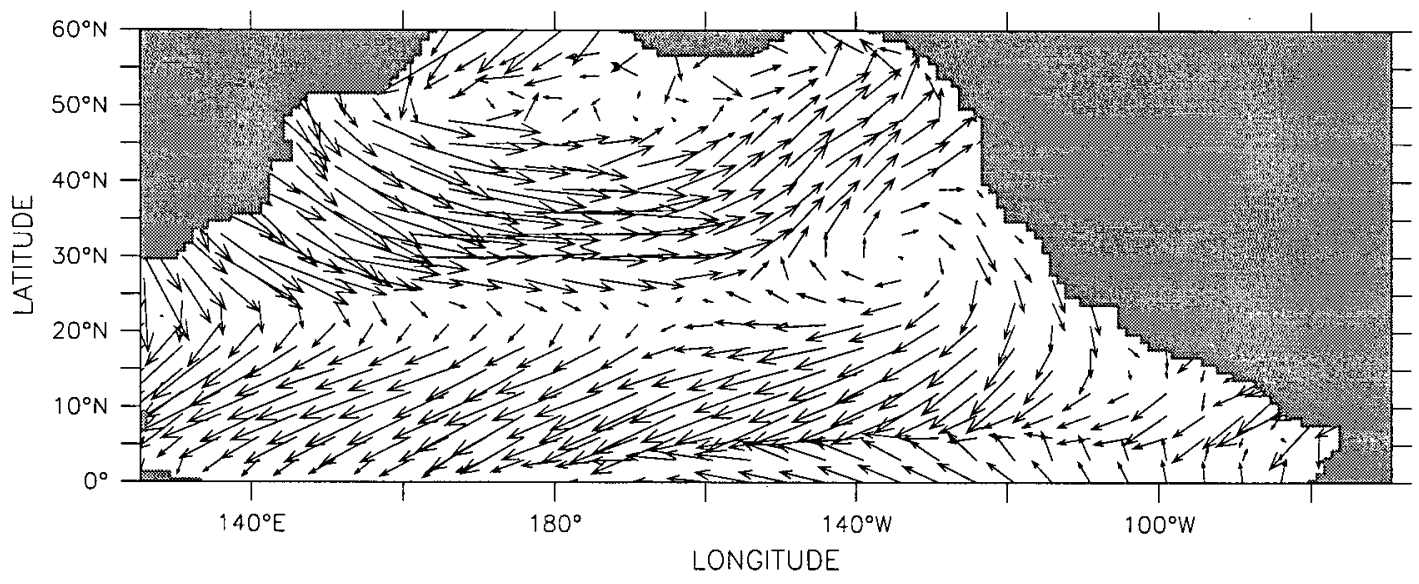

$\longrightarrow \quad 1.00$

(b)

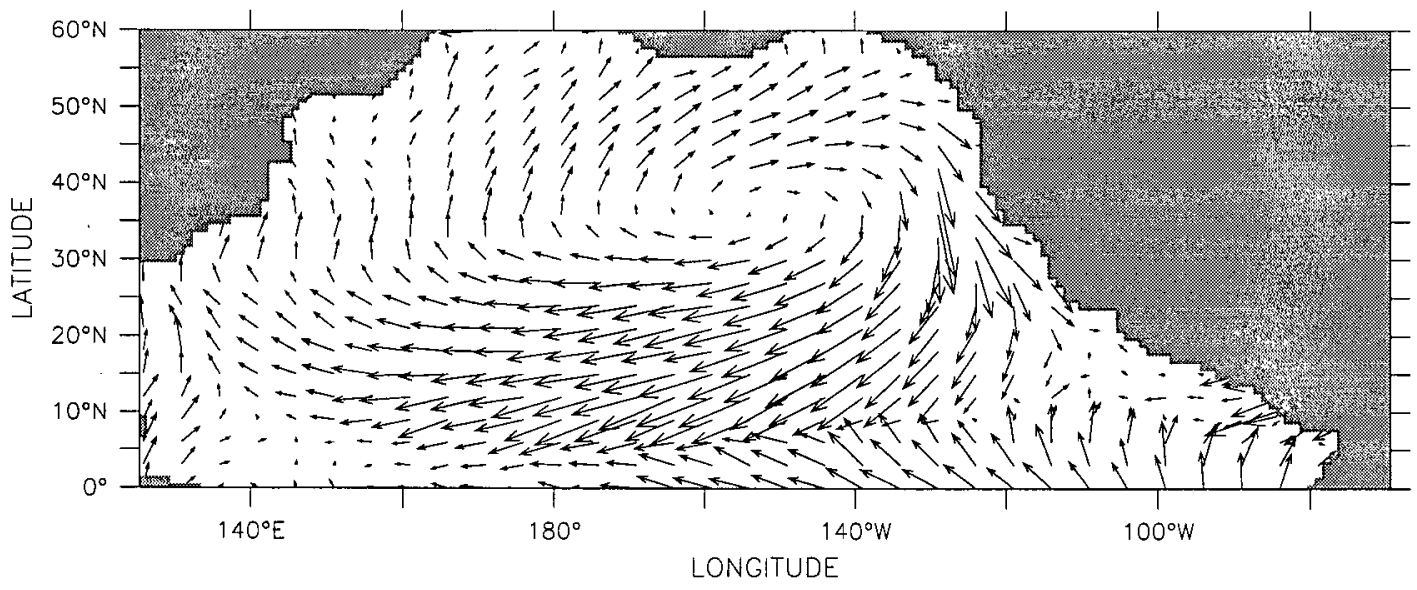

$\longrightarrow 1.00$

Figure 4.1: The vector plots of surface wind stress for (a) January and (b) July. The units are $d y n / \mathrm{cm}^{2}$. 


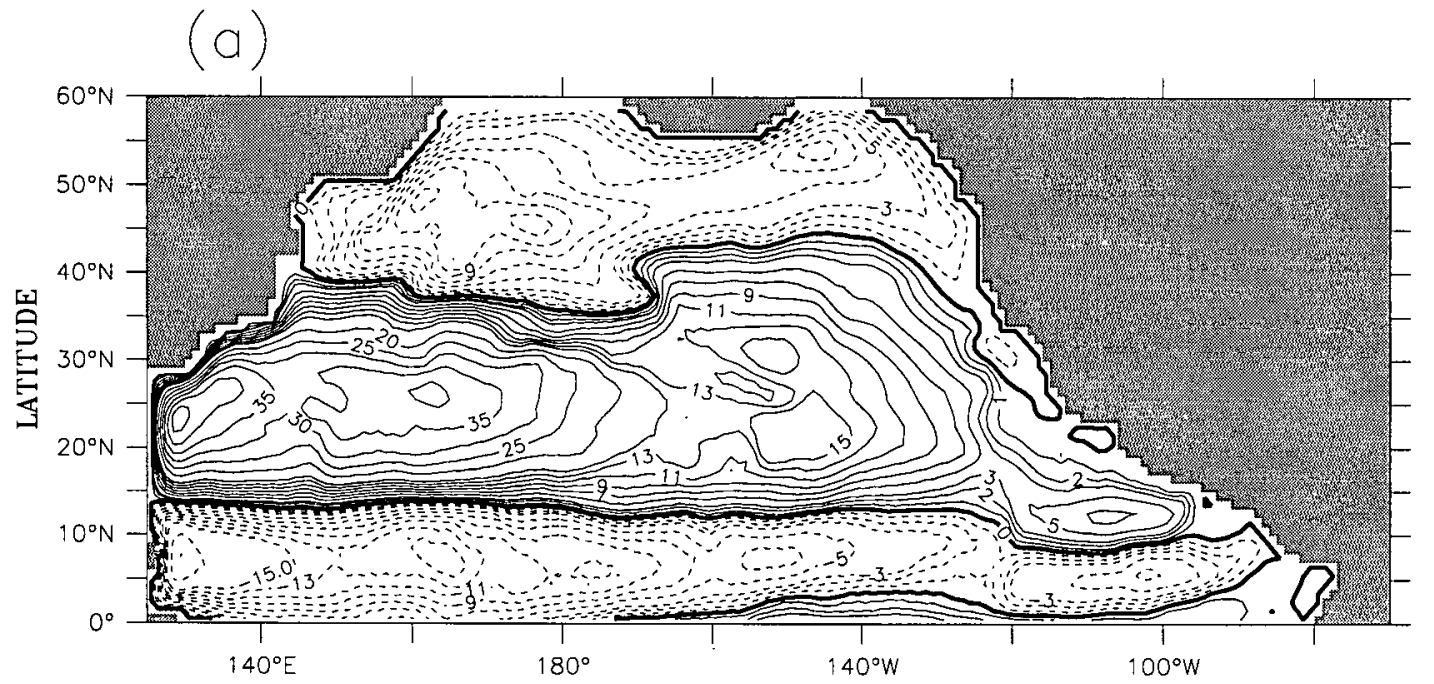

(b)

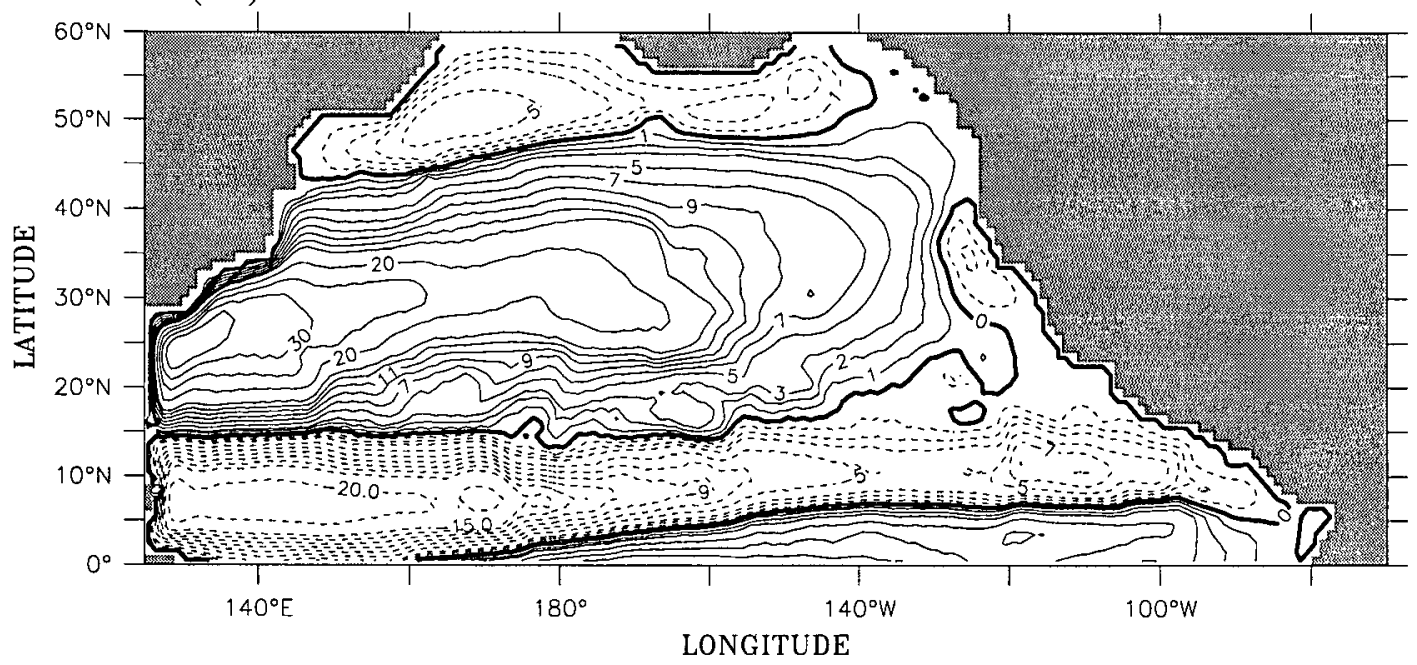

Figure 4.2: The vertically integrated transport streamfunction for (a) January and (b) July. The contour values are $\pm 1, \pm 2, \pm 3, \pm 5, \pm 7, \pm 9, \pm 11, \pm 13, \pm 15, \pm 20, \pm 25, \pm 30$, $\pm 35, \pm 40, \pm 45 \mathrm{~Sv}$. 
of the Alaska gyre is $9 \mathrm{~Sv}$. As the season progresses to summer, the wind field over the North Pacific has shifted north and has weakened (Fig.4.1b). Fig 4.2b shows the circulation in the ocean in summer. Basically it has similar patterns to the one in the winter, but with the subtropical gyre and the tropical gyre moved northward to $47^{\circ} \mathrm{N}$ and $15^{\circ} N$, respectively, and the subarctic gyre shrunk and receded. The strength of three gyre transports are relatively weaker, with a Kuroshio of $35 \mathrm{~Sv}$, and an Oyashio of $5 \mathrm{~Sv}$. The Alaska Gyre has receded to almost above $50^{\circ} \mathrm{N}$, with a maximum transport of $2 \mathrm{~Sv}$.

It is well known that the Kuroshio Current in the subtropical gyre is the most prominent phenomenon in the North Pacific Ocean. Even though it is rather difficult to compare the simulated transport with the observational data because of the problem of choosing a reference level of no motion for the relative transport calculation from the observed hydrographic data, a rough comparison between the simulated current and the observed data can be made to verify the model results. Taft [1972] showed that the relative transport of the Kuroshio around $139^{\circ} \mathrm{E}$ is about $42 \mathrm{~Sv}$ all year round. Nitani [1972] showed that the transport of the Kuroshio east of Taiwan is about $40 \mathrm{~Sv}$ on average. Pickard and Emery [1990] stated that the volume transport of the Kuroshio is about $40 \mathrm{~Sv}$. Hence the simulated Kuroshio agrees quantitatively well with the observational values.

In Huang [1979(a)], a similar primitive equation ocean model yielded $63 \mathrm{~Sv}$ for the Kuroshio and $33 \mathrm{~Sv}$ for the Oyashio. The likely reason why his study yielded stronger western boundary currents is that he used lower viscosity. The lower viscosity tends to increase the transport, especially in the western boundary region, and also narrows the scale of western intensification. Experiments with different viscosities in this model showed that transport variations of $5 \mathrm{~Sv}$ were possible with horizontal viscosity changing from $1 . * 10^{8} \mathrm{~cm}^{2} \mathrm{~s}^{-1}$ to $2.5 * 10^{8} \mathrm{~cm}^{2} \mathrm{~s}^{-1}$. Comparing to the subarctic gyre simulated in Hsieh [1987] which used basically the same ocean model but had poor resolution of 
the bottom topography with only 5 vertical levels, my current study obtained weaker difference in the transport strength between the western part of the subarctic gyre and the eastern part.

\subsection{The velocity}

\subsubsection{The horizontal velocity}

The surface layer current (including both barotropic and baroclinic components) is shown in Fig.4.3. For a legible vector plot, only half of the data points in the zonal dimension and one-third in the meridional dimension were plotted. In high latitudes, the magnitude of the currents are small. Values under $0.75 \mathrm{cms}^{-1}$ are not drawn and some blank areas appear, especially in summer (Fig.4.3b). It is evident that the surface current is dominated by the Ekman wind-induced flow, moving to the right of the wind stress in the Northern Hemisphere as shown in Fig. 4.3. The model simulation portrayed the major observed currents. In the mid-latitude region from the subtropic to the subarctic, the Kuroshio and the Oyashio currents merge around $40^{\circ} \mathrm{N}$ to form the beginning of the broad and slow North Pacific Current (NPC). The Alaska Current is indicated by a few arrows pointing north right along the coast of North America above $45^{\circ} N$. The California Current (CC) is the southward flow in the area of $25^{\circ} \mathrm{N}-45^{\circ} \mathrm{N}, 140^{\circ} \mathrm{W}-115^{\circ} \mathrm{W}$. The westward-flowing North Equatorial Current (NEC) is shown between $10^{\circ} \mathrm{N}$ and $\left.25^{\circ} N\right)$. The North Equatorial Countercurrent (NECC) lies around $5^{\circ} N-10^{\circ} N$ where it is generally observed. It is difficult to see the Countercurrent in the picture because it is partly hidden by the big arrows of westward-flowing South Equatorial Current (SEC)

along the equator. For the classical locations of these currents, the reader is refered to page 236 of Pickard and Emery [1990].

The seasonal variations in the surface current systems are simulated. The strongest 

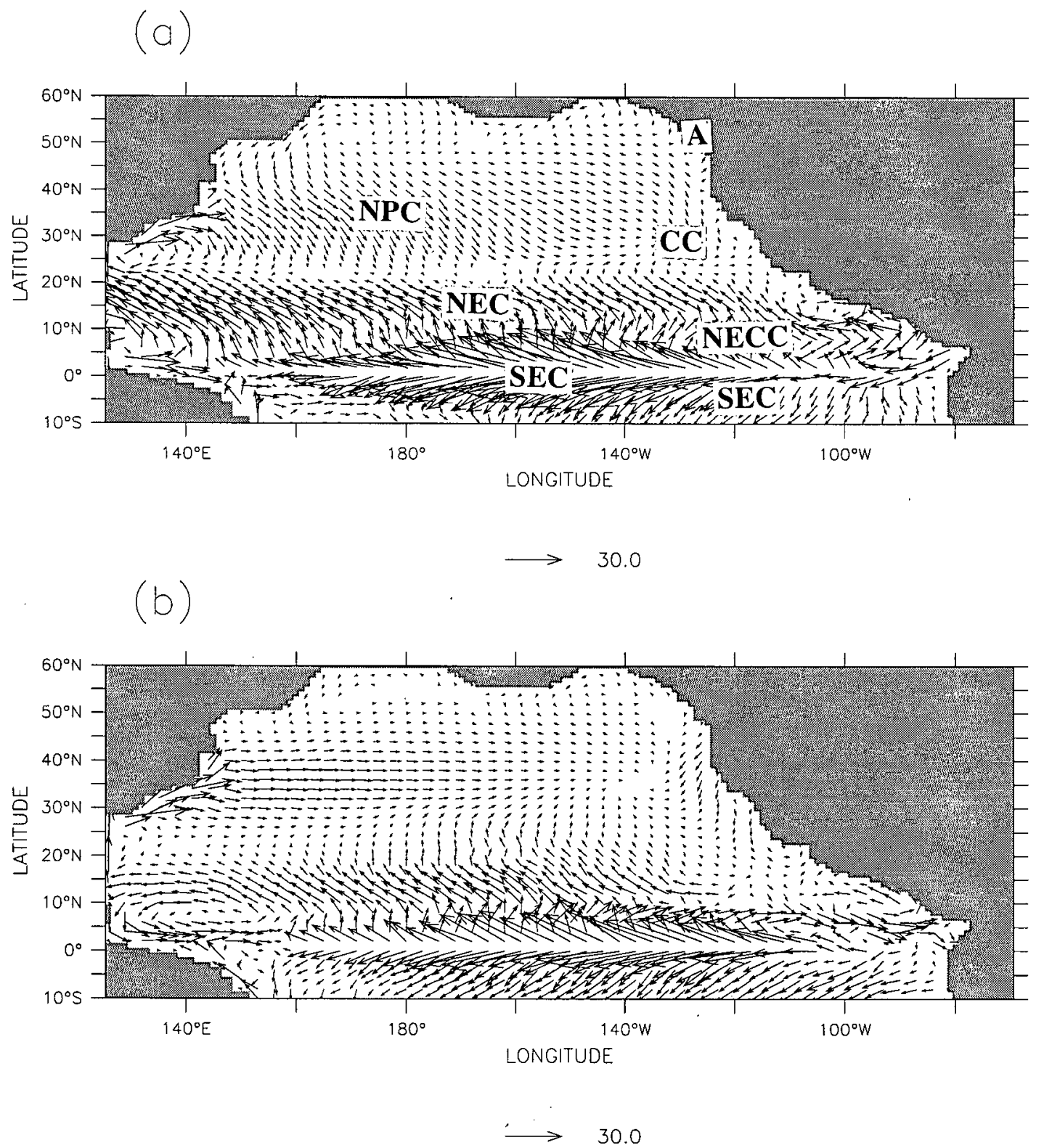

Figure 4.3: The simulated current velocity at $15 \mathrm{~m}$ depth in (a) January and (b) July. The vector scales are $30 \mathrm{cms}^{-1}$. NPC=North Pacific Current, NEC=North Equatorial Current, NECC=North Equatorial Countercurrent, $\mathrm{SEC}=$ South Equatorial Current, $\mathrm{CC}=$ California Current, $\mathrm{A}=$ Alaska Current. 
South Equatorial Current occurs around $140^{\circ} \mathrm{E}$ with speeds up to $64 \mathrm{cms}^{-1}$ in winter as a result of the southeast trade winds, becoming relatively weaker in summer with speeds up to $51 \mathrm{cms}^{-1}$. The North Equatorial Countercurrent (NECC) varies seasonally in strength and position. It is more noticeable in summer as shown in Fig.4.3b and lies between $5^{0} \mathrm{~N}-10^{\circ} \mathrm{N}$ extending all the way from the equatorial western Pacific to the eastern Pacific. During winter it almost disappears to the west of $160^{\circ} \mathrm{W}$. Tomczak and Godfrey [1994] explained that in winter the Countercurrent is only fed from the North Equatorial Current because northwest monsoon prevents the South Equatorial Current from feeding the NECC. Tsuchiya [1974] indicated that the variation of NECC is closely associated with the shift of the ITCZ in the atmospheric circulation. In summer when ITCZ lies at its northernmost position around latitudes $11^{\circ} \mathrm{N}-15^{\circ} \mathrm{N}$, the NECC is strong and broad. The North Equatorial Current is stronger in winter than in summer as shown in Fig.4.3.

The Kuroshio Current flows faster during summer with a simulated speed of $48 \mathrm{cms}^{-1}$, $20 \%$ stronger than its winter speed of $40 \mathrm{cms}^{-1}$. Huang [1979(a)] simulated $37 \mathrm{cms}^{-1}$ for the Kuroshio speed during summer and $33 \mathrm{cms}^{-1}$ in winter. Tomczak and Godfrey [1994] indicated that seasonal variation of the sea level difference across Tokara Strait $\left(130^{\circ} \mathrm{E}, 30^{\circ} \mathrm{N}\right)$ implies an increase of $13 \%$ in current speed from winter to summer. So the simulated current speeds are consistent with others.

For the vertically integrated flow, the eastern part of the Pacific Ocean plays a role of horizontal recirculation in the ocean-wide gyres. This is true for the region away from coastal boundaries but does not hold over short periods or close to the shelf. Along the west coast of North American, the winds have large seasonal variations - equatorward winds prevail along the coast during summer which drives the surface flow offshore to produce coastal upwelling and a lower sea level along the coast, which leads to an equatorward surface current due to the geostrophic balance. It is this process that produces 
the cooling of SST and associated cooling of air along the coastal region. In winter, winds are quite variable and often southerly, as a result the surface flow is weaker and a poleward flow at the surface could exist over the shelf due to the southerly winds.

To the north of the Californian upwelling region, the Alaska Current, also called the Alaska Coastal Current, flows northward. It is stronger in winter than in summer, when the winds tends to oppose the flow.

Fig.4.4 shows the seasonal current patterns simulated in the fourth layer (at $130 \mathrm{~m}$ depth). Over most of the North Pacific Ocean, the currents flow in a near zonal direction, except in the western boundary region. By comparing with the surface currents, the Ekman dynamic effect appears greatly reduced below the surface. The most prominent difference between these subsurface currents and the surface currents is the existence of the eastward flowing Equatorial Undercurrent for all seasons in the fourth layer.

\subsubsection{The vertical velocity}

The modelled vertical velocities at the bottom of the second layer (60 m depth) during DJF and JJA are shown in Fig.4.5. Light grey indicates the upwelling area, while darker grey represents the downwelling region. The contour values are not at equal intervals. By comparing with the vertical velocities at the first layer and other layers, it is found that the second layer tends to have the largest vertical speed.

The vertical velocity field shown in Fig.4.5 has gone through a Laplacian smoothing scheme which can be expressed as

$$
Z_{s}=Z+0.25 *[(Z N+Z S+Z E+Z W) / 4-Z]
$$

where $Z_{s}$ is the new smoothed value and $Z N, Z S, Z E$, and $Z W$ are the four unsmoothed closest neighbours of $\mathrm{Z}$ [Xie and Hsieh, 1995]. There is intense upwelling in the equatorial 
(a)
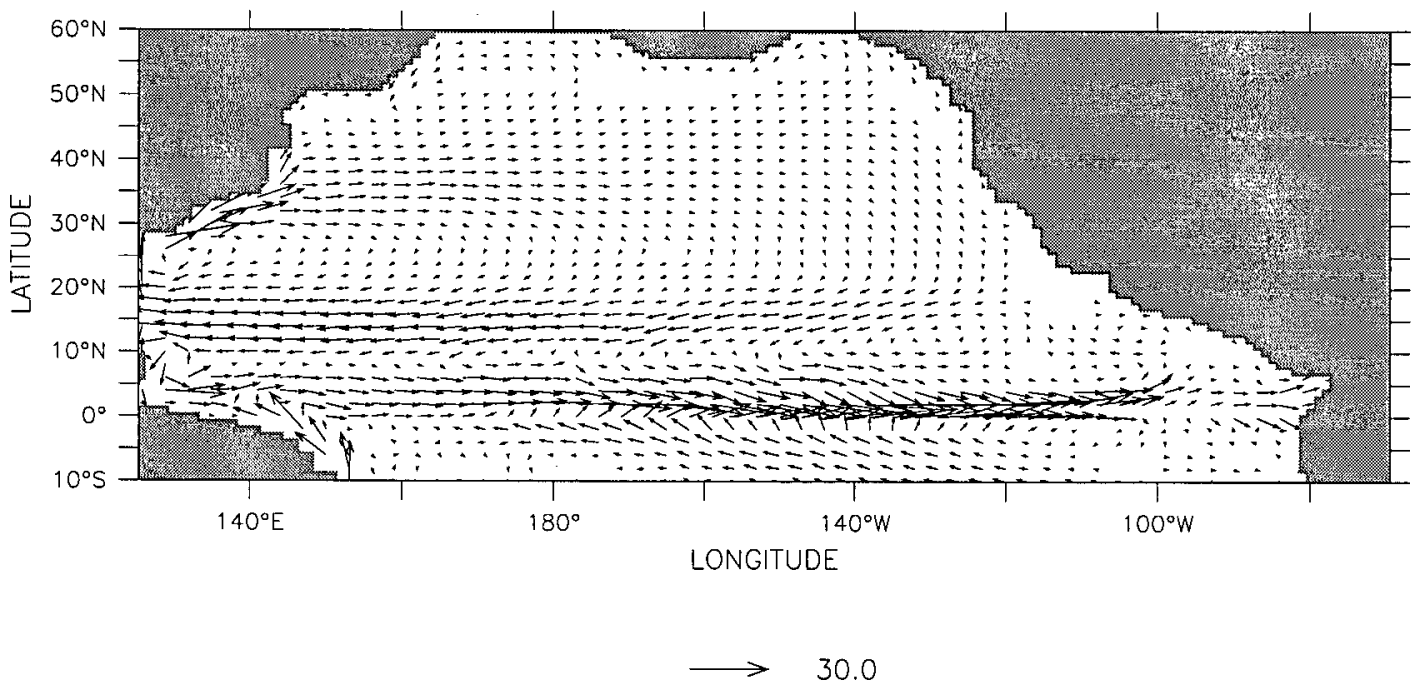

(b)

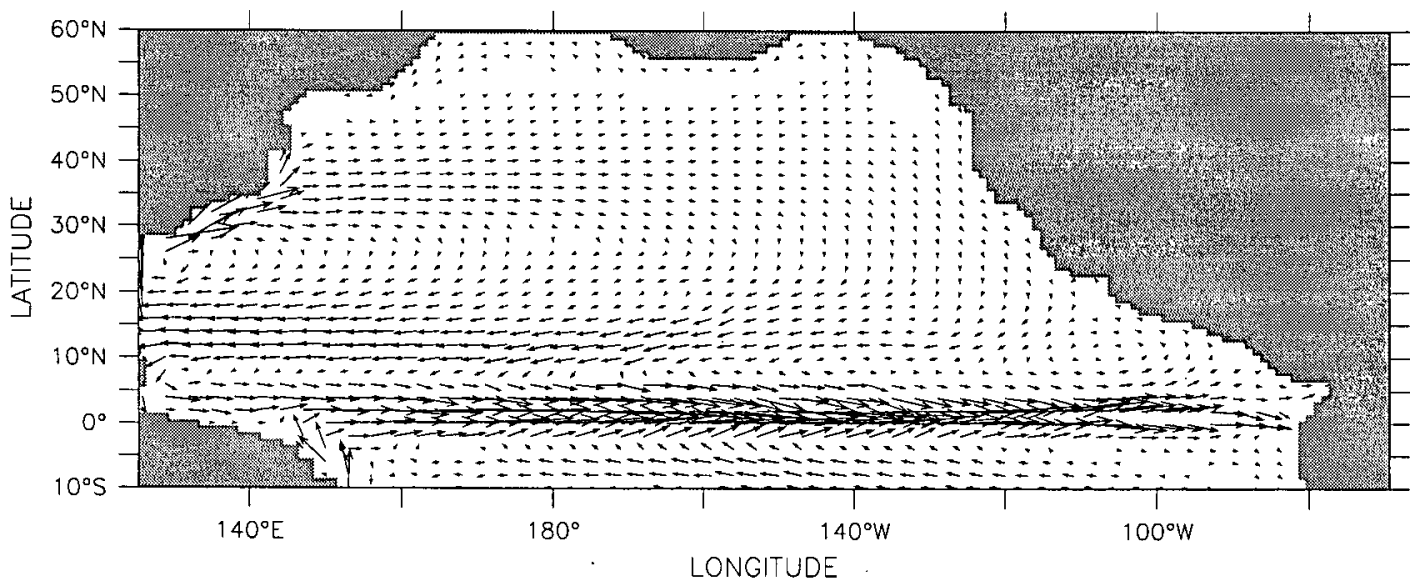

Figure 4.4: The simulated current velocity at the fourth model layer of $130 \mathrm{~m}$ depth in (a) January and (b) July. The vector scales are $30 \mathrm{cms}^{-1}$. 



Figure 4.5: The simulated vertical velocity at $60 \mathrm{~m}$ depth in (a) DJF and (b) JJA. The light grey area indicates upwelling. The dark grey area downwelling. The contour values are $\pm 10, \pm 20, \pm 50, \pm 100, \pm 200, \pm 250, \pm 300 \mathrm{~cm} /$ day . 
region and along much of the western boundary in all seasons. The western boundary upwelling penetrates to approximately $800 \mathrm{~m}$ depth without diminishing in magnitude, while the upwelling along the equatorial region does not penetrate to deep levels. The value of upwelling in the equatorial band at a depth of 130 meters is only $20 \mathrm{~cm} / \mathrm{day}$. General downwelling covers the whole subtropical area, while upwelling covers the subarctic area.

The largest upwelling in the equatorial region occurs in the winter season, with a maximum value of $363 \mathrm{~cm} \mathrm{day} y^{-1}$ at $0^{0} \mathrm{~N}, 141^{0} \mathrm{~W}$. The maximum upwelling in the equatorial region in summer is $295 \mathrm{~cm} d a y^{-1}$ at $1^{0} \mathrm{~N}, 139^{\circ} \mathrm{W}$. Generally the downwelling in the subtropic region and the upwelling in the subarctic region are stronger in winter than in summer. The upwelling region in the subarctic area is much broader in winter (as shown in Fig. 4.5a) than in summer. Along the west coast of North America, in summer, the active coastal upwelling region extends from $25^{\circ} \mathrm{N}$ to the north up to the northern boundary of the model domain. In winter, the west coast has patches of downwelling alternating with patches of upwelling.

In addition, in summer, between the tropical and subtropical downwelling region, there are two upwelling tongues. One extends eastward from the Philippines, while the other extends westward from Mexico. In the wind-induced vertical velocity pattern in July computed from COADS wind stress [Xie and Hsieh, 1995], there are similar upwelling tongues in these area, though the tongues are shorter than those simulated in this study. The tongues are unnoticeable in the winter season. The upwelling tongues are located at the ITCZ (Inter-Tropical Convergence Zone) and may be related to the ITCZ [Xie and Hsieh, 1995]. In summer, the ITCZ is intensified and lies at its northernmost position. Its seasonal migration and change in intensity could lead to seasonal changes in the upwelling tongues in the subtropical downwelling domain.

The zonally averaged vertical velocity as a function of latitude in DJF and JJA 


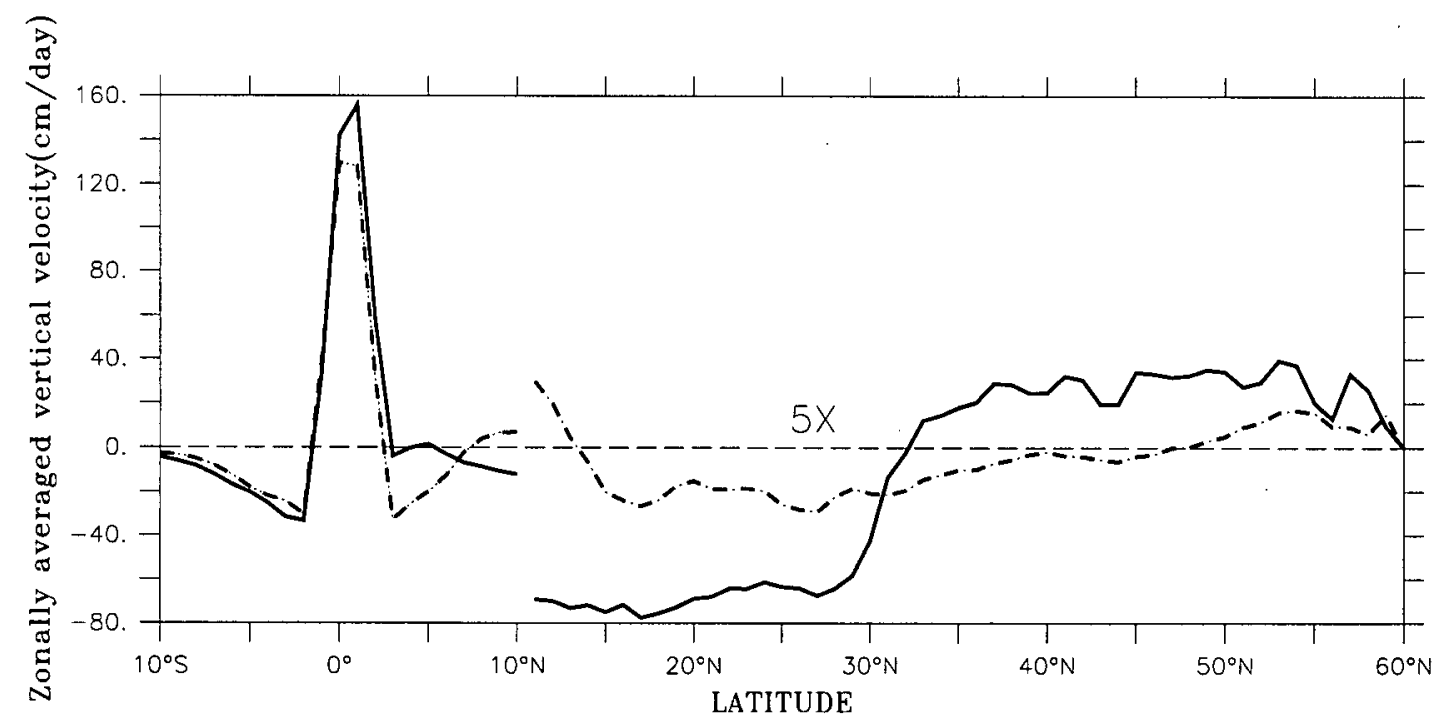

Figure 4.6: The zonally averaged vertical velocity at $60 \mathrm{~m}$ depth in DJF (solid line) and JJA (dash-dotted line). The value of velocity between $10^{\circ} \mathrm{N}$ and $60^{\circ} \mathrm{N}$ is multiplied by 5 for better visualization. 
is shown in Fig.4.6. The vertical velocity above $10^{\circ} \mathrm{N}$ is multiplied by 5 for better visualization. It clearly exhibits the three different bands, equatorial upwelling band, subtropical downwelling and subarctic upwelling bands. The maximum value of zonally averaged vertical velocity is $156 \mathrm{~cm} \mathrm{day}^{-1}$ in winter, and $129 \mathrm{~cm} \mathrm{day}{ }^{-1}$ in summer.

These simulated results can be compared with those of other authors. Xie and Hsieh [1995] estimated a maximum zonally averaged upwelling value of $140 \mathrm{~cm} \mathrm{day} y^{-1}$ and a maximum value of $519 \mathrm{~cm} d a y^{-1}$ occurring at $152^{\circ} \mathrm{W}, 1^{0} \mathrm{~N}$ in the middle of the Pacific in July. Bubnov [1987] obtained an upwelling value of $319 \mathrm{~cm} \mathrm{day}^{-1}$ at a depth of 25-125 $\mathrm{m}$ at $163^{\circ} \mathrm{W}-167^{\circ} \mathrm{W}$ in central Pacific. Halpern [1980] reported an upwelling value of $259 \mathrm{~cm} \mathrm{day} y^{-1}$ at $50 \mathrm{~m}$ depth. So the simulated results are within reasonable range.

\subsection{Temperature}

The simulated sea surface temperature patterns at $15 \mathrm{~m}$ depth during DJF and JJA are shown in Fig.4.7, together with the observed COADS SST fields. Generally there is agreement between the simulated and the observed surface temperature patterns, as expected since the model SST is relaxed to the observed field. Large meridional temperature gradients exist in the area where the Kuroshio and the Oyashio merge. A broad warm area is found in the western tropical region. An equatorial cooling zone extends from the central equatorial Pacific to the eastern boundary.

However, there are some discrepancies between the simulated and the observed SST. In winter, the simulated water in the western tropical area is warmer than observed. A sharper temperature gradient occurs off the western boundary around $40^{\circ} \mathrm{N}$. In the subarctic region and off the coast of North America the simulated water is warmer than observed, while the eastern equatorial region is cooler than observed. In contrast, the simulated summer temperatures are cooler than the observed in the western tropical area, 

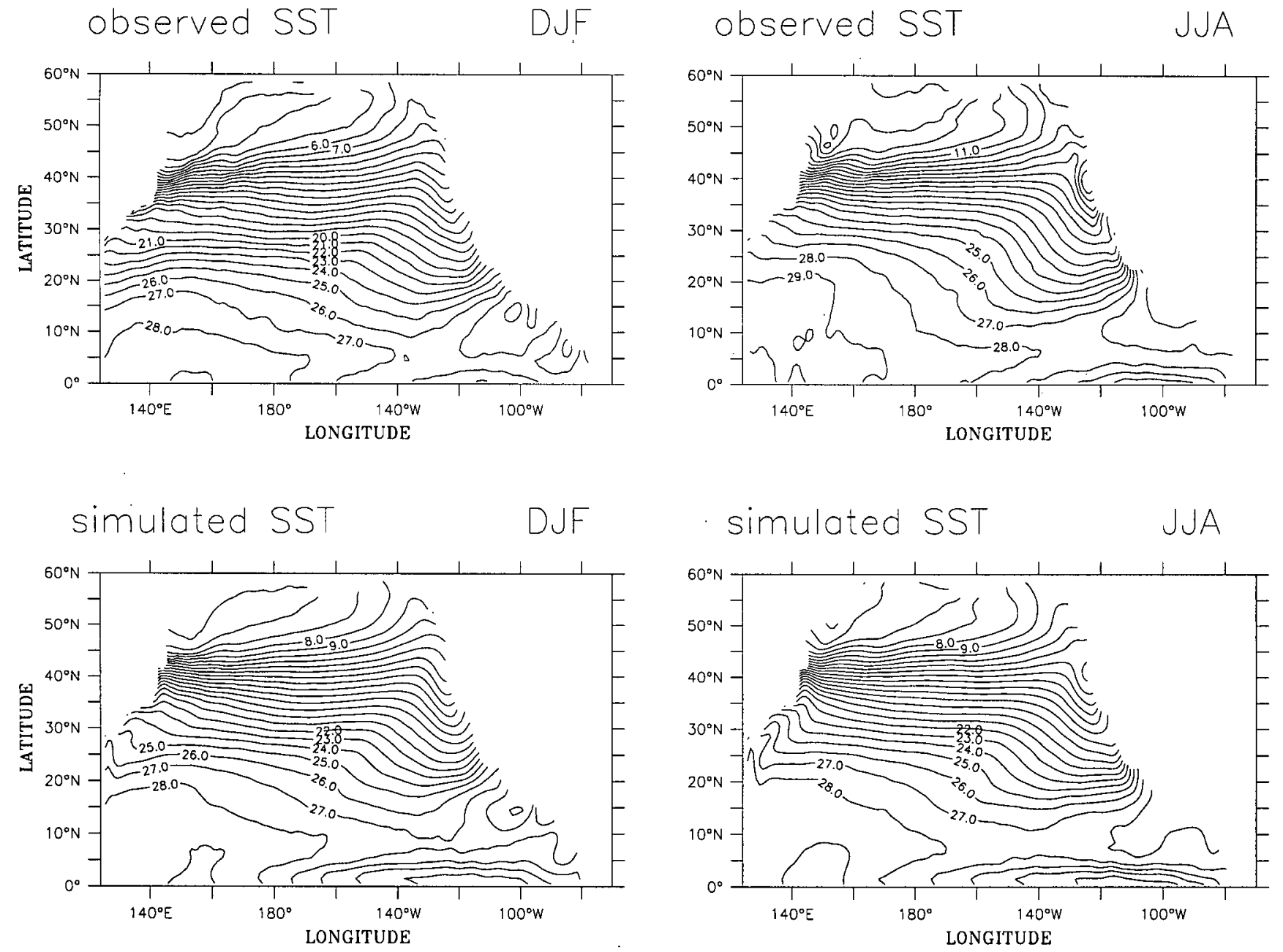

Figure 4.7: The observed SST (upper panel) and simulated SST (lower panel) in DJF and JJA respectively. 
subarctic area and off the coast of North America, which largely reduces the amplitude of the seasonal variation of the SST. This deficiency could be due to the linear surface relaxation boundary condition, without any surface feedback mechanism.

\subsection{Meridional circulation and heat transport}

Fig.4.8 and 4.9 depict the simulated meridional mass transport in January and July, respectively. In low latitudes, there are two strong meridional circulations on either side of the equator, which are largely associated with the Ekman suction at the equator [Bryan et al, 1975]. They are very effective in transporting the heat poleward since surface water is much warmer than water at deeper layers in the tropical area. At low latitudes that the thermohaline forcing and wind forcing work in the same direction to generate strong meridional cells. In middle latitudes however, the westerly winds drive surface waters equatorward which tends to oppose the thermohaline forcing. Thus the meridional cell in the westerly zone tends to be weaker and hence less effective in transporting heat.

A comparison of Fig.4.8 and 4.9 indicates that the seasonal variation is strong in the meridional circulation in the Pacific. This is because in the Pacific the thermohaline circulation is very weak and the meridional circulation predicted by the model is largely associated with wind stress forcing which has strong seasonal variation. In winter, the meridional circulation is stronger than that in summer both in low- and mid-latitudes. Upper layer warmer waters always flow across the equator from the summer hemisphere to the winter hemisphere. Cooler deep waters compensate by flowing in the opposite direction. This implies that the heat is always transported from the summer hemisphere to the winter hemisphere.

This description of the meridional circulation prepares us for a discussion of the meridional heat transport. 


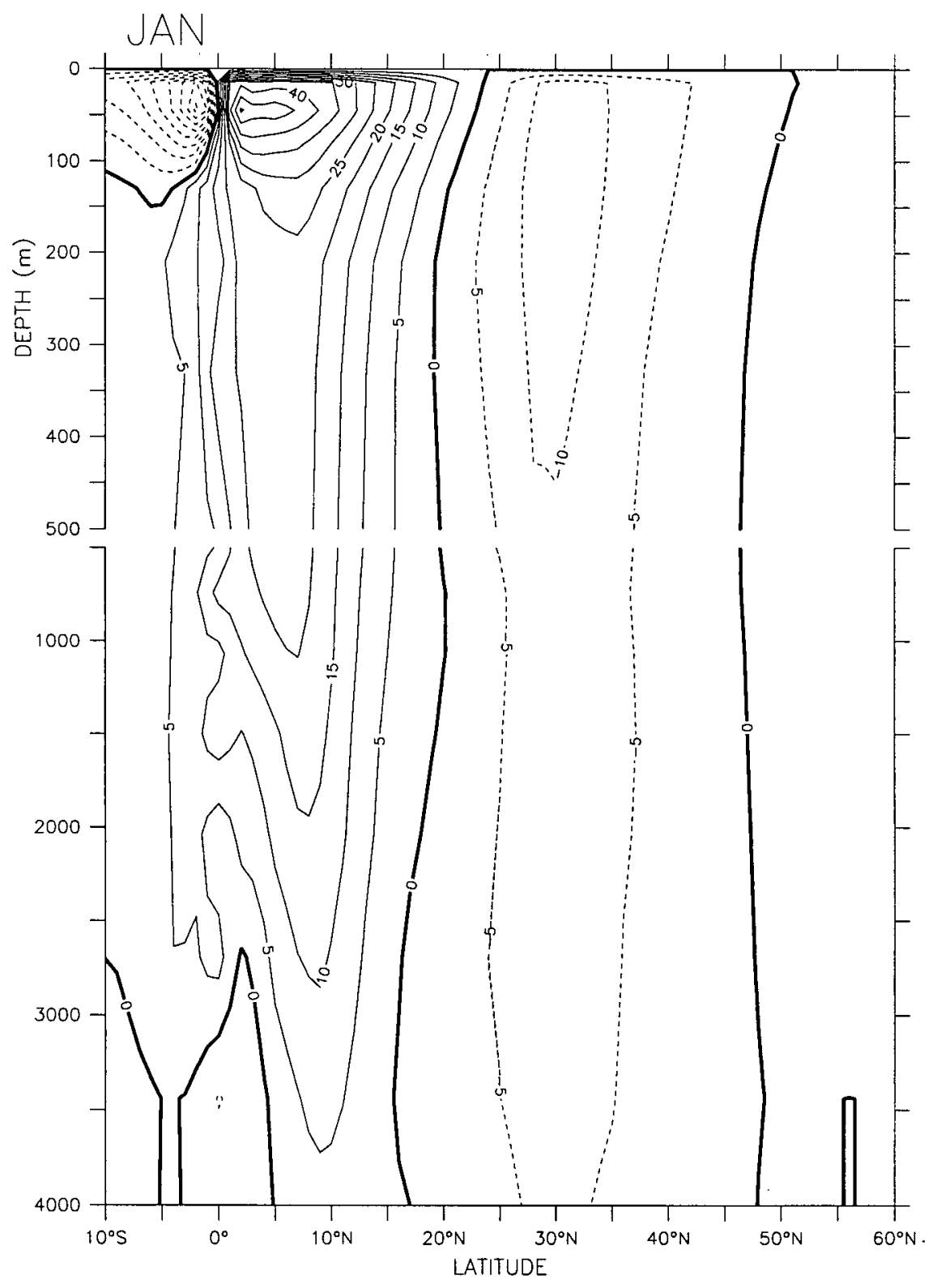

Figure 4.8: The simulated meridional mass transport (megatons/s) in January. Solid contours denote clockwise circulation; dashed contours, anti-clockwise circulation. 


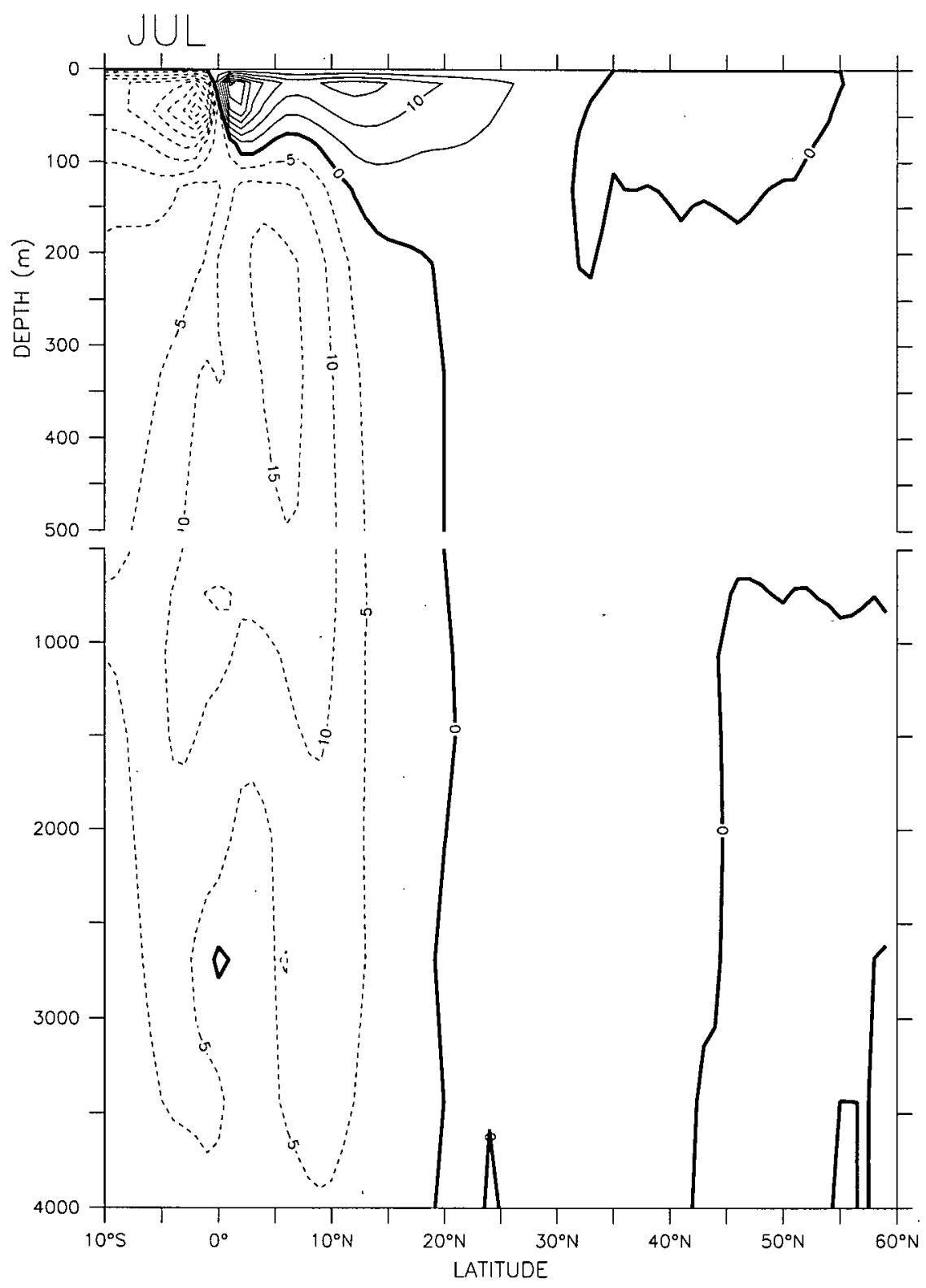

Figure 4.9: The simulated meridional mass transport (megatons/s) in July. 
In order to analyse the heat transport and understand the fractional contribution of various types of heat transport, it is necessary to divide the total meridional heat transport into three fractional components. According to Bryan, [1982], Bryan and Lewis, [1979] and Bryan et al, [1975], the heat transport across a given latitudinal wall may be given as

$$
\{H T\}=\rho C_{p}\left\{[v][\theta]+\left[v^{\prime} \theta^{\prime}\right]+A_{H H} a^{-1} \partial_{\phi}[\theta]\right\}
$$

where

$$
\{\}=\int_{-H}^{0} \int_{\lambda_{1}}^{\lambda_{2}}() a \cos \phi d \lambda d z
$$

and

$$
[]=\frac{1}{\lambda_{2}-\lambda_{1}} \int_{\lambda_{1}}^{\lambda_{2}}() d \lambda
$$

where $\lambda$ is the longitude and the prime denotes the deviation of a variable from its longitudinal mean [].

The first term on the right hand side of equation (4.2), designated as the overturning component, is the component of transport contributed by the correlations of zonally averaged currents and zonally averaged temperatures which are associated with overturning in the meridional plane. The second term, designated as the gyre component, is the transport component due to the correlations of velocity and temperature in the horizontal plane. Physically the first component may be thought of as the heat transport owing to the poleward flow of warm surface waters and the return flow of deep cold water. The second term can be counted as a net transport of heat by warm western boundary current moving poleward compensated by a return flow of colder water on the eastern side of the ocean. The last term is a horizontal diffusion term which represents the effect of mixing heat down-gradient. 

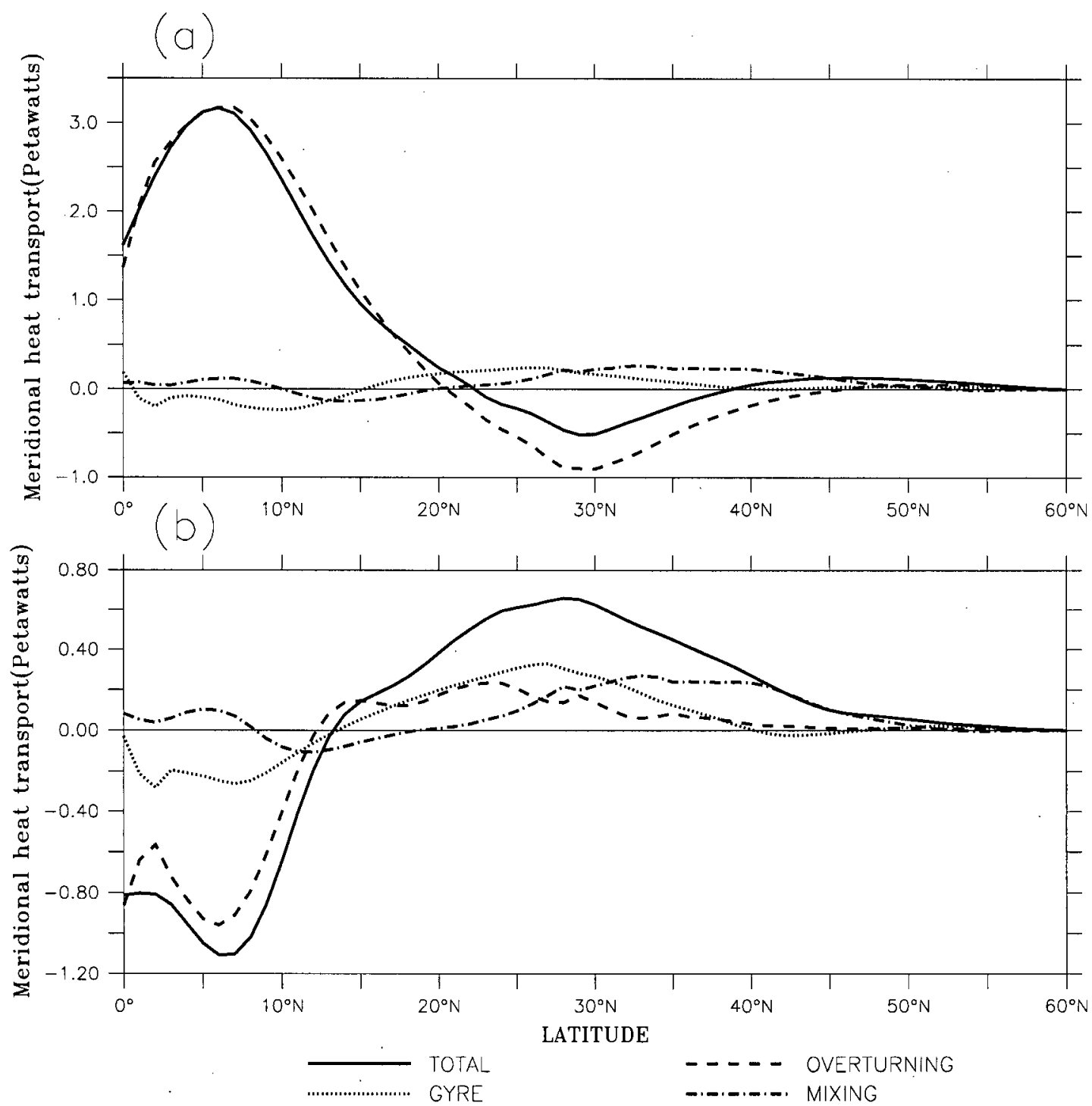

Figure 4.10: The simulated total and three fractional meridional heat transports (petawatts) in January (a) and in July (b). Northward heat transport is positive. 
The model computed the meridional heat transport for the the North Pacific Ocean shown in Fig.4.10. One of the most noticeable features in Fig.4.10 is that the total heat transport (solid line) is dominated by the contribution from the overturning component except in the extratropical latitudes during summer. In winter, the meridional circulation (Fig. 4.8) is stronger, with the strongest meridional cell located between the equator and $20^{\circ} \mathrm{N}$, effectively transporting heat northward, with the maximum heat transport at $7^{\circ} \mathrm{N}$. The meridional circulation in mid-latitudes is counter-clockwise, transporting heat equatorward, thus the negative value in Fig 4.10a. As the season progresses to the summer, the meridional circulation (Fig. 4.9) in the northern hemisphere changes, with a shallow clockwise cell confined above $100 \mathrm{~m}$ and a deep anti-clockwise circulation below it in the low latitudes. The net effect of these two circulations on the heat transport is negative, i.e. transporting the heat equatorward in the low latitudes. In extratropical latitudes, the meridional circulation is very weak, thus the meridional heat transport by the overturning component is weak (Fig. 4.10b).

The gyre component and diffusion component have very little seasonal change both quantitatively and in sign. They play a role in poleward heat transport in extratropical latitudes (south of $40^{\circ} \mathrm{N}$ ) where they tend to work in the same poleward direction, especially in the summer when the contribution from the overturning component is very weak.

The magnitude of the poleward heat transport in low latitudes varies from 3 petawatts in January to -1.1 petawatts in July. The positive sign of the heat transport along the equator in January is an indicator (Fig. 4.10a) that the heat is transported from the summer hemisphere to the winter hemisphere, and vice versa for the negative sign of the heat transport along the equator in July (Fig. 4.10b). This is consistent with the result shown in Fig. 4.8 and Fig. 4.9. Compared to the study of Bryan [1982], the poleward heat transport of this study in January is larger by about 1 pw. However, he pointed out 
that his simulated maximum heat transport is only $25 \%$ of that given by Oort and Vonder Haar [1976] who calculated the ocean heat transport as a residual term by combining heat storage data from the oceans with atmospheric heat balance estimates. Bryan's value at $24^{\circ} \mathrm{N}$ is only $50 \%$ of that estimated by Hall and Bryden [1982] and Roemmich [1980].

The possible explanation for the discrepancy between the maximum value of heat transport of this study and that of Bryan [1982] is that the model resolution, and model parameters such as horizontal viscosity and horizontal diffusivity in our study are different from those in Bryan's study. Bryan and Lewis [1979] performed an experiment in which the horizontal resolution is increased by a factor of 4 , meanwhile the horizontal viscosity was decreased by a factor of 8 and the horizontal diffusivity by a factor of 2 , then the heat flux at $24^{\circ} \mathrm{N}$ increased from $0.6 \mathrm{pw}$ to $0.9 \mathrm{pw}$. This indicates that the simulated heat transport is dependent on the many parameters of the model. The model resolution in this study is almost 6 times higher than that used in Bryan's study. While the horizontal viscosity is 4 times less than that in his study. So the heat transport discrepancy between this study and his is expected. 


\section{Chapter 5}

\section{Climate Regime Shift}

In Chapter 4, the spin-up run was performed with a monthly climatology of surface forcings. Starting from the end of this basic run, two new experiments are conducted, Exp.B with the surface forcing replaced by the pre-1976 monthly climatological wind stress and SST, and Exp.C by the post-1976 climatological values, to study how the ocean circulation is changed as a result of the 1976-77 climate regime shift.

The time integration for both Exp.B and Exp.C is carried out for 6 years from the end of year 21 of the Basic run. The average kinetic energy (KE) densities for each is shown in Fig. 5.1. It shows no significant interannual variations for the last two years. The difference in model state between year 5 and year 6 is examined. It is found that the vertical velocity at $60 \mathrm{~m}$ depth has changed by a maximum of $5.0 \mathrm{~cm} /$ day in the equatorial region, and by less than $1.0 \mathrm{~cm} /$ day in all other regions. At other depths, the change in vertical velocity is less than $2 \mathrm{~cm} /$ day, confined to the equatorial region. These are extremely small compared with the magnitudes of the vertical velocity in those areas. For the temperature field, there are several sparsely distributed points in the merging area of Kuroshio and Oyashio, where the SST changed by a maximum value of $0.2^{0} \mathrm{C}$. In all other areas, the SST has changed by less than $0.05^{\circ} \mathrm{C}$. At all other depths, the change in temperature is less than $0.1^{\circ} \mathrm{C}$. So the model is considered to be in a quasi-steady state after 6 years of time integration. A similar time scale for an ocean model to reach quasi-steady state was found in Semtner and Chervin, [1988], Hsieh, [1987] and Anderson

and Corry, [1985]. Fig. 5.1 also shows the magnitude of the average KE density to be 


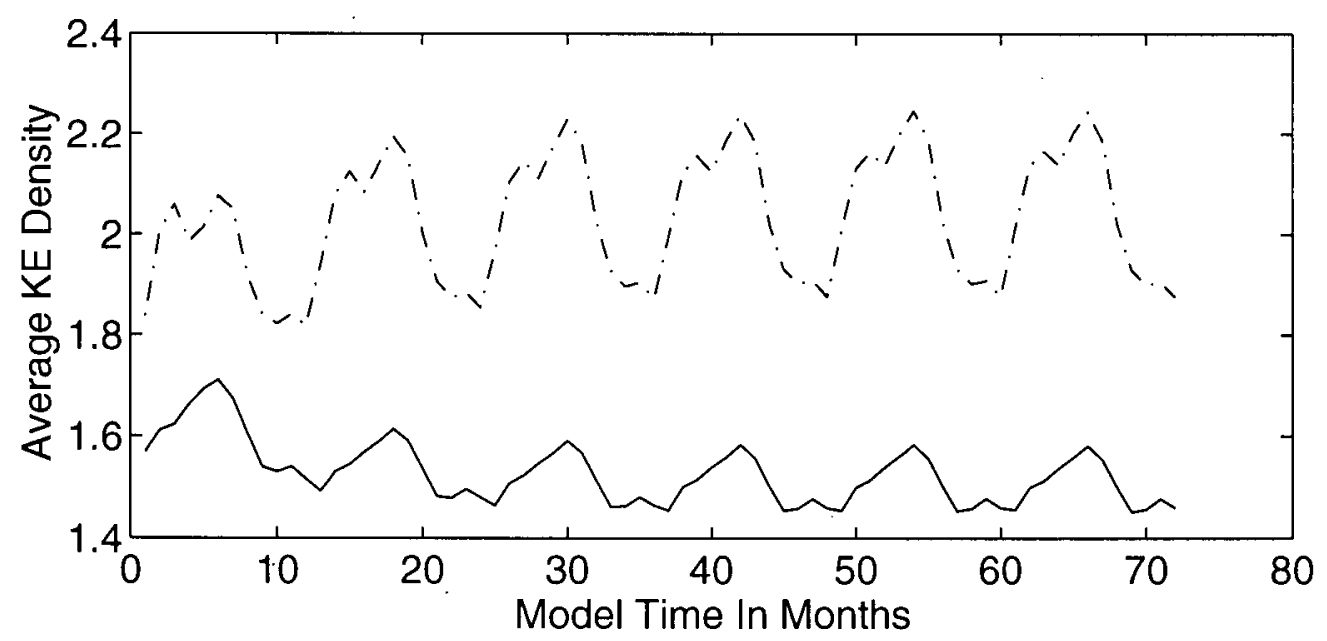

Figure 5.1: Average kinetic energy density of the model ocean as a function of time in months for Exp.B (pre-1976) (solid line) and Exp.C (post-1976) (dash-dotted line). 
larger in the post-1976 case than in the pre-1976 case, mainly due to the stronger surface wind stress forcing in the former case.

The interdecadal variations of various oceanic variables are analysed based on the simulated data for the sixth year of Exp.B (pre-1976) and Exp.C (post-1976).

\subsection{Variations in transport streamfunction}

The vertically integrated transport streamfunctions for Exp.C (post-1976) and Exp.B (pre-1976) in January of year six are shown in Fig. 5.2. Generally the basic three gyral patterns are simulated in both the pre-1976 case and the post-1976 case, and are similar to each other. However, there are differences in the latitudinal range and the strength of the three gyres between the two cases. The subarctic gyre extends further south in the post-1976 case than in pre-1976 case, with the southernmost boundary down to $33^{\circ} \mathrm{N}$ and $36^{\circ} \mathrm{N}$ respectively. This is simply caused by the southward extension of the westerlies resulting from the southward shift of the Aleutian Low system after 1976, as described in Chapter 3. The Kuroshio and Oyashio transports reach $50 \mathrm{~Sv}$ and $20 \mathrm{~Sv}$ in the post-1976 case, while they are only $40 \mathrm{~Sv}$ and $11 \mathrm{~Sv}$ in the pre-1976 case.

The difference in the vertically integrated transport streamfunctions between the two cases is displayed in Fig. 5.3. In the subarctic area, the difference shows a cyclonic circulation, which indicates that subarctic gyre in the post-1976 case is stronger than in the pre-1976 case. This is expected as the intensification of the Aleution Low system for the 1976-88 period results in an increase in the wind stress curl in that area, which spins up the gyral circulation based on the Sverdrup relation.

Another noticeable feature on Fig. 5.3 is the decrease in the transport streamfunction in the eastern and northern part of the Gulf of Alaska, which seems inconsistent with the conventional view that the strengthening Aleutian Low would intensify the gyre 
circulation. Lagerloef [1995] conducted an EOF analysis of the SST and dynamic height in the Gulf of Alaska for the period of 1968-1990. He found that the intensified Aleutian Low did not appear to spinup the gyre, instead, the gyre is relatively intense (low dynamic height and cold SST ) in the 1970s but relatively relaxed (positive dynamic height anomalies and warm SST ) in the 1980s. So the result of this modelling study is in agreement with his analysis. Indeed, the wind stress in the Alaska region for the pre-1976 period is dominated by the westerlies, while for the post-1976 period by more southwesterly winds (Fig. 3.3). It is discernible that in the northern and eastern part of the Gulf of Alaska the wind stress difference is clockwise (Fig. 3.4a), i.e. negative curl. It is this clockwise wind stress variation that is responsible for the weakening in the gyral circulation in that area. The change in the wind stress evidently changes the pattern of the Ekman transport and Ekman pumping, thus the thermal structure in this area. This will be discussed later.

The intensified westerlies in mid-latitudes and slightly increased easterlies in the trop.ics imply that the anti-cyclonic wind stress curl is increased in the subtropics. This results in the strengthening of the subtropic gyre circulation as shown in Fig. 5.3. The southward intrusion of the increased subtropic gyre shows that the strength of the tropic gyre is reduced.

\subsection{Variations in velocity and associated variations in temperature}

\subsubsection{Variations in horizontal velocity and associated variations in temper- ature}

The surface current patterns $(15 \mathrm{~m})$ in January for the pre-1976 case and the difference in surface currents between post-1976 case and pre-1976 case are shown in Fig. 5.4. In general, both the surface current and the change in the surface current reflect the fact 

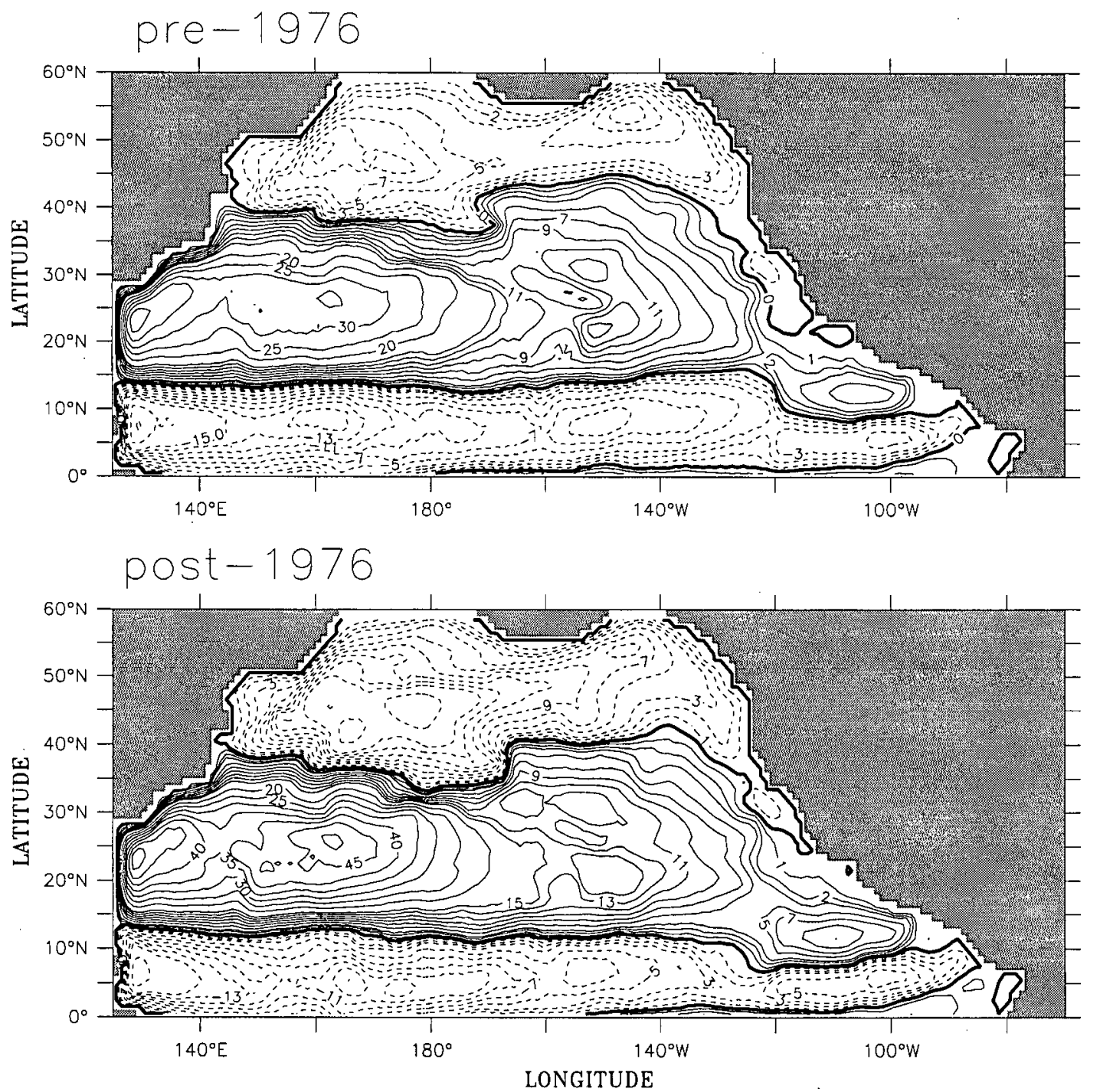

Figure 5.2: The vertically integrated transport streamfunction in January at sixth year of Exp.B (pre-1976) and Exp.C (post-1976). The contour values are $\pm 1, \pm 2, \pm 3, \pm 5, \pm 7, \pm 9, \pm 11, \pm 13, \pm 15, \pm 20, \pm 25, \pm 30, \pm 35, \pm 40, \pm 45, \pm 50 \mathrm{~Sv}$. 


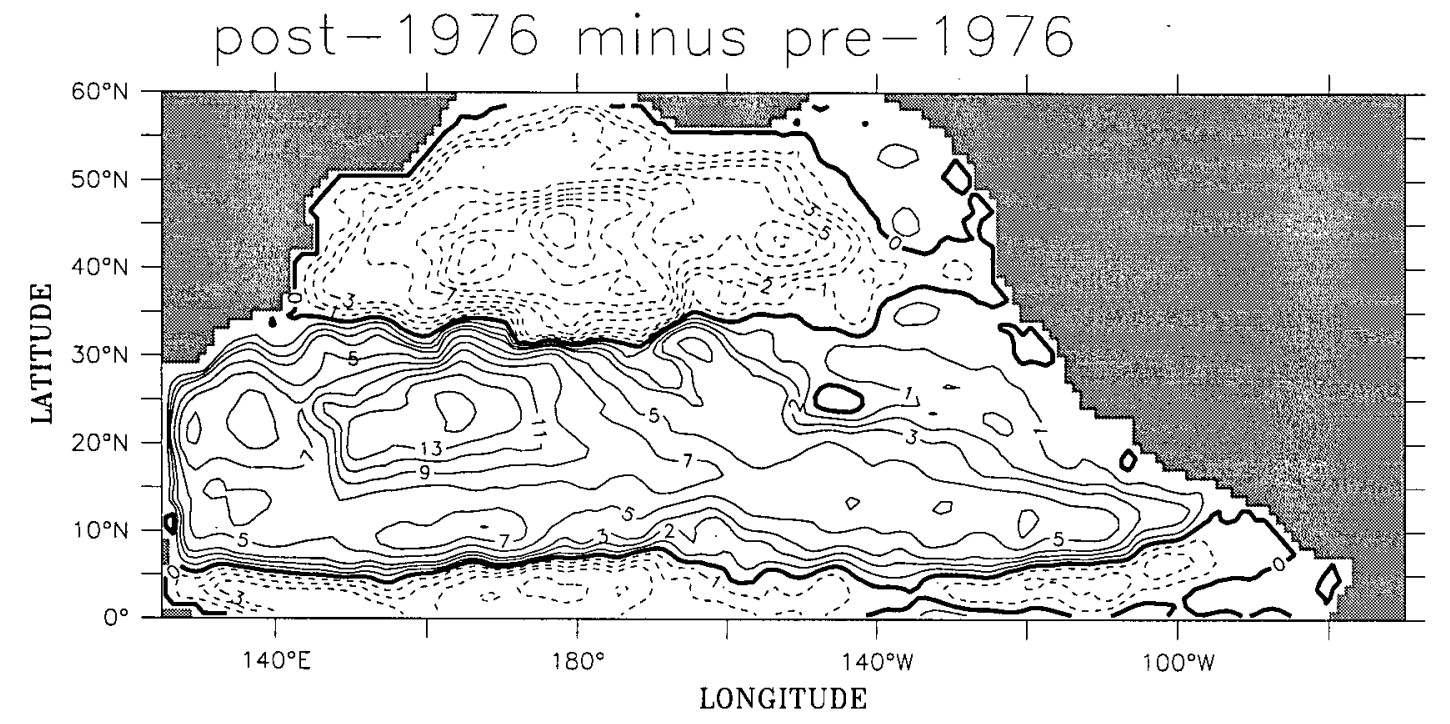

Figure 5.3: The difference between Exp.C and Exp.B in vertically integrated transport streamfunction in January at the sixth year. The contour values are $\pm 1, \pm 2, \pm 3, \pm 5, \pm 7, \pm 9, \pm 11, \pm 13, \pm 15, \pm 20 S v$. 

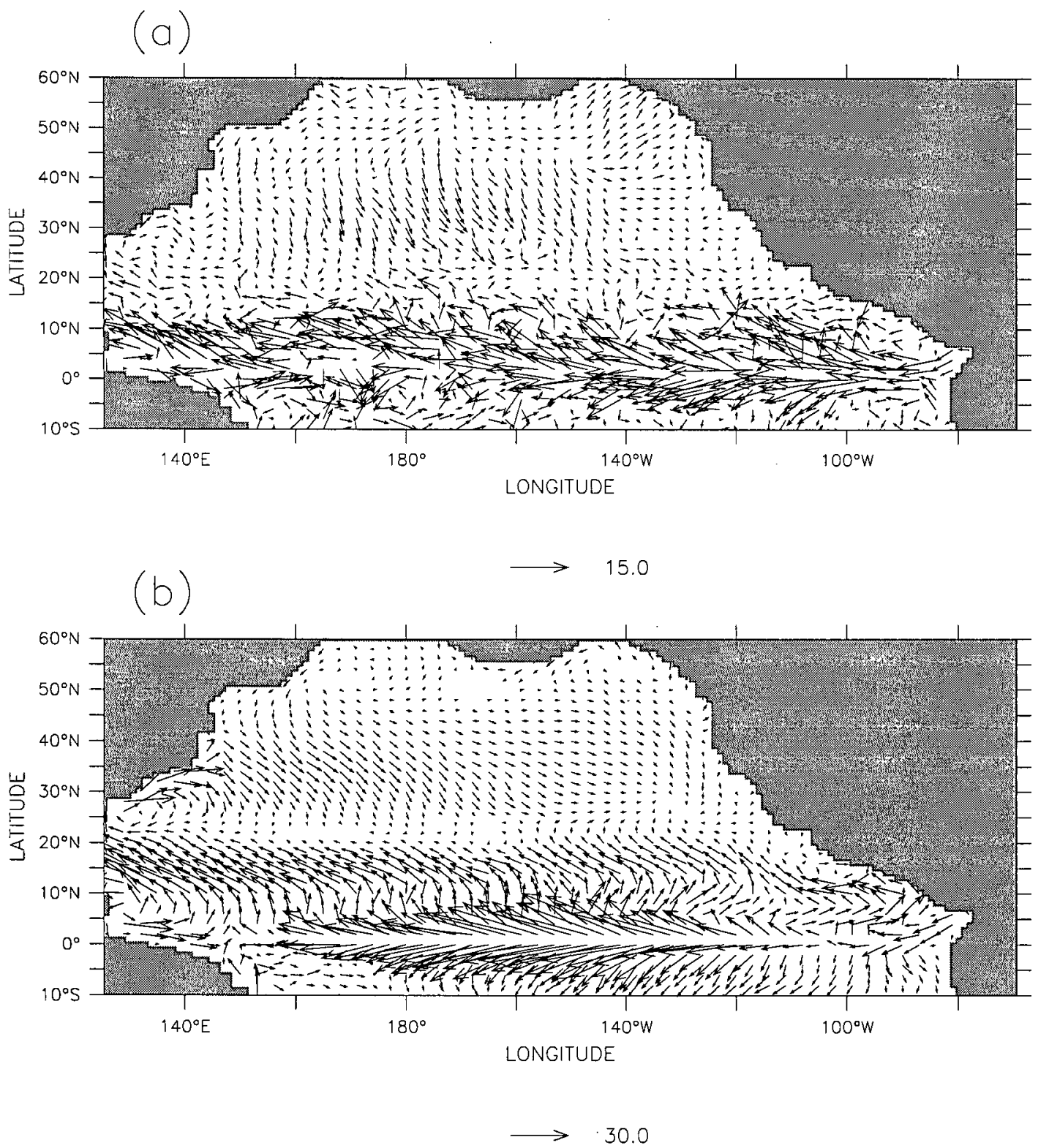

Figure 5.4: (a) The difference in surface current (15 $\mathrm{m}$ depth) between the post-1976 and pre-1976 in January at the sixth year. (b) The surface current velocity at $15 \mathrm{~m}$ depth for pre-1976 case in January at the sixth year. 


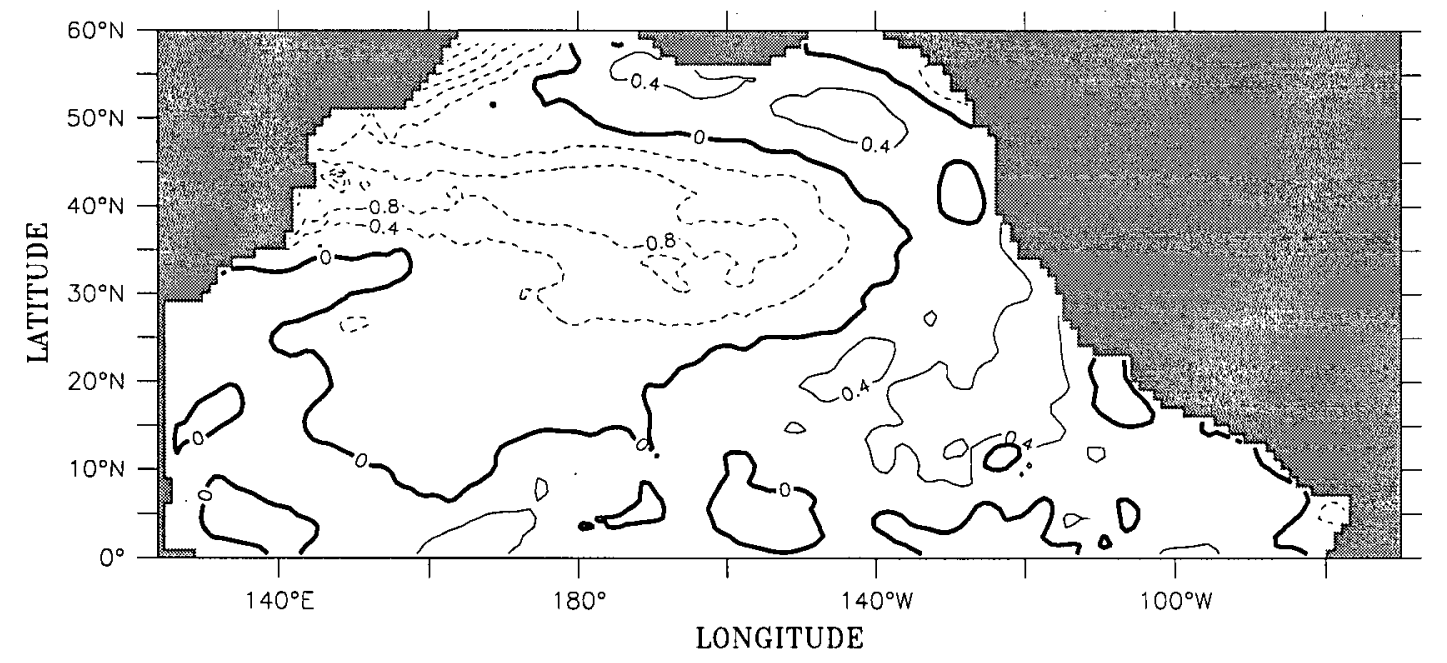

Figure 5.5: The simulated variation in SST between post-1976 case and pre-1976 case in $\mathrm{DJF}$ at sixth year. The contour interval is $0.4^{\circ} \mathrm{C}$. 
that the Ekman dynamics is dominant in the surface layer. In the Gulf of Alaska, the anomalous surface current flows northeastward, induced by anomalous southerly wind stress (Fig. 3.4a). This anomalous northeastward Ekman drift transports the warm surface water from the south to the northern coastal area, leading to the convergence of surface water and the increase in SST. In contrast, in the pre-1976 case the surface flows are southeastward, due to the westerly wind stress there (Fig 3.3a), bringing the cold water from the Gulf of Alaska to the southern part, maintaining the cold SST distribution. So the anomalous advection during the 1976 climate shift would be an important mechanism for the coastal warming of Alaska.

In the central North Pacific between $25^{\circ} N$ and $45^{\circ} N$, there is a broad, enhanced strengthened surface Ekman drift flowing southward, induced by the increased westerly in the Aleutian Low system during the 1976 climate shift. With the large north-south temperature gradient field between mid and high latitudes, the drift would advect the colder water from high latitudes to mid latitudes, producing large scale negative temperature changes near the surface (Fig. 5.5). In the Bering Sea, increased southwest flows transport very cold water from the northern part of the Bering Sea to the south, helping to create the negative temperature anomaly in the central North Pacific. In the mid-latitude eastern Pacific, i.e. near the west coast of North American, the increased eastward flows may bring slightly warmer water from the central Pacific to the coast, causing the warming along the coast. In low latitudes, even though the changes in wind stress are weaker than in higher latitudes, the small Coriolis parameter leads to large surface Ekman drift currents. The variations of the flows are quite noisy, but are generally directed northwestward north of the equator, and weak along the equator, especially on the western side. The increased northwestward flows in the North Equatorial Current system advect the slightly warmer water from low latitudes (about $10^{\circ} \mathrm{N}$ ) to the tropics (about $20^{\circ} \mathrm{N}$ ), especially on the eastern side where the temperature gradients are larger 
than those on the western side.

The simulated SST change between the post-1976 and pre-1976 periods (Fig. 5.5) shows a large negative change in the central North Pacific. It also shows that there is warming along the west coast up to Alaska (except for the B.C. coast) and in low latitudes all the way from the western tropics to the eastern tropical Pacific, with slightly larger temperature changes in the eastern tropical Pacific. The simulated cooling along B.C. coast could be related to the cooling at the same area in SST climatological relaxation fields in Fig. 3.5. This pattern of changes in SST is as expected from the above analysis. The intensified surface Ekman drifts generate anomalous horizontal advections, hence resulting in the simulated change in the surface thermal structure. Lagerloef [1995], Huang [1979(b)] and Namias [1965] indicated that the anomalous advection of the normal temperature distributions can generate ocean thermal anomalies. Thus the anomalous surface horizontal advection is an important mechanism in generating the change in SST.

The simulated SST changes are very similar to those derived from the two climatologies of the post-1976 and pre-1976 periods, with a pattern correlation coefficient of 0.88 . Such a good correlation is partially due to the fact that the model SST is relaxed to the SST climatology for the corresponding period during both experiments.

Further comparison between Fig. 3.5 and Fig. 5.5 shows that the simulated negative temperature change in the central North Pacific is slightly more intense than that derived from the two observed climatologies of the post-1976 and pre-1976 periods. The surface boundary condition I adopted in the model for temperature is the relaxation of the model SST to the prescribed reference climatology of the period. Hence the model will not create SST anomalies, but instead, tend to damp the anomalies and stabilize the model SST towards the reference climatology. So the simulated stronger negative temperature changes may suggest that the surface wind stress forcing produces larger SST change between the post-1976 case and the pre-1976 case than those specified in 
the surface relaxation boundary condition from the two reference SST climatologies. One can imagine that the intensified wind stress applied to the surface boundary in the model generates a stronger cooling in the central North Pacific, with the model relaxation surface boundary condition for SST trying to damp the excessive cooling. Finally the two boundary conditions reach a balance state, with the simulated temperature variations slightly stronger than prescribed in the boundary conditions for SST. In other areas, the simulated SST changes appear to be similar to those prescribed, which may indicate that the SST variations created by the changed wind stress are still within the range of the prescribed variations or exactly equal the prescribed variations. Hence no significant differences exist between the simulated and the prescribed SST variations.

Fig. 5.4 only shows the variations of the surface current system. The variations of the subsurface current system may be more interesting. Fig. 5.6a is the difference of the meridional velocity component $\mathrm{V}$ between the post-1976 case and the pre-1976 case in the vertical section along $155^{\circ} \mathrm{W}$ in January. The vertical section of $\mathrm{V}$ for the pre-1976 case is shown in Fig. 5.6b. In the middle and high latitudes, $\mathrm{V}$ shows an increase with a maximum value of $3 \mathrm{~cm} / \mathrm{s}$ (southward), indicating that $\mathrm{V}$ in the post-1976 case has increased by $150 \%$ in comparison with the $2 \mathrm{~cm} / \mathrm{s}$ (southward) in the pre-1976 case (Fig. $5.6 \mathrm{~b})$. The variations are mainly limited to above $50 \mathrm{~m}$. The strengthened $\mathrm{V}$ is the result of the intensified westerlies in the Aleutian Low system. In the low latitudes of the northern hemisphere, V (Fig. 5.6b) above $50 \mathrm{~m}$ depth is northward while below that depth down to $200 \mathrm{~m}$ it is southward. The variation of $\mathrm{V}$ (Fig. 5.6a) is mostly confined to above $100 \mathrm{~m}$ depth. Previously it was mentioned that the increased horizontal advection could be an important factor in causing the SST variations. The V component would play a more important role than the $\mathrm{U}$ component since the meridional temperature gradient is generally much larger than the zonal gradient. The variations of $\mathrm{V}$ being mainly within the top $200 \mathrm{~m}$ suggest that horizontal advection associated with the 1976 climate shift 
may not be an important factor in determining the variations in the thermal structure below $200 \mathrm{~m}$ depth. I also examined the $\mathrm{V}$ component and its variations along different longitudes, with similar conclusions.

Fig. $5.7 \mathrm{a}$ is the difference of the zonal velocity component $\mathrm{U}$ between the post-1976 case and the pre-1976 case in the vertical section along $155^{\circ} \mathrm{W}$ in January. The vertical profile of $\mathrm{U}$ in January for the pre-1976 case is shown in Fig. 5.7b. Four major surface currents are clearly shown in Fig. 5.7b, namely, the South Equatorial Current (SEC) flowing westward, the North Equatorial Counter Current (NECC) flowing eastward, the North Equatorial Current (NEC) flowing westward and the North Pacific Current (NPC) flowing eastward. Under the SEC is the Equatorial Undercurrent (EUC) centred around $150 \mathrm{~m}$ depth. Further down, there is a current at the equator, the Equatorial Intermediate Current (EIC). For the classical locations of these currents, the reader is refered to page 241 of Pickard and Emery [1990]. Fig. 5.7a shows that the variations in U are limited to above $400 \mathrm{~m}$ depth. In the low latitudes, the SEC is strengthened, the EUC above 200 $\mathrm{m}$ depth is weakened, but slightly enchanced below $200 \mathrm{~m}$, while both the NECC and the NEC are intensified. Since the zonal temperature gradient is much smaller than the meridional and vertical gradients, the variations in the zonal velocity component may not make an important contribution to the ocean temperature variations.

\subsubsection{Variations in vertical velocity and associated variations in temperature}

The change in the surface wind stress associated with the 1976 climate shift leads to the change in the surface currents as shown in Fig. 5.4a. There is increased divergence in the subarctic region, moderately increased convergence in the subtropic and divergence in the equatorial region. Consequently the upwelling and downwelling are changed.

Fig. 5.8a shows the difference of the vertical velocity pattern at $60 \mathrm{~m}$ depth in winter between the post-1976 case and pre-1976 case, and Fig. 5.8b the vertical velocity pattern 

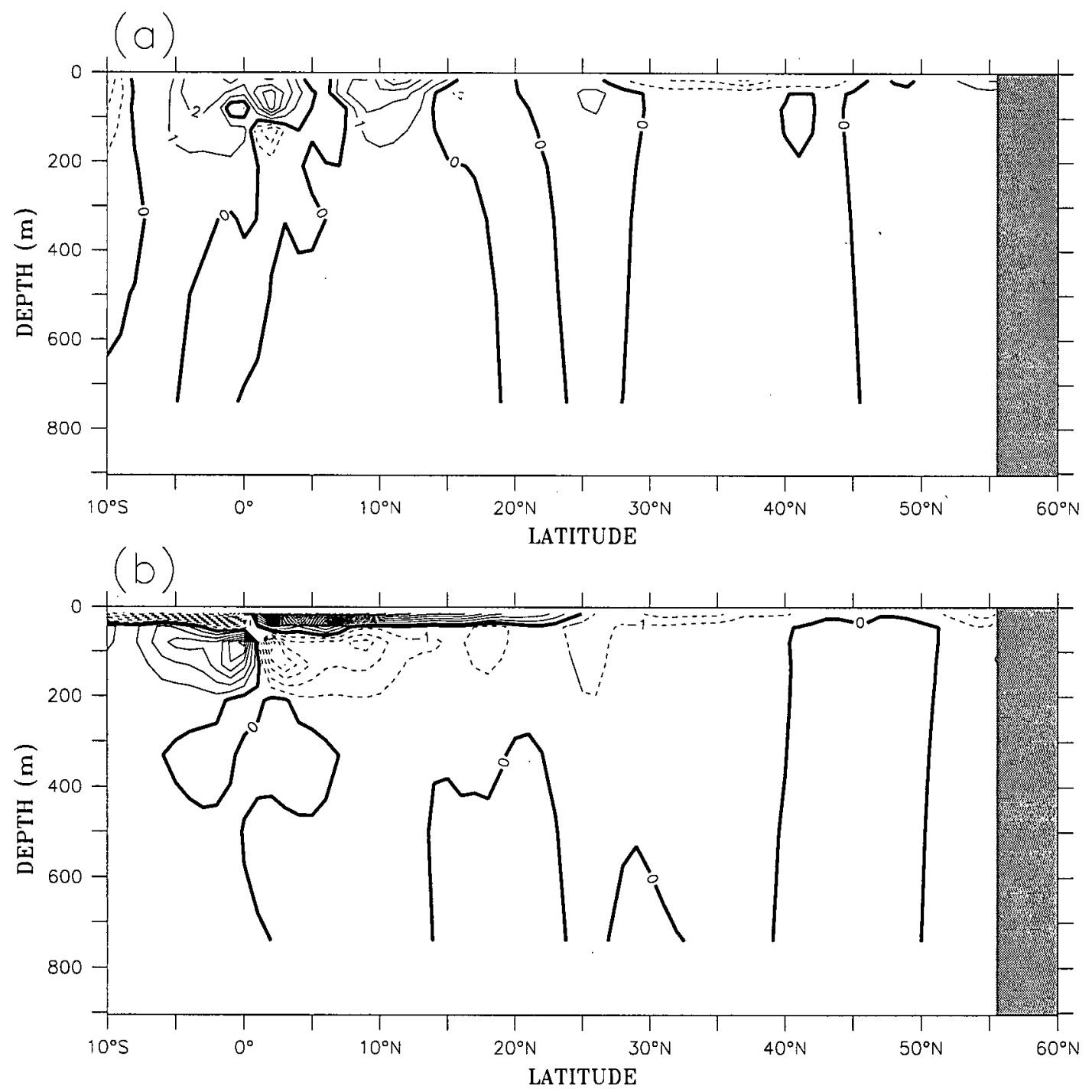

Figure 5.6: (a) The meridional section of the difference in meridional velocity component $\mathrm{V}$ along $155^{\circ} \mathrm{W}$ in January at the sixth year between the post-1976 and the pre-1976 cases. (b) The meridional section of $\mathrm{V}$ for the pre-1976 case. The contour intervals in both (a) and (b) are $1 \mathrm{~cm} / \mathrm{s}$, with solid contours for northward flow and dashed contours for southward flow. 

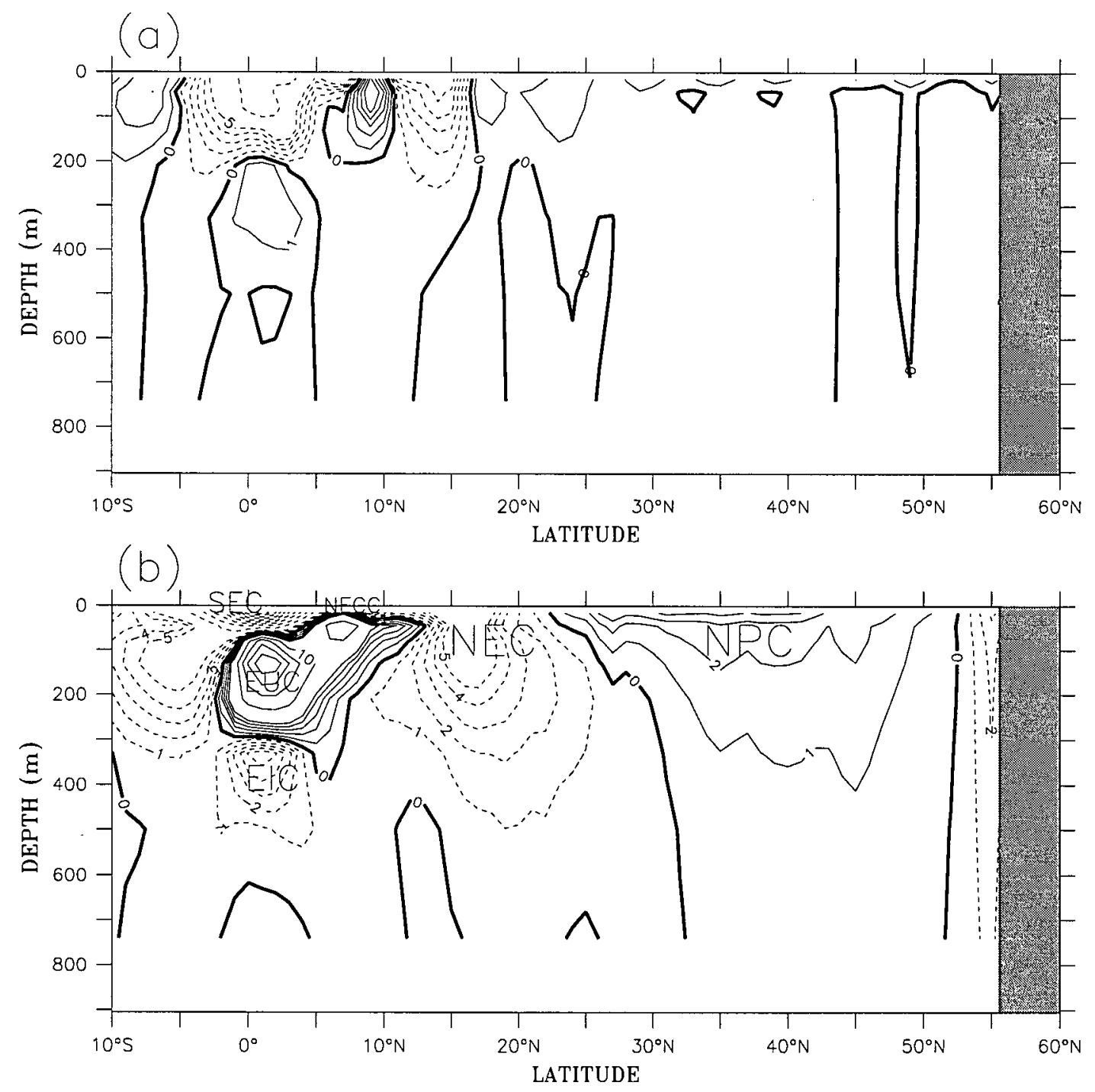

Figure 5.7: (a) The meridional section of the difference of the zonal velocity component $\mathrm{U}$ along $155^{\circ} \mathrm{W}$ in January at the sixth year between post-1976 and pre-1976. (b) The meridional section of $U$ for the pre-1976 case. The contour values in both (a) and (b) are $\pm 1, \pm 2, \pm 3, \pm 4, \pm 5, \pm 10, \pm 15, \pm 20 \mathrm{~cm} / \mathrm{s}$, with solid contours for eastward flow and dashed contours for westward flow. NPC=North Pacific Current, NEC=North Equatorial Current, NECC=North Equatorial Countercurrent, SEC=South Equatorial Current, $\mathrm{EUC}=$ Equatorial Undercurrent, $\mathrm{EIC}=$ Equatorial Intermediate Current. 

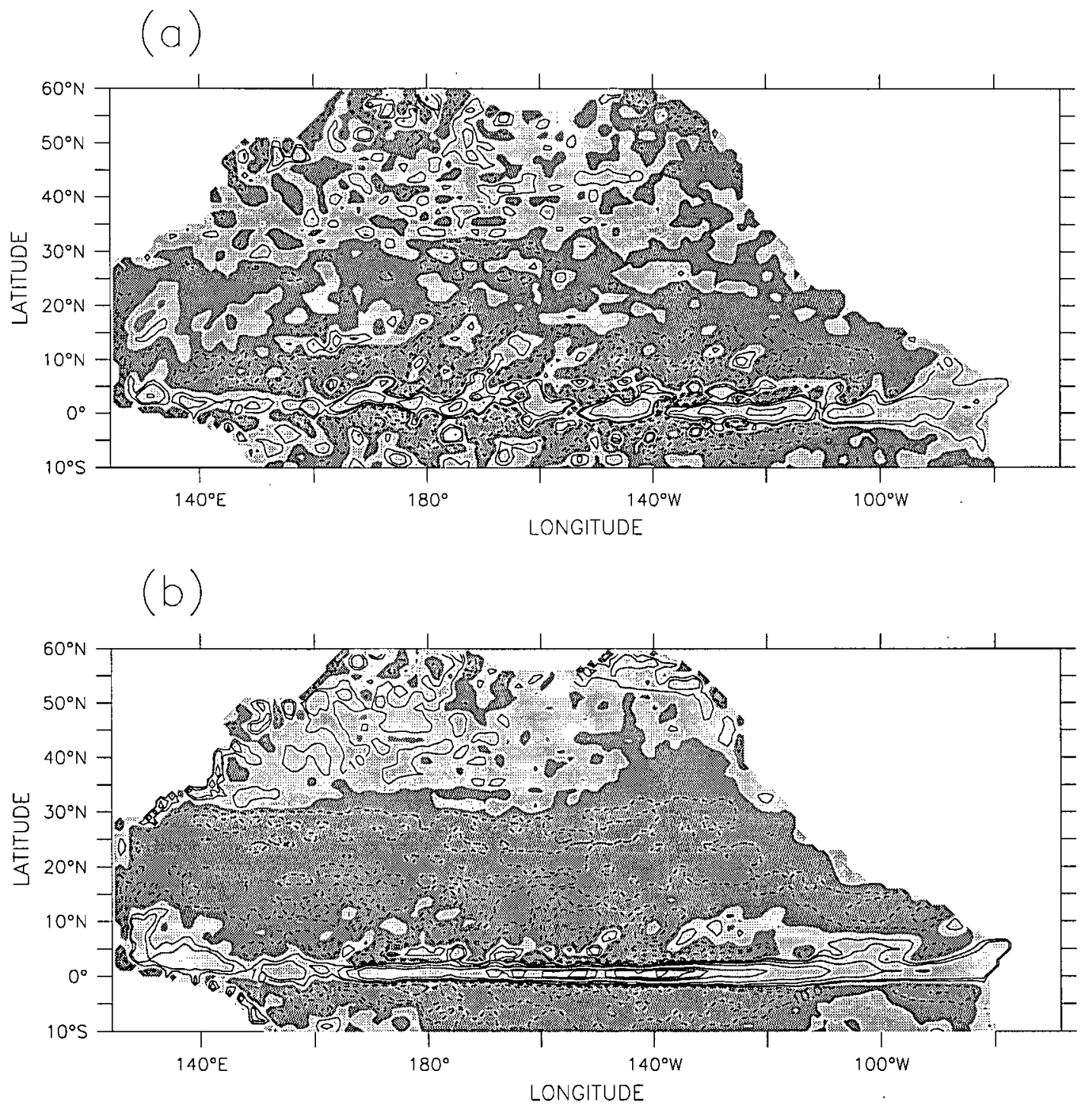

Figure 5.8: (a) The difference of vertical velocity at $60 \mathrm{~m}$ depth in DJF between the post-1976 case and pre-1976 case. The light grey indicates positive anomaly (i.e. either the upwelling is increased or the downwelling is decreased), dark grey negative anomaly. (b) The vertical velocity at $60 \mathrm{~m}$ depth in DJF for the pre-1976 case. The light grey indicates upwelling, dark grey downwelling, The contour values in both (a) and (b) are $\pm 10, \pm 20, \pm 50, \pm 100, \pm 200, \pm 250, \pm 300 \mathrm{~cm} /$ day. 


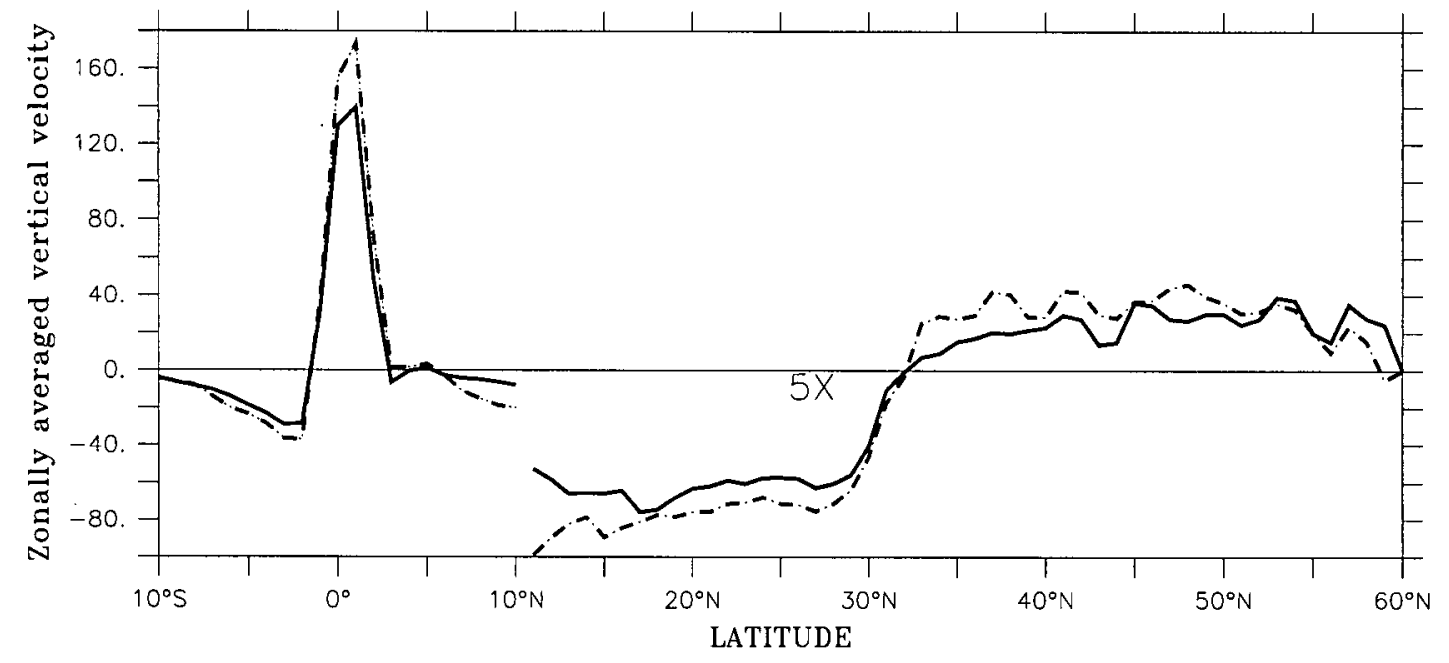

Figure 5.9: The zonally averaged vertical velocity $(\mathrm{cm} /$ day) at $60 \mathrm{~m}$ depth in DJF for the pre-1976 case (solid line) and the post-1976 case (dot-dashed line) respectively. 
at $60 \mathrm{~m}$ depth for the pre-1976 case. The vertical velocity field presented in this Chapter has gone through a Laplacian smoothing scheme, as described in Chapter 4. The general patterns shown in Fig. 5.8b are similar to that in the climatological run (Fig. 4.5a), with strong upwelling along the equator, moderate downwelling and upwelling in the subtropic and subarctic regions, respectively. However, the differences between the post-1976 and the pre-1976 are noticeable. The post-1976 case has a maximum equatorial upwelling of $404 \mathrm{~cm} /$ day at $145^{\circ} \mathrm{W}, 0^{\circ} \mathrm{N}$ (not shown), much stronger than that of $368 \mathrm{~cm} /$ day at $139^{\circ} \mathrm{W}, 1^{0} \mathrm{~N}$ in the pre-1976 case. The upwelling along the equator is increased all the way from the western equatorial Pacific to the eastern equatorial Pacific (Fig. 5.8a). In the subarctic region, the pattern of difference in vertical velocity is quite noisy, but generally the upwelling is increased, with most of the area having positive anomalies. The maximum anomaly reaches $20 \mathrm{~cm} /$ day. Along the west coast of north America (Fig. 5.8a), there is an increase in downwelling or decrease in upwelling, expanding down from the northern boundary of the model domain to $40^{\circ} N$, as expected from the variations in surface currents. The enhanced northeastward surface currents, induced by increased southerly wind stress, flow onshore and induce more downwelling along the coast, which is consistent with the weakening of the Alaskan gyre circulation.

In order to more quantitatively compare the two vertical velocity fields at $60 \mathrm{~m}$ depth, they are zonally averaged and plotted as functions of latitude in Fig. 5.9. The values between $10^{\circ} \mathrm{N}$ and $60^{\circ} \mathrm{N}$ are multiplied by 5 for better visualization. It clearly shows that in the subarctic area (south of $52^{\circ} N$ ), the upwelling is strengthened in the post-1976 case, with a maximum increase of $4.4 \mathrm{~cm} /$ day at $37^{\circ} N$ (i.e. an increase of $108 \%$ with respect to the pre-1976 case). North of $52^{\circ} \mathrm{N}$, the zonally averaged upwelling is decreased, which is consistent with the fact that there is enhanced downwelling in this latitudinal band for the post-1976 case. In the subtropical area, the increased downwelling from the enhanced convergence of surface waters is also seen in Fig. 5.9. The upwelling along the 
equator is increased, but by a lesser percentage than the change in the subarctic region. The meridional section of the vertical velocity difference between the two cases along $155^{\circ} \mathrm{W}$ longitude (Fig. 5.10) shows that in the subarctic area there are large regions of anomalous upwelling, and in the subtropical area, anomalous downwelling is interrupted by narrow upwelling bands. The change in the equatorial region is generally dominated by the increased upwelling, in a narrow zonal band in the upper layer and wider band in the lower layer.

Generally the major changes are confined above $400 \mathrm{~m}$ depth. There are a few centres of large change in the broad downwelling area. The strongest one is located at $5^{\circ} N$ and $100 \mathrm{~m}$ depth with a maximum value above $30 \mathrm{~cm} /$ day. Another center is located at $15^{0} \mathrm{~N}$ and approximately $100 \mathrm{~m}$ depth with the maximum value of above $25 \mathrm{~cm} /$ day. Two other weaker centers are at $22^{\circ} N$ and $30^{\circ} N$. In the subarctic area, the increased upwelling is generally moderate. However, as shown in Fig. 5.9, upwelling in the subarctic area has been enhanced by a larger percentage than in any other area. In the equatorial region, a decreased upwelling centre is situated right at the equator and centred at $50 \mathrm{~m}$ depth, with two increased upwelling centers located on its two sides. Right under the decreased upwelling center, there is an increased upwelling center centred at $100 \mathrm{~m}$ depth. At 280 m depth, there are two enhanced upwelling centers on either side of the equator at $4^{0} N$ and $4^{0} S$.

These evident changes in the upwelling and downwelling from the surface down to a depth of a few hundreds of meters match the simulated temperature changes in the subsurface. Fig. 5.11a shows the meridional section of the temperature variation along $155^{\circ} \mathrm{W}$ between the post-1976 case and the pre-1976 case, while Fig. $5.11 \mathrm{~b}$ shows the meridional section of temperature distribution along $155^{\circ} \mathrm{W}$ for the pre-1976 case. The most prominent feature in Fig. 5.11a is that the temperature variations are mainly confined above $400 \mathrm{~m}$ depth along this longitude. No significant changes are found in 


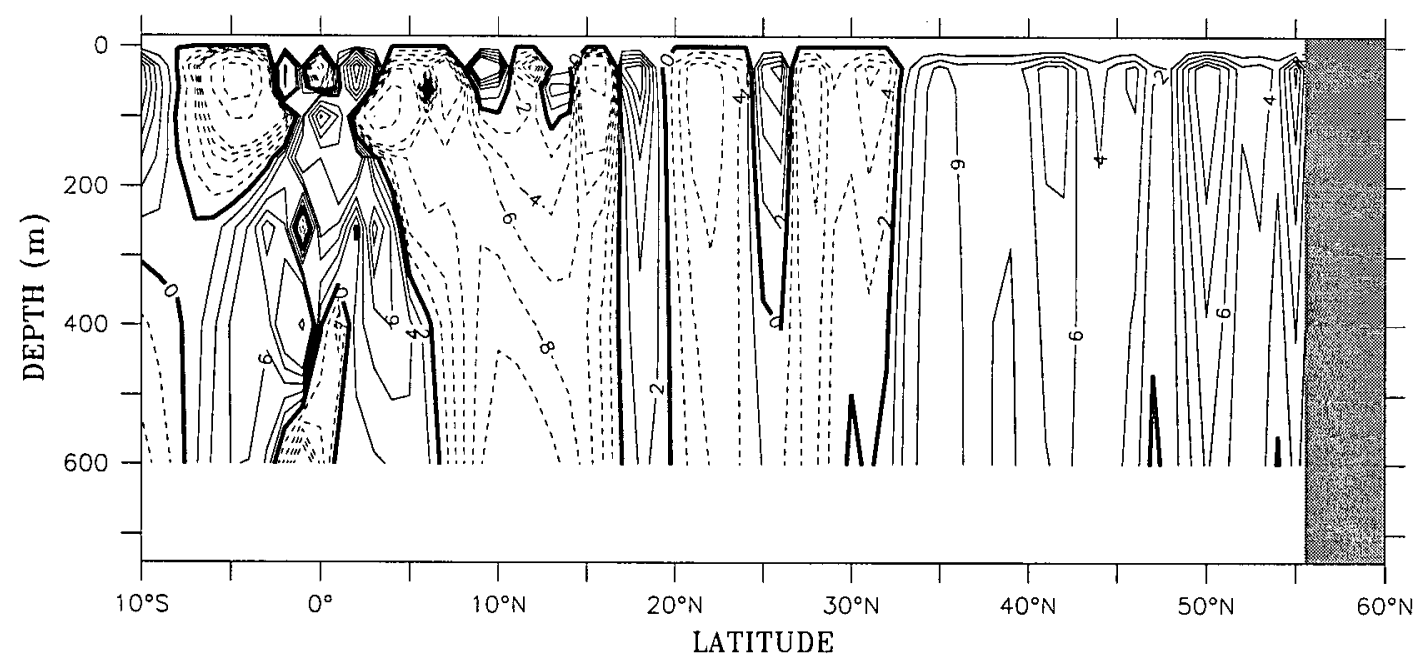

Figure 5.10: The meridional section of vertical velocity change in DJF along $155^{\circ} \mathrm{W}$ between the post- 1976 case and the pre-1976 case. The contour values are $\pm 2, \pm 4, \pm 6$, $\pm 8, \pm 10, \pm 20, \pm 30, \pm 40, \pm 50 \mathrm{~cm} /$ day. 

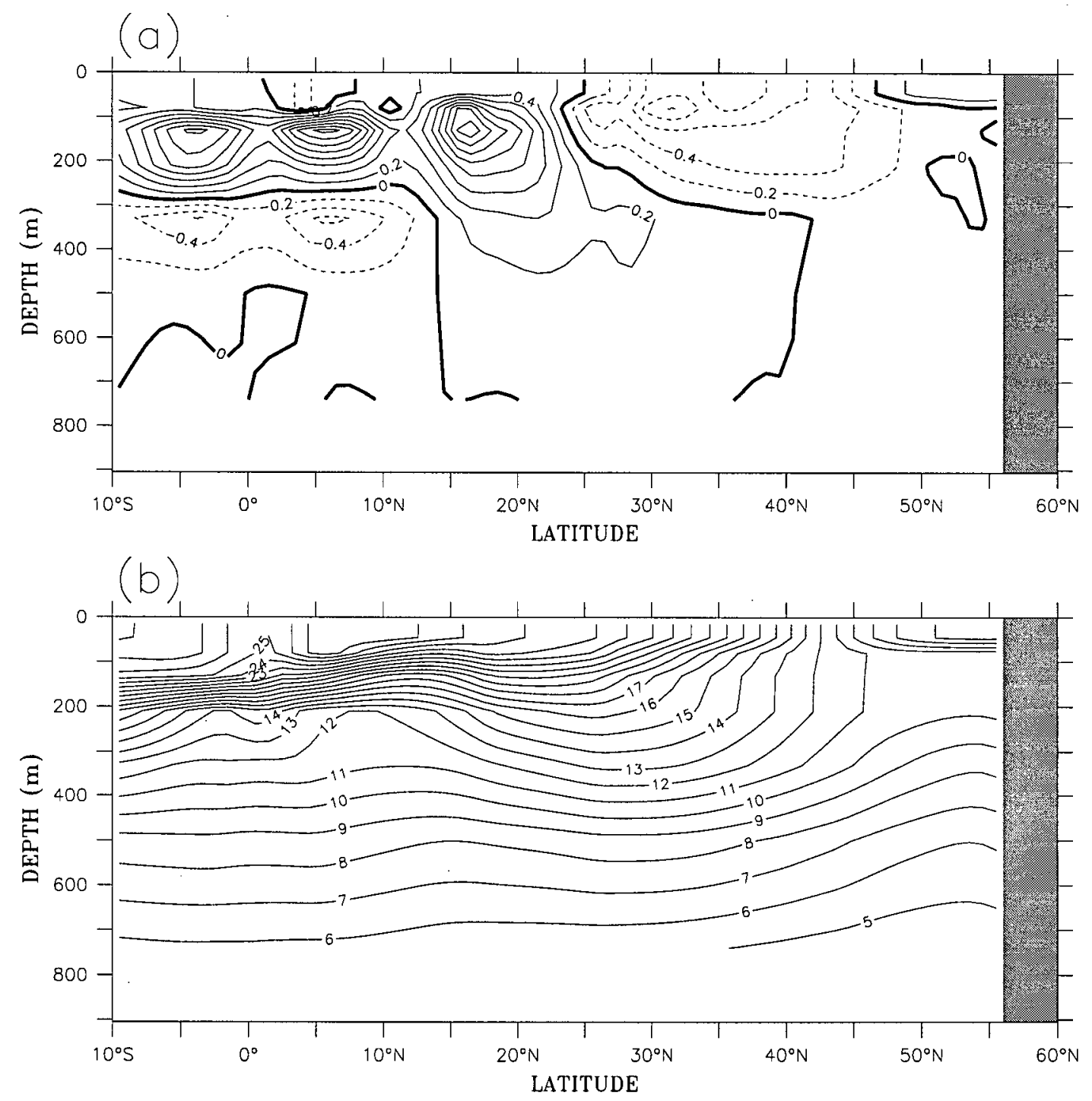

Figure 5.11: (a) The meridional section of temperature change along $155^{\circ} \mathrm{W}$ in DJF between the post- 1976 case and the pre-1976 case. The contour interval is $0.2^{\circ} \mathrm{C}$. (b) The meridional section of temperature distribution along $155^{\circ} \mathrm{W}$ for the pre- 1976 case in DJF. The contour interval is $1^{\circ} \mathrm{C}$. 


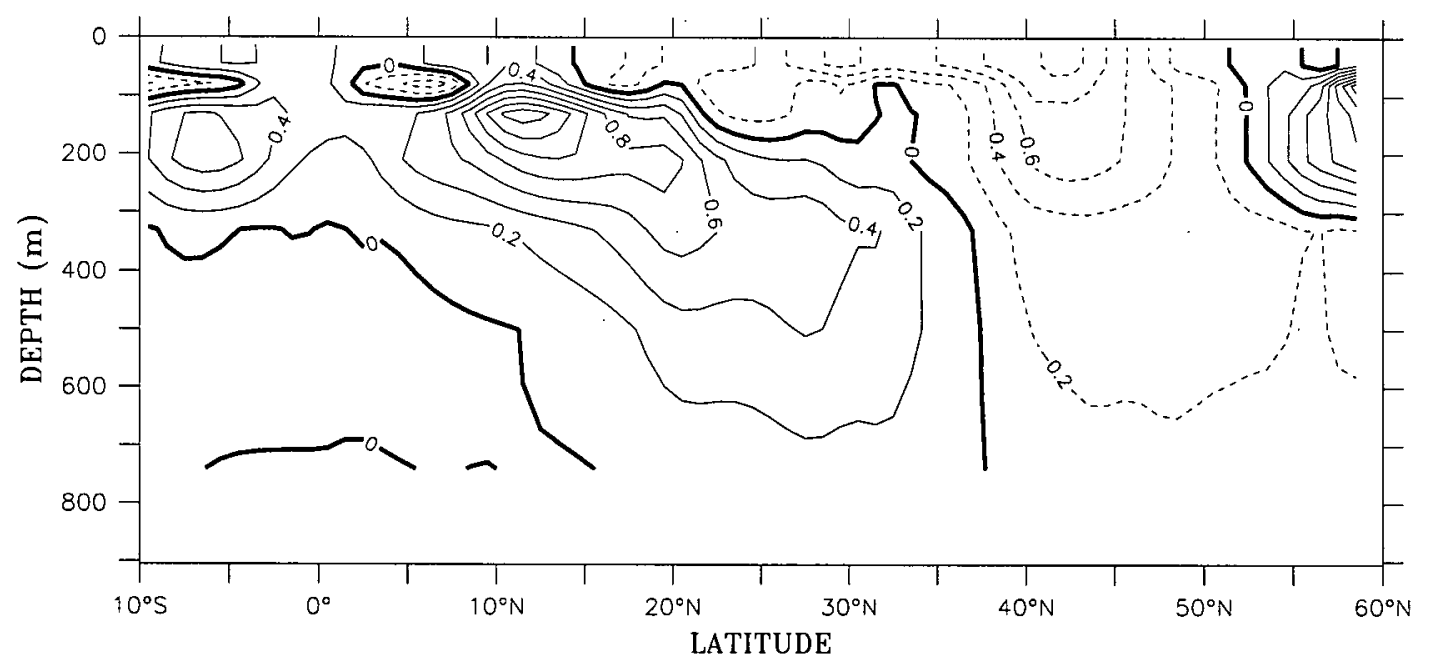

Figure 5.12: (a) The meridional section of temperature variation along the date line $\left(180^{\circ}\right)$ in DJF between the post-1976 case and the pre-1976 case. The contour interval is $0.2^{\circ} \mathrm{C}$. 
deeper waters.

In low latitudes, there is a positive temperature anomaly centered at $5^{\circ} \mathrm{N}$ and 120 m depth. Comparing to the change in vertical velocity (Fig. 5.10), it is clear that the positive temperature change matches the strongest downwelling anomaly center, with the former located slightly lower than the latter. The vertical temperature distribution (Fig. 5.11b) shows that the vertical temperature gradient at $5^{0} N$ and $100 \mathrm{~m}$ depth is very large. Therefore the enhanced downwelling brings warmer water down to increase the water temperature in the layer below and form the temperature anomaly centered below the enhanced downwelling center. The same mechanism can be applied to explain the other two positive temperature anomalies centered at $16^{\circ} \mathrm{N}$ and $4^{0} \mathrm{~S}$ respectively. Similarly, the two anomalous upwelling centers located at a depth of $280 \mathrm{~m}$ on either side of the equator are responsible for the two weaker negative temperature anomalies centered at $320 \mathrm{~m}$ depth.

In the equatorial region, the upwelling changes in the upper waters do not appear to have much effect on the local temperature since the upwelling changes are located above $80 \mathrm{~m}$ depth (Fig. 5.10) where the vertical temperature gradient is almost zero (Fig. 5.11b).

In mid-latitudes, the temperature changes are negative, with a maximum of $-1.0^{\circ} \mathrm{C}$ at $80 \mathrm{~m}$ depth and $32^{\circ} \mathrm{N}$. Again the relatively strong increase in upwelling at $50^{\circ} \mathrm{N}$ does not appear to decrease the temperature there because the vertical temperature gradients in this area are very small.

Thus the simulated temperature change in the subsurface area is mainly determined by the product of the vertical velocity change and the vertical temperature gradient. Both factors are significant from low to high latitudes. The simulated subsurface thermal structures show significant changes, with positive temperature changes in the enhanced downwelling area (subtropical area), and negative temperature changes in the increased 
upwelling area (subarctic area).

The depth range to which the subsurface temperature variations extend is slightly different for different longitude sections. Along the date line (Fig. 5.12), the temperature variation penetrates down to $650 \mathrm{~m}$ depth, deeper than that along $155^{\circ} \mathrm{W}$. A depth of $650 \mathrm{~m}$ is the typical range to which the subsurface temperature change penetrates in the western Pacific. The reason for this deeper penetration of temperature change is that the downwelling or upwelling changes along these longitudes penetrate down to about $650 \mathrm{~m}$ depth (not shown) in mid and high latitudes. Thus, both the strength of the subsurface temperature change and the depth to which it extends are determined by the strength of the upwelling or downwelling changes (including its depth range) and the vertical temperature gradients. The simulated results are consistent with those obtained through statistical data analysis by Antonov [1993], who found no significant temperature changes deeper than 500-600 $\mathrm{m}$ in the North Pacific Ocean for the time period of 1957-1981.

Another notable feature is that increased upwelling in the subarctic area only extends southward to $33^{0} \mathrm{~N}$ (Fig. 5.10), while the negative temperature change extends to $25^{\circ} \mathrm{N}$ in the upper water (Fig. 5.11a). This phenomenon is even more evident in the meridional section of the temperature change along $180^{\circ}$ (Fig. 5.12), with the negative temperature change in the surface water extending southward to $15^{\circ} \mathrm{N}$. As discussed in the previous section, this southward extension of the negative temperature change is partly the result of the increased southward surface Ekman drift induced by the intensified westerlies and the large meridional temperature gradients, and hence limited to near the surface. In low latitudes, the temperature change near the surface is relatively small. This is due to both the horizontal advection change and vertical velocity change occurring in a region of relatively small meridional and vertical temperature gradients.

A cold anomaly generally influences biological primary productivity. During cold 
anomalies, the thermocline is closer to the surface, bringing the subsurface nutrient reservoir closer to the surface, hence an increase in primary productivity [Barber and Chavez, 1983]. Venrick et al. [1987] found a significant increase in primary productivity in the central North Pacific since the late 1970s. They identified that the increased surface cooling combined with the increased winter wind stress would lead to increased vertical

mixing and upward transport of new nutrients into the euphotic zone. McFarlane and Beamish [1992] also showed that the cooling of the central North Pacific Ocean increases nutrient supply to the surface waters. Meanwhile, the intensified Aleutian Low enhances upwelling, further increasing the transport of nutrients into surface waters. This intensified Low also enhances the advection of the increased amount of nutrients and plankton to and along the coast thereby improving the fishery productivity along the coast.

\subsection{Variations in meridional mass and heat transport}

Fig. 5.13 shows the change in the meridional mass transport between the post-1976 case and the pre-1976 case in January. The changes in both the surface boundary conditions, i.e. the surface wind stress and the SST, can contribute to the change in the meridional mass transport. One would speculate that the change in SST (Fig. 3.5), with cooling in the central North Pacific, and warming along the equator, eastern tropical Pacific and the coastal area off North America, would change the density structure of the surface water via the surface relaxation boundary condition, generating the tendency of downward movement in the cooling area, and upward movement in the warming area. The resulting variation in thermohaline circulation is expected to be a broad and clockwise meridional mass loop. However, the simulated change in meridional mass transport (Fig. 5.13) shows a strong clockwise cell only in low latitudes, with an anti-clockwise cell in mid and high latitudes. The increased Ekman suction along the equator strengthens the 


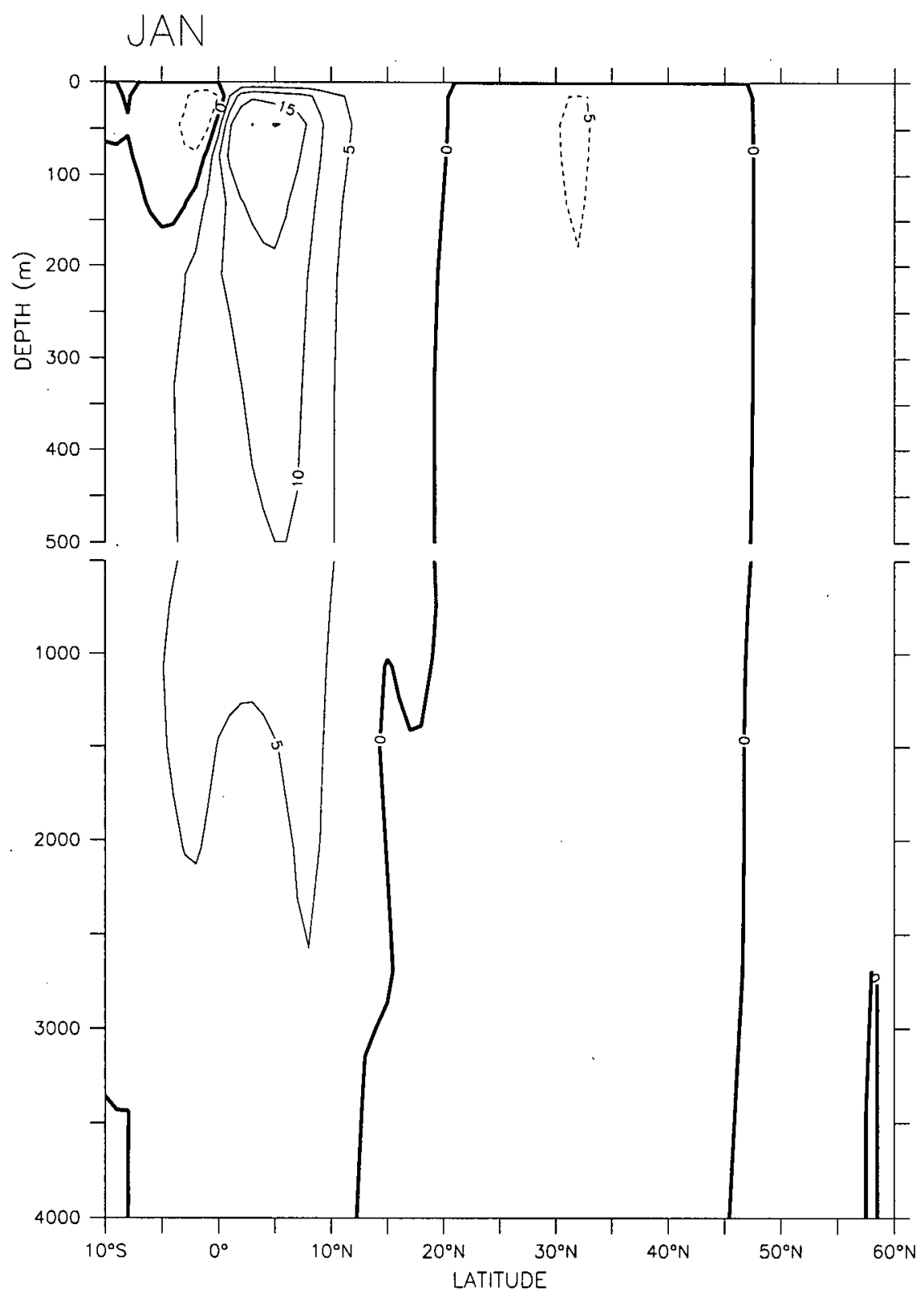

Figure 5.13: (a) The difference in meridional mass transport between the post-1976 case and the pre-1976 case in January. The contour interval is 5 megatons/s. 
clockwise meridional cell just north of the equator, whereas the intensified westerlies of the Aleutian Low system increases the equatorward surface Ekman drift in the mid and high latitudes (as seen in Fig. 5.6a, the V component is increased), leading to the enhanced anti-clockwise meridional cell. As the Ekman mass transport is inversely related to the Coriolis parameter $f$, the change in the mass transport is stronger in the equatorial region than in the mid-latitudes even though the change in the westerlies is stronger than the equatorial winds.

The total meridional heat transports for the post-1976 and the pre-1976 case are shown in Fig.5.14a. For better visualization, the heat transport between $30^{\circ} \mathrm{N}$ and $60^{\circ} \mathrm{N}$ is redrawn in Fig 5.14b. As described in Chapter 4, the total meridional heat transport can be divided into three fractional components. The meridional heat transports by the overturning component for both cases is shown in Fig. 5.15. Fig. 5.16 presents the meridional heat transport contributed by the gyre component and by diffusion.

The total heat transport has a maximum value at low latitudes for both the post-1976 case and the pre-1976 case. A comparison between Fig. 5.15 and 5.16 shows that the total meridional heat transport is mainly determined by the overturning component in low latitudes. There, the equatorial Ekman suction generates meridional cells (Fig. 4.8), transporting heat poleward efficiently by carrying the warm surface waters poleward in the upper branch with a compensating equatorward flow of cold waters below. In middle latitudes, the westerly wind zone produces equatorward Ekman transport, causing the equatorward net heat transport. In high latitudes, winds are weak and mostly easterlies. Therefore a weaker poleward Ekman transport combined with weaker vertical temperature gradients there yield smaller heat transport. The thermohaline forcing is working in the same direction as the wind forcing in low and high latitudes, but in the opposite direction in mid-latitudes, though the thermohaline effect is generally weak in the North Pacific. 

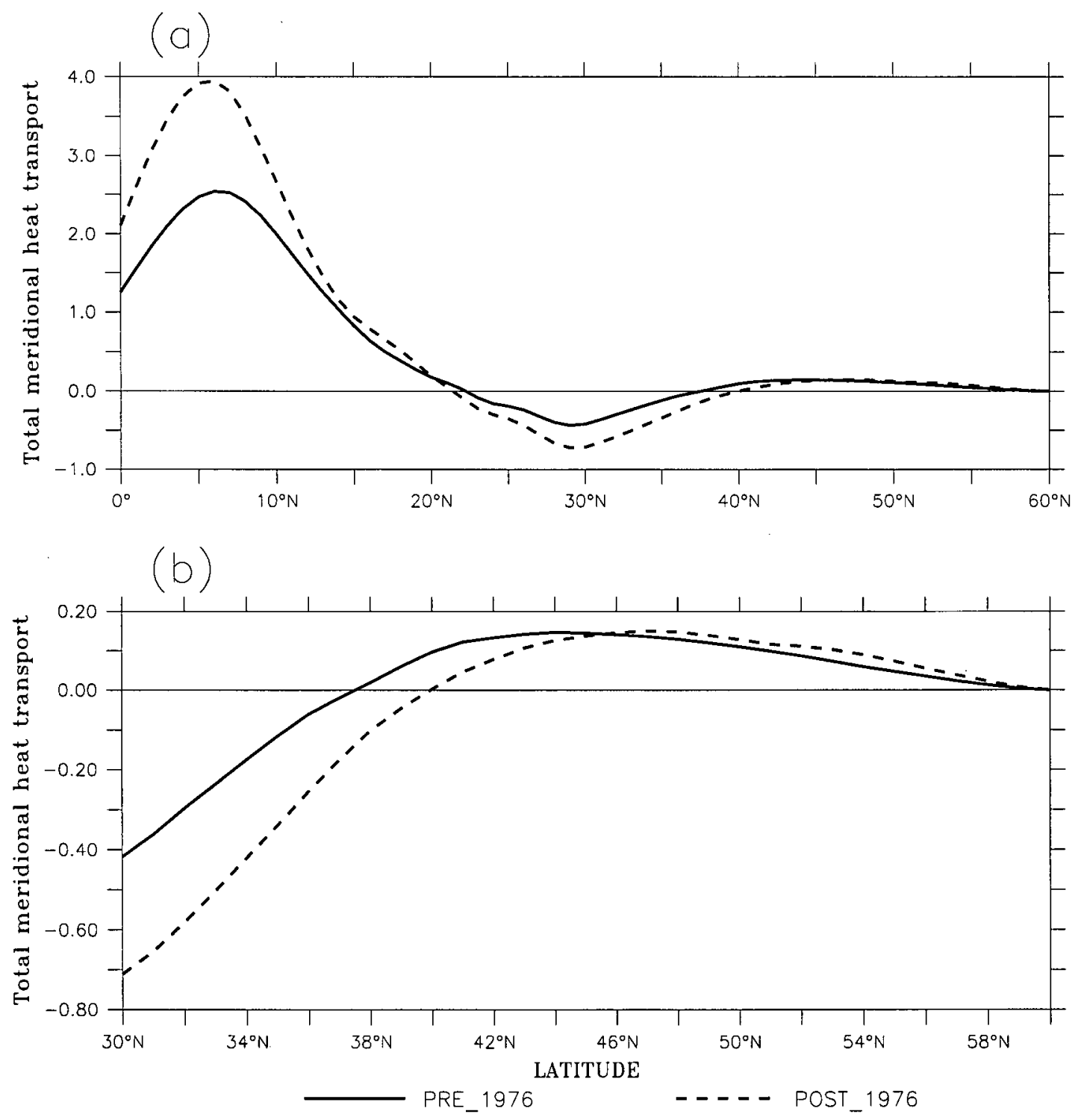

Figure 5.14: (a) The total meridional heat transport for the post-1976 case (dashed curve) and the pre-1976 case (solid curve) in January. (b) The redrawn total meridional heat transport between $30^{\circ} \mathrm{N}$ and $60^{\circ} \mathrm{N}$ for better visualization. Units are in petawatts. 

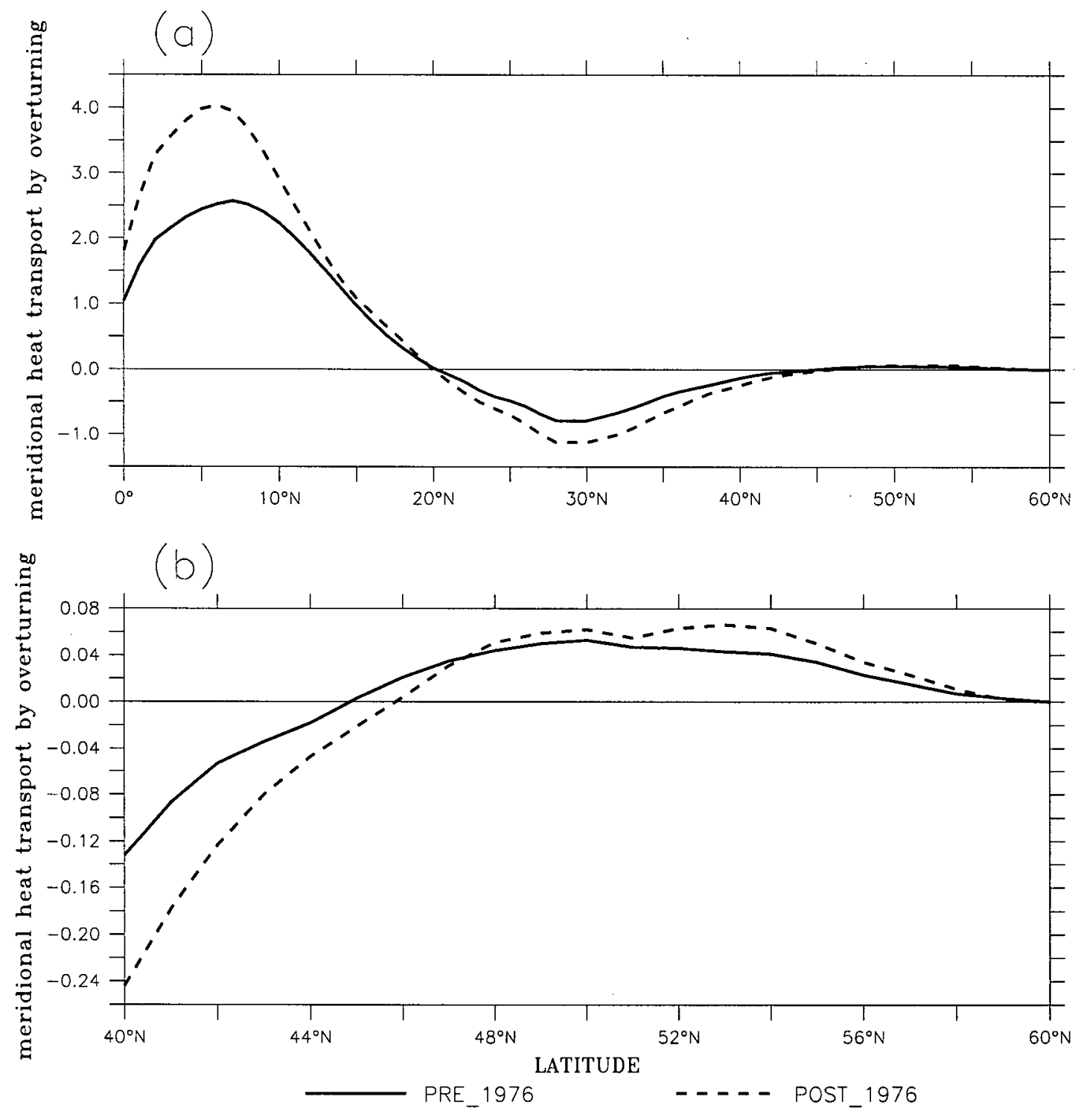

Figure 5.15: (a) The meridional heat transport contributed by the overturning component for the post-1976 case and the pre-1976 case in January. (b) The redrawn overturning component of heat transport between $40^{\circ} \mathrm{N}$ and $60^{\circ} \mathrm{N}$ for better visualization. Units are in petawatts. 

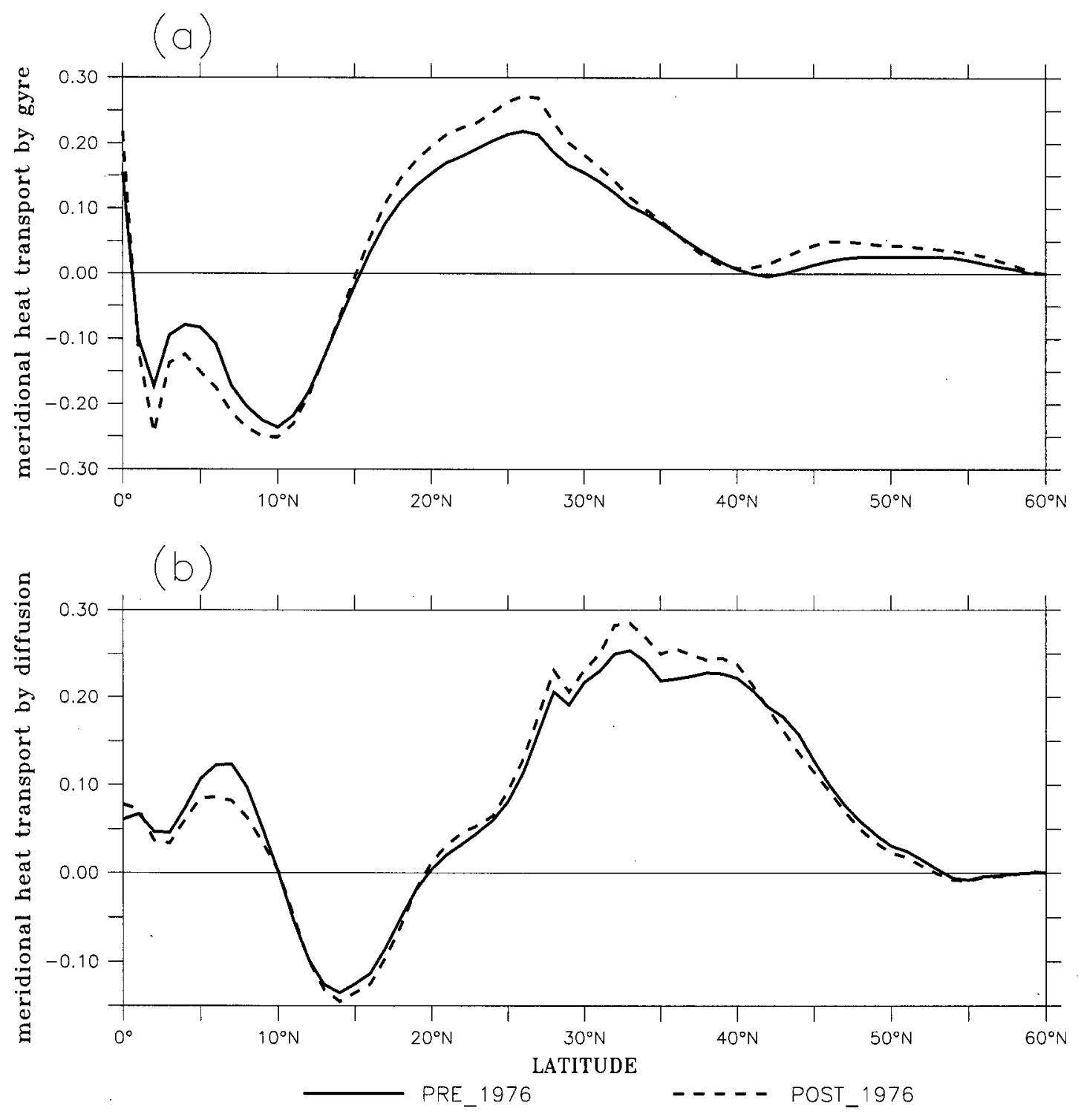

Figure 5.16: (a) The gyre component of the meridional heat transport for the post-1976 case and the pre-1976 case in January. (b) The diffusion component of the meridional heat transport for the post-1976 case and the pre-1976 case in January. Units are in petawatts. 
The change in the surface wind stress as a result of the 1976 climate shift will produce changes in the meridional heat transport. By comparing Fig. 5.14a with Fig. 5.15a, it is seen that in low latitudes the change in the heat transport due to the overturning component is the major effect changing the total heat transport. The largest variation of 1.5 petawatts on both Fig. $5.14 \mathrm{a}$ and Fig. $5.15 \mathrm{a}$ occurs at $7^{0} N$ where the peak heat transport lies. The significant change in the meridional circulation at low latitudes (Fig. 5.13 ) is responsible for the large change in heat transport.

In middle latitudes, the contribution from the change in the overturning component is still the most important in determining the change in total heat transport. However, contributions from the gyre and diffusion components are not negligible. The equatorward heat transport by the overturning component is increased by a maximum of about 0.3 petawatts at $28^{\circ} N$, while the increased poleward heat transport by the gyre component has a maximum of 0.06 petawatts at $27^{\circ} \mathrm{N}$, and 0.04 petawatts by the diffusion component at $32^{\circ} \mathrm{N}$. Thus the change contributed by the overturning component is partly offset by the diffusion and gyre components. Therefore the total change in heat transport at mid-latitudes (Fig. 5.14) is less than that contributed by the overturning component alone.

The increase in equatorward heat transport in mid-latitudes by the overturning component mainly results from the increased meridional circulation in these latitudes (Fig. 5.13), which is largely due to the intensification of the westerlies in the Aleutian Low system. The gyre component in mid-latitudes tends to transport heat poleward by having a warm northward western boundary current compensated by a cold return flow on the eastern boundary. Thus the intensified subtropical gyre (Fig. 5.3), resulting from the 1976 climatic shift, causes the increase in poleward heat transport by the gyre component in this latitude band. The diffusion component is determined by the meridional temperature gradient. In mid-latitudes the meridional temperature gradients are always 
down gradient poleward. By looking at the simulated temperature change at the surface (Fig. 5.5) and below the surface (Fig. 5.11a and 5.12), it is seen that the meridional temperature gradients are enhanced between $20^{\circ} \mathrm{N}$ and $50^{\circ} \mathrm{N}$, thus the heat transport by the diffusion term is increased.

In high latitudes (north of $45^{\circ} \mathrm{N}$ ), the total meridional heat transport is poleward, but very small. All three fractional components are poleward, except for the diffusion component north of $53^{\circ} \mathrm{N}$. Generally the poleward overturning and gyre components in this latitudal band are enhanced by the 1976 climate shift, while the poleward diffusion component is decreased. The total change in the poleward heat transport in high latitudes is an increase of the order of $10^{-2}$ petawatts.

As a result of the 1976 climate shift, the simulated ocean circulation shows significant changes. The largest change in the meridional heat transport is in low latitudes. Poleward transport is increased mainly owing to the fact that the largest change in meridional circulation occurs there. In mid-latitudes the increase in equatorward heat transport contributed by the overturning component is partly offset by the increase in poleward heat transports from the gyre and the diffusion components. The heat transport in high latitudes is poleward, but very small. The change, showing a very small increase, is about $30 \%$ higher than the heat transport in the pre-1976 case. 


\section{Chapter 6}

\section{An Estimate of the Salinity Effect}

\subsection{Introduction}

As pointed out in Chapter 3, monthly surface salinity data for the past four decades is not available. Hence I could not construct a pre-1976 (1952-1975) surface salinity monthly climatology nor a post-1976 (1976-1988) climatology. During the course of all experiments a monthly climatology of the sea surface salinity (SSS) field obtained from the World Ocean Atlas [1994] has been employed. Since salinity is likely to have been changed by the climate shift of 1976 , then the following questions arise: Are the results of the present study meaningful by having applied the same monthly climatology of SSS to all the climate shift experiments? Would the results of the present study have been changed significantly if both the pre-1976 and post-1976 SSS monthly climatology were available and were applied to all the climate shift experiments? Answers to these questions are not known simply because SSS data are not adequate. Nevertheless, we can still try to seek possible answers by using available and limited information on the trends of salinity variability over the past few decades at some particular observation stations in the northeast Pacific.

\subsection{Design of the experiment}

Freeland and Whitney [1997] calculated the temperature and salinity trends at station Papa $\left(145^{\circ} \mathrm{W}, 50^{\circ} \mathrm{N}\right)$ and three coastal sampling stations along the Pacific coast of Canada 
based on three decades of observational data. The results reveal that there are significant trends in surface temperature and salinity at the four stations. At station $\mathrm{P}$ the temperature trend is $+1.96^{\circ} \mathrm{C} /$ century and the salinity trend is $-0.43 \mathrm{ppt} /$ century.

The climate shift experiments carried out in this study cover the climatology period of pre-1976 (1952-1975) and post-1976 (1976-1988). The middle year of each climatology period is in 1963 and 1982 respectively, separated by 19 years. To calculate the temperature and salinity trends during the two climatological periods, the changes per century from Freeland and Whitney are multiplied by 0.19 (i.e. 19 years), yielding SST and SSS changes at station $\mathrm{P}$ between the two climatological periods of $+0.372^{\circ} \mathrm{C}$ and -0.0817 respectively. Since the monthly climatological SST for the two climatological periods is available, the deviation of the annual mean SST between the two climatologies at station $\mathrm{P}$ can be computed. The deviation is $+0.428^{\circ} \mathrm{C}$, which approximately matches the one estimated from Freeland and Whitney's studies.

So far salinity changes over the entire North Pacific are still not available. However, as described on page 51 of Pickard and Emery, [1990]

$\ldots$ in the upper water, $\ldots$ the density is determined chiefly by temperature in the open ocean (except in the polar seas)...... The variations in salinity which occur in open ocean waters are usually not sufficient in their effect upon density to override the effect of temperature. ... As a consequence of this less important role in dictating the density structure, salinity acts as a "passive tracer" indicating the flow directions of water masses by their salinity signatures (minima and maxima)....

So the interdecadal variation in salinity at low and mid latitudes will not be taken into account in this study to estimate the salinity effect. In high latitudes, it is assumed that the change in salinity for the region north of $40^{\circ} \mathrm{N}$ between the two climatological 
periods is the same everywhere as the change found for station P. Hence a value of 0.0817 is subtracted from the monthly climatology salinity data for each month at each grid point in the area north of $40^{\circ} \mathrm{N}$, with a taper assumed between $40^{\circ} \mathrm{N}$ and $35^{\circ} \mathrm{N}$ by linearly decreasing the value of the change in salinity from 0.0817 to 0 . The resulting salinity field is considered as a possible climatology field for the period of 1976-88. Together with the available wind stress and SST surface forcing fields in this climatological period, the model is run again for six years from the end of Exp.A. The solutions of this experiment, designated as Exp.S, will be compared with those of Exp.C to determine the salinity effect.

\subsection{Results of the experiment}

The difference in the vertical velocity field at 60 meters depth between the two experiments is examined. It turns out that the two curves depicting the zonally averaged vertical velocity for the two experiments basically overlap. Their differences are extremely small. The values of zonally averaged vertical velocity at each latitude between $0^{\circ} \mathrm{N}$ and $60^{\circ} N$ for Exp.C and the differences between Exp.S and Exp.C are presented in Table 6.1.

The horizontal pattern of the difference in the vertical velocity at 60 meters depth in the subarctic region has difference values at each individual grid point of less than 0.1 $\mathrm{cm} /$ day except for those in the merging area of the Kuroshio and Oyahio which can reach $0.5 \mathrm{~cm} /$ day. The difference is so small that it is negligible compared to the magnitude of upwelling and downwelling in this area, as shown in Fig. 5.8. The difference values in the equatorial region is less than $0.5 \mathrm{~cm} /$ day, which is certainly very small in comparison with the strong upwelling along the equator. However, it indicates that the change in salinity in high latitudes can affect the circulation in a remote area even though the effect is tiny in this study. 


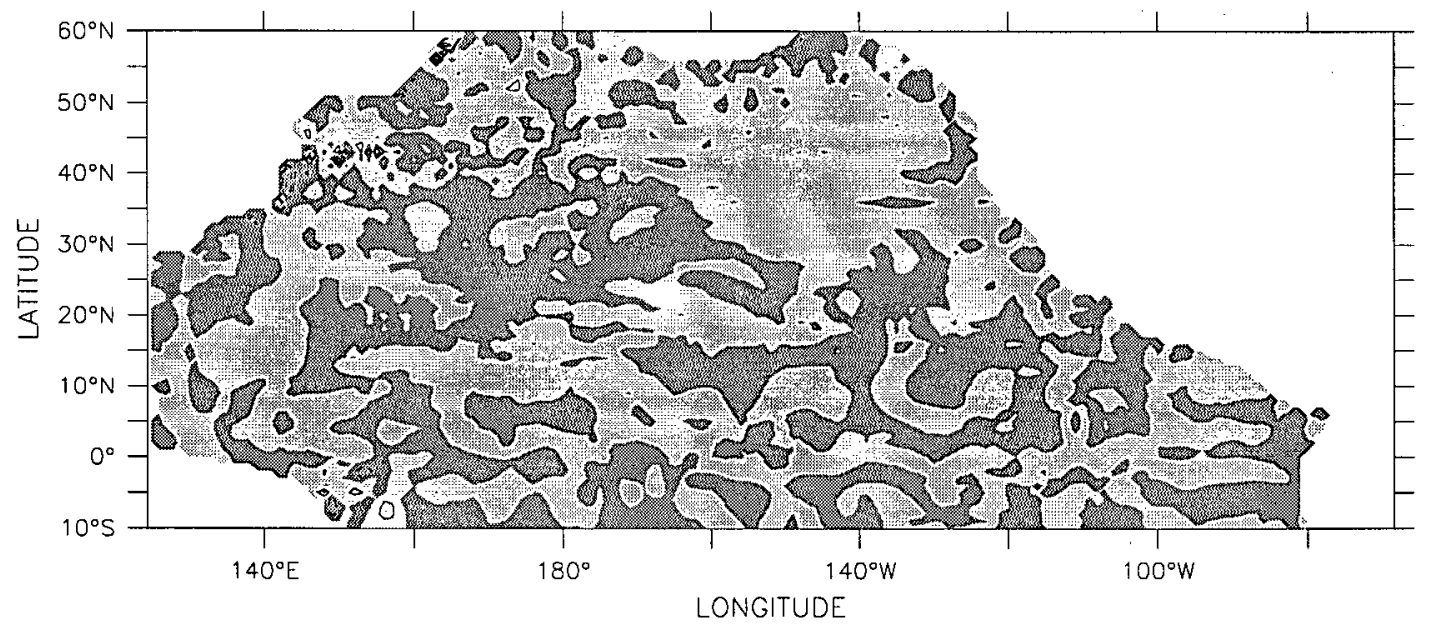

Figure 6.1: The difference in vertical velocity pattern at depth 60(m) during DJF between Exp.S (post-1976 with salinity modified) and Exp.C (post-1976). The light grey indicates positive values, the dark grey negative values. The contour intervals are $\pm 0.5, \pm 1, \pm 2, \pm 3$ $\mathrm{cm} /$ day. In most areas, the difference is less than 0.5. Indeed, it is unimportant in comparison with the magnitude of vertical velocity shown in Fig. 5.5. 


\begin{tabular}{|c|c|c|c|c|c|}
\hline \multirow[t]{2}{*}{ latitude ${ }^{0} N$} & \multicolumn{2}{|c|}{ vertical velocity } & \multirow[t]{2}{*}{ latitude ${ }^{0} N$} & \multicolumn{2}{|c|}{ vertical velocity } \\
\hline & Exp.C & Exp.S-Exp.C & & Exp.C & Exp.S-Exp.C \\
\hline 0 & 155.206 & $-1.10 \mathrm{E}-02$ & 31 & -3.479 & $-4.00 \mathrm{E}-04$ \\
\hline 1 & 173.617 & $2.00 \mathrm{E}-03$ & 32 & -0.661 & $4.60 \mathrm{E}-03$ \\
\hline 2 & 70.798 & $2.60 \mathrm{E}-02$ & 33 & 5.043 & $-1.60 \mathrm{E}-03$ \\
\hline 3 & 1.435 & $3.50 \mathrm{E}-02$ & 34 & 5.796 & $2.00 \mathrm{E}-03$ \\
\hline 4 & 1.611 & $1.00 \mathrm{E}-02$ & 35 & 5.512 & $-1.10 \mathrm{E}-02$ \\
\hline 5 & 3.337 & $-3.40 \mathrm{E}-02$ & 36 & 5.905 & $-4.18 \mathrm{E}-02$ \\
\hline 6 & -2.569 & $-2.10 \mathrm{E}-02$ & 37 & 8.406 & $-1.48 \mathrm{E}-02$ \\
\hline 7 & -11.075 & $2.00 \mathrm{E}-03$ & 38 & 8.136 & $-2.38 \mathrm{E}-02$ \\
\hline 8 & -14.969 & $1.20 \mathrm{E}-02$ & 39 & 5.748 & $-2.72 \mathrm{E}-02$ \\
\hline 9 & -18.606 & $1.00 \mathrm{E}-02$ & 40 & 5.717 & $-1.44 \mathrm{E}-02$ \\
\hline 10 & -19.924 & $2.40 \mathrm{E}-03$ & 41 & 8.518 & . $1.22 \mathrm{E}-02$ \\
\hline 11 & -19.771 & $-4.01 \mathrm{E}-04$ & 42 & 8.358 & $-8.20 \mathrm{E}-02$ \\
\hline 12 & -17.920 & $0.00 \mathrm{E}+00$ & 43 & 5.979 & $3.20 \mathrm{E}-03$ \\
\hline 13 & -16.450 & $2.00 \mathrm{E}-04$ & 44 & 5.621 & 8.60E-03 \\
\hline 14 & -15.679 & $-2.00 \mathrm{E}-04$ & 45 & 7.334 & $1.36 \mathrm{E}-02$ \\
\hline 15 & -17.861 & $-1.98 \mathrm{E}-04$ & 46 & 7.483 & $2.66 \mathrm{E}-02$ \\
\hline 16 & -16.884 & $0.00 \mathrm{E}+00$ & 47 & 8.818 & $2.10 \mathrm{E}-02$ \\
\hline 17 & -16.223 & $5.99 \mathrm{E}-04$ & 48 & 9.194 & $4.00 \mathrm{E}-03$ \\
\hline 18 & -15.431 & 4.00E-04 & 49 & 7.896 & $5.00 \mathrm{E}-03$ \\
\hline 19 & -15.636 & $4.01 \mathrm{E}-04$ & 50 & 7.216 & $-3.00 \mathrm{E}-03$ \\
\hline 20 & -15.103 & $-7.99 \mathrm{E}-04$ & 51 & 6.107 & $-2.98 \mathrm{E}-02$ \\
\hline 21 & -15.087 & $9.99 \mathrm{E}-04$ & 52 & 6.309 & $-9.80 \mathrm{E}-03$ \\
\hline 22 & -14.256 & $9.99 \mathrm{E}-04$ & 53 & 7.134 & $3.40 \mathrm{E}-03$ \\
\hline 23 & -14.122 & $-5.99 \mathrm{E}-04$ & 54 & 6.512 & $2.20 \mathrm{E}-03$ \\
\hline 24 & -13.528 & $-1.00 \mathrm{E}-03$ & 55 & 3.952 & $2.74 \mathrm{E}-02$ \\
\hline 25 & -14.240 & $-7.80 \mathrm{E}-03$ & 56 & 1.916 & $7.44 \mathrm{E}-02$ \\
\hline 26 & -14.360 & $-7.20 \mathrm{E}-03$ & 57 & 4.624 & $-1.88 \mathrm{E}-02$ \\
\hline 27 & -15.017 & $-9.99 \mathrm{E}-04$ & 58 & 3.084 & $8.60 \mathrm{E}-02$ \\
\hline 28 & -14.246 & $-6.60 \mathrm{E}-03$ & 59 & -0.981 & $-1.44 \mathrm{E}-02$ \\
\hline 29 & -12.721 & $-6.80 \mathrm{E}-03$ & 60 & 0.0 & 0.0 \\
\hline 30 & -9.231 & $-8.20 \mathrm{E}-03$ & & & \\
\hline
\end{tabular}

Table 6.1: The value of zonally averaged vertical velocity at each latitude during DJF for Exp.C and the difference between Exp.S and Exp.C. The units are $\mathrm{cm} /$ day. 


\begin{tabular}{|c|c|c|c|c|c|}
\hline \multirow[t]{2}{*}{ latitude ${ }^{0} N$} & \multicolumn{2}{|c|}{ heat transport } & \multirow[t]{2}{*}{ latitude ${ }^{0} N$} & \multicolumn{2}{|c|}{ heat transport } \\
\hline & Exp.C & Exp.S-Exp.C & & Exp.C & Exp.S-Exp.C \\
\hline 0 & 2.107 & $-9.00 \mathrm{E}-03$ & 30 & -0.711 & $-7.00 \mathrm{E}-03$ \\
\hline 1 & 2.601 & $-1.20 \mathrm{E}-02$ & 31 & -0.653 & $-7.00 \mathrm{E}-03$ \\
\hline 2 & 3.072 & $-1.20 \mathrm{E}-02$ & 32 & -0.580 & $-6.00 \mathrm{E}-03$ \\
\hline 3 & 3.463 & $-9.00 \mathrm{E}-03$ & 33 & -0.502 & $-6.00 \mathrm{E}-03$ \\
\hline 4 & 3.748 & $-6.00 \mathrm{E}-03$ & 34 & -0.420 & $-5.00 \mathrm{E}-03$ \\
\hline 5 & 3.916 & $-7.00 \mathrm{E}-03$ & 35 & -0.338 & $-4.00 \mathrm{E}-03$ \\
\hline 6 & 3.946 & $-9.00 \mathrm{E}-03$ & 36 & -0.254 & $-4.00 \mathrm{E}-03$ \\
\hline 7 & 3.815 & $-1.00 \mathrm{E}-02$ & 37 & -0.174 & $-4.00 \mathrm{E}-03$ \\
\hline 8 & 3.515 & $-1.00 \mathrm{E}-02$ & 38 & -0.101 & $-5.00 \mathrm{E}-03$ \\
\hline 9 & 3.110 & $-8.00 \mathrm{E}-03$ & 39 & -0.045 & $-4.00 \mathrm{E}-03$ \\
\hline 10 & 2.664 & $-7.00 \mathrm{E}-03$ & 40 & 0.003 & $-5.00 \mathrm{E}-03$ \\
\hline 11 & 2.223 & $-5.00 \mathrm{E}-03$ & 41 & 0.046 & $-4.00 \mathrm{E}-03$ \\
\hline 12 & 1.816 & $-6.00 \mathrm{E}-03$ & 42 & 0.078 & $-5.00 \mathrm{E}-03$ \\
\hline 13 & 1.453 & $-7.00 \mathrm{E}-03$ & 43 & 0.107 & $-7.00 \mathrm{E}-03$ \\
\hline 14 & 1.153 & $-7.00 \mathrm{E}-03$ & 44 & 0.126 & $-7.00 \mathrm{E}-03$ \\
\hline 15 & 0.940 & $-8.00 \mathrm{E}-03$ & 45 & 0.137 & $-6.00 \mathrm{E}-03$ \\
\hline 16 & 0.791 & $-8.00 \mathrm{E}-03$ & 46 & 0.146 & $-5.00 \mathrm{E}-03$ \\
\hline 17 & 0.655 & $-8.00 \mathrm{E}-03$ & 47 & 0.150 & $-5.00 \mathrm{E}-03$ \\
\hline 18 & 0.520 & $-7.00 \mathrm{E}-03$ & 48 & 0.148 & $-5.00 \mathrm{E}-03$ \\
\hline 19 & 0.358 & $-6.00 \mathrm{E}-03$ & 49 & 0.139 & $-5.00 \mathrm{E}-03$ \\
\hline 20 & 0.194 & $-4.00 \mathrm{E}-03$ & 50 & 0.128 & $-6.00 \mathrm{E}-03$ \\
\hline 21 & 0.057 & $-3.00 \mathrm{E}-03$ & 51 & 0.116 & $-8.00 \mathrm{E}-03$ \\
\hline 22 & -0.086 & $-2.00 \mathrm{E}-03$ & 52 & 0.111 & $-9.00 \mathrm{E}-03$ \\
\hline 23 & -0.219 & $-2.00 \mathrm{E}-03$ & 53 & 0.103 & $-9.00 \mathrm{E}-03$ \\
\hline 24 & -0.296 & $-2.00 \mathrm{E}-03$ & 54 & 0.090 & $-9.00 \mathrm{E}-03$ \\
\hline 25 & -0.351 & $-3.00 \mathrm{E}-03$ & 55 & 0.073 & $-8.00 \mathrm{E}-03$ \\
\hline 26 & -0.434 & $-6.00 \mathrm{E}-03$ & 56 & 0.055 & $-7.00 \mathrm{E}-03$ \\
\hline 27 & -0.551 & $-5.00 \mathrm{E}-03$ & 57 & 0.038 & $-6.00 \mathrm{E}-03$ \\
\hline 28 & -0.661 & $-6.00 \mathrm{E}-03$ & 58 & 0.022 & $-4.00 \mathrm{E}-03$ \\
\hline 29 & -0.720 & $-6.00 \mathrm{E}-03$ & 59 & 0.008 & $-2.00 \mathrm{E}-03$ \\
\hline & & & 60 & 0.000 & 0.000 \\
\hline
\end{tabular}

Table 6.2: The value of total meridional heat transport at each latitude in January for Exp.C and the difference between Exp.S and Exp.C. The units are petawatts. 
The total meridional heat transport for Exp.C and the difference between Exp.S and Exp.C are shown in Table 6.2. The difference in meridional heat transports between the two experiments is negligibly small.

In summary, changes in the surface salinity forcing fields by an amount of 0.0817 in subpolar latitudes do not have significant impacts on the major results discussed in Chapter 5 . 


\section{Chapter 7}

\section{Conclusions}

A numerical investigation into the oceanic changes associated with the 1976 climate regime shift has been carried out with the GFDL ocean general circulation model. First, the model was spun up from the rest state with the surface boundary forced by the wind stress monthly climatology and relaxed to the SST and SSS monthly climatology. The time integration was carried out for 21 years until the model reached a quasi-equilibrium state. Second, in order to compare the results from the climate shift experiments, this climatological run was extended for 6 more years. Then the simulated results at year 27 were collected (Exp.A). It has been shown that the model accurately simulated the major features of the climatological ocean fields with reasonable seasonal variations.

From the end of year 21 of the climatological run, two additional experiments are performed, Exp.B with the surface forcing replaced by the pre-1976 (1952-1975) monthly climatological wind stress and SST fields, and Exp.C by the post-1976 (1976-1988) monthly climatological values. During all the experiments the same SSS monthly climatology is used. The integration is carried out for 6 years for each of the two additional experiments.

The simulated ocean circulations exhibit significant change in response to the changes in atmosphere forcing. The intensification of the Aleutian Low system in winter, associated with stronger wind stress, spins up the subarctic gyre and the subtropic gyre, except in the northern and eastern part of the Gulf of Alaska, where the Alaskan gyral circulation is weakened.

The large scale surface cooling in the central North Pacific and the warming along the 
west coast of North America are simulated, as they are mainly produced by the intensified surface Ekman drifts associated with the deepening of the Aleutian Low. The results show that anomalous horizontal advection is a very important mechanism in producing thermal anomalies near the surface, especially in mid and high latitudes.

The deepening of the Aleutian Low generates stronger surface divergence in the subarctic area and stronger convergence in the subtropic. Consequently the upwelling system is strengthened in the subarctic region, having the maximum increase by $108 \%$ at a depth of $60 \mathrm{~m}$. The downwelling in the subtropic area is enhanced as well. Along the coast of North America north of $40^{\circ} \mathrm{N}$, there is a stronger increase in downwelling, which is consistent with the weakening of the Alaska gyral circulation.

The meridional sections of the changes in the vertical velocity show that the significant changes in the vertical velocity are confined above depths of a few hundred meters. The increased upwelling in the subarctic, together with the vertical temperature gradients, produces large scale cooling in the subsurface, and vice versa for the increased downwelling in the subtropic, generating large scale warming there. The significant changes in the subsurface thermal structure are generally limited to above $650 \mathrm{~m}$ depth, which is mainly determined by the product of the vertical velocity change and the vertical temperature gradients.

The change in the large scale circulation in the ocean certainly leads to changes in the meridional circulation and heat transport. In low latitudes, the poleward heat transport is increased mainly from the strengthening of the meridional circulation there. In mid-latitudes, the heat transport is equatorward, and is enhanced mainly by the meridional component, though the gyre and diffusion components are not negligible. In high latitudes, the heat is transported poleward, but is very small. The change is even smaller and generally increased.

The estimation of the salinity effect on the results of the present study was carried 
out by assuming that the change in salinity in the subarctic region between the two climatological periods are the same everywhere as those observed at station P. The results of the experiments show that the change in surface salinity forcing fields by an amount of $0.0817 \mathrm{ppt}$ in subarctic latitudes does not have significant impacts on the results of the current study. 


\section{Bibliography}

Alexander, M. (1992). Midlatitude atmosphere-ocean interaction during El Niño. I. the North Pacific Ocean. J. Climate, 5:944-958.

Anderson, D.L.T. and R.A. Corry (1985). Seasonal transport variations in the Florida Straits: A model study. J. Phys. Oceanogr., 15:773-786.

Antonov, J. (1993). Linear trends of temperature at intermediate and deep layers of the North Atlantic Ocean and the North Pacific Ocean. J. Climate, 6:1928-1942.

Barber, R.J. and F.P.Chavez (1983). Biological consequences of El Niño. sicence, 222:1203-1210.

Beamish, R.J. and D.R. Bouillon (1993). Pacific salmon production trends in relation to climate. Can. J. Fish. Aquat. Sci., 50:1002-1016.

Bryan, K. (1982). Seasonal variation in meridional overturning and poleward heat transport in the atlantic and pacific oceans: a model study. J. Mar. Res., 40, supplement:38-53.

Bryan, K. and L.J. Lewis (1979). A water mass model of the world ocean. J. Geophys. Res., 84(C5):2503-2517.

Bryan, K. and M.D. Cox (1967). A numerical investigation of the oceanic general circulation. Tellus, 19:54-80. 
Bryan, K. and M.D. Cox (1968). A nonlinear model of an ocean driven by wind and differential heating: Part I Description of the three-dimensional velocity and density fields. J. Atmos. Sci., 25:945-967.

Bryan, K. and M.D. Cox (1972). An approximate equation of state for numerical models of ocean ciuculation. J. Phys. Oceanogr, 2:510-514.

Bryan, K., S. Manabe and R.C. Pacanowski (1975). A global ocean-atmosphere climate model . Part II The oceanic circulation. J. Phys. Oceanogr., 5:30-46.

Bubnov, V.A. (1987). Vertical motion in the central equatorial Pacific. Oceanol. acta, Proc. Int. Symp. on Equatorial Vertical Motion, 6:15-17.

Chen, J-H (1971). Ph.D. thesis, Princeton University. page 102.

Cox, M.D. (1970). A mathematical model of the Indian Ocean. Deep-Sea Res., 17:47-75.

Douglas, A.V., D.R. Cayan and J. Namias (1982). Large-scale changes in North Pacific and North American weather patterns in recent decades. Mon. Wea. Rev., 110:18511862.

Ebbesmeyer, C.C., D.R. Cayan, D.R. Mclain, F.H. Nichols, D.H. Peterson, K.T. Redmond (1991). 1976 step in the Pacific Climate: forty environmental changes between 1968-1975 and 1977-1984. In: J.L Betancourt and V.L, Tharp (eds) Proceedings of the 7th annual Pacific climate(PACLIM) workshop,. Technical Report 26, California Department of Water Resources, Interagency Ecological Studies Program.

Emery W.J. and K. Hamilton (1985). Atmospheric forcing of interannual varibility in the Northeast Pacific Ocean: connections with El Niño. J. Geophys. Res., 90, No. C1:857-868. 
Flohn, H. and A. Kapal (1988). Regional variability of trends (1949-1979) of surface parameters in equatorial oceans. Trop. Ocean-Atmos. Newsletter, 45:4-7.

Freeland, H.J. and F.A. Whitney (1997). Evidence of secular change in the Northeast Pacific Ocean. International WOCE Newsletter, (26):34-36.

Gate, W.L. and A. B. Nelson (1975). A new (revised) tabulation of the Scripps topography on a 1 degree global grid. Part II: Ocean depths, darpa report.

Graham, N.E. Decadal-scale climate variability in the 1970 s and 1980 s: Observations and model results. In :Proceedings of the fifteenth annual climate diagnostic workshop, ,us Department of Commerce/NOAA/NWS/NMC/CAC pb91-171082.

Graham, N.E. (1994). Decadal scale climate variability in the tropical and North Pacific during the 1970's and 1980's:obversations and model results. Clim. Dyn., 10:135162.

Hall, M. and J. Bryden (1982). Direct estimates and mechanism of ocean heat transport. Deep-Sea Res., 29:339-359.

Halpern, D. (1980). Vertical motion at the equator in the eastern Pacific (abstract). EOS, 61:998.

Harrison, D.E (1989). On climatological monthly mean wind stress and wind stress curl fields over the world ocean. J. Climate, 2:57-70.

Hellerman, S. and M. Rosenstein (1983). Normal monthly wind stress over the world ocean with error estimates. J. Phys. Oceanogr., 13:1093-1104. 
Hsieh, W.W. (1987). A numerical study of the seasonal cycle in the northeast Pacific Ocean as driven by the wind stress and surface heat flux. Atmos.-Ocean, 25(4):375386.

Huang, J.C.K. (1979(a)). Numerical simulation studies for oceanic anomalies in the North Pacific basin: II. Seasonally varying motions and structures. J. Phys. Oceanogr., $9: 37-56$.

Huang J.C.K. (1979(b)). Numerical case studies for oceanic thermal anomalies with a dynamic model. J. Geophys. Res., 84 (C9):5717-5726.

Lagerloef, G.S.E. (1995). Interdecadal variations in the Alaska gyre. J. Phys. Oceanogr., $25: 2242-2258$.

Large, W.G. and S. Pond (1981). Open ocean momentum flux measurements in moderate to strong winds. J. Phys. Oceanogr., 11(3):324-326.

LeBlond, P.H. and L.A. Mysak (1978). Waves in the ocean. Elsevier, New York.

McFarlane, G.A. and R.J. Beamish (1992). Climatic influence linking copepod production with strong year-classes in sablefish, anoplopoma fimbria. Can. J. Fish. Aquat. Sci., 49:743-753.

Mclain, D.R. (1983). Coastal ocean warming in the northeast Pacific, 1976-1983. In W.G:Pearcy (ed) The influence of ocean conditions on the production of salmonids in the North Pacific. Oregon State University, Sea Grant Program, ORESUW-83001.

Miller, A.J., D.R. Cayan, T.P. Barnett, N.E. Graham and J.M. Oberhuber (1994). Interdecadal variability of the Pacific Ocean: Model response to observed heat flux and wind stress anomalies. Clim. Dyn., 9:287-302. 
Munk, W.H. (1950). On the wind-driven ocean circulation. J. Meteor., 7:79-93.

Mysak, L.A. (1986). El Niño, interannual variability and fisheries in the northeast Pacific ocean. Can. J. Fish. Aquat. Sci., 43:464-497.

Namias J. (1965). Macroscopic association between monthly sea surface temperature and the overlying wind. J. Geophys. Res., 70(10):2307-2318.

Nitani,H. (1972). Beginning of the Kuroshio. Kuroshio, H. Stommel andK. Yoshida. University of Washington Press.

Nitta, T. and S. Yamada (1989). Recent warming of tropical sea surface trmperature and its relationship to the northern hemisphere circulation. J. Meteorol. Soc. Japan, $67: 375-383$.

Oort, A.H., and T.H. Vonder Haar (1976). On the observed annual cycle in the oceanatmosphere heat balance over the northern hemisphere. J. Phys. Oceanogr., 6:781800.

Pacanowski, R.C. and S.G.H. Philander (1981). Parameterization of vertical mixing in numerical models of tropical oceans. J. Phys. Oceanogr., 11:1443-1451.

Pacanowski, R.C., K.W. Dixon and A. Rosati (1991). The G.F.D.L. modular ocean model users guide. Technical Report 2, Geophysical Fluid Dynamics Laboratory, Princeton, New Jersey, United States Department OF Commerce, National Oceanic and Atmospheric Administration.

Pickard, G. and W. Emery (1990). Descriptive Physical Oceanography. 5th edition.

Ramage, C.S. (1987). Secular change in reported surface wind speeds over the ocean. $J$. Clim. Appl. Meteor., 26:525-528. 
Roemmich, D. (1980). Estimation of meridional heat flux in the North Atlantic by inverse methods. J. Phys. Oceanogr., 10:1972-1983.

Royer, T.C. (1989). Upper ocean temperature variability in the northeast Pacific Ocean: Is it an indicator of global warming? J. Geophys. Res., 94(12):18175-18183.

Semtner, A.J. (1974). An oceanic general circulation model with bottom topography. Technical Report 9, UCLA Dept. of Meteorology.

Semtner, A.J., and R.M. Chervin (1988). A simulation of the global ocean circulation with resolved eddies. J. Geophys. Res., 93(C12):15,502-15,522.

Tabata S. (1991). Annual and interannual variability of baroclinic transports across Line $\mathrm{P}$ in the northeast Pacific Ocean. Deep-Sea Res., 38, Suppl 1:S221-S245.

Taft, B.A. (1972). Characteristics of the flow of the Kuroshio South of Japan. Kuroshio, H.Stommel and K.Yoshida. University of Washington Press.

Tomczak, M. and J.S. Godfrey (1994). Regional Oceanography: An Introduction. Pergamon, Oxford.

Trenberth, K.E. (1990). Recent observed interdecadal climate changes in the northern hemisphere. Bull. Am. Met. Soc., 71:988-993.

Trenberth, K.E. and J.W. Hurrell (1994). Decadal atmosphere-ocean variations in the Pacific. Clim. Dyn., 9:303-319.

Trenberth, K.E., W.G. Large and J.G. Olson (1989). The effective drag coefficient for evaluating wind stress over the oceans. J. Climate, 2:1507-1515.

Tsuchiya, M. (1974). Variation of the surface geostrophic flow in the eastern intertropical Pacific Ocean. Fish. Bull., 72:1075-1086. 
Venrick, E.L., J.A. McGowan, D.R. Cayan, T.L. Hayward (1987). Climate and chlorophyll a:long-term trends in the central north pacific ocean. Science, 238:70-72.

Woodruff, S.D., R.J. Slutz, R.L. Jenne and P.M. Steurer (1987). The comprehensive ocean-atmosphere data set. Bull. Am. Met. Soc., 68:1239-1250.

World Ocean Atlas (1994). CD-ROM data set documentation. Technical report, National Oceanography Data Center, Ocean Climate Laboratory, US Department of commerce, NOAA, National Enviromental Satellite Data and Information Service.

Xie, L. and W.W. Hsieh (1995). The global distribution of wind-induced upwelling. Fisheries Ocenography., 4:52-67. 